\title{
Wired for learning : how computers can support interaction in small group learning in higher education
}

Citation for published version (APA):

de Leng, B. A. (2009). Wired for learning : how computers can support interaction in small group learning in higher education. [Doctoral Thesis, Maastricht University]. Mediview.

https://doi.org/10.26481/dis.20091208bl

Document status and date:

Published: 01/01/2009

DOI:

$10.26481 /$ dis.20091208bl

Document Version:

Publisher's PDF, also known as Version of record

\section{Please check the document version of this publication:}

- A submitted manuscript is the version of the article upon submission and before peer-review. There can be important differences between the submitted version and the official published version of record.

People interested in the research are advised to contact the author for the final version of the publication, or visit the DOI to the publisher's website.

- The final author version and the galley proof are versions of the publication after peer review.

- The final published version features the final layout of the paper including the volume, issue and page numbers.

Link to publication

\footnotetext{
General rights rights.

- You may freely distribute the URL identifying the publication in the public portal. please follow below link for the End User Agreement:

www.umlib.nl/taverne-license

Take down policy

If you believe that this document breaches copyright please contact us at:

repository@maastrichtuniversity.nl

providing details and we will investigate your claim.
}

Copyright and moral rights for the publications made accessible in the public portal are retained by the authors and/or other copyright owners and it is a condition of accessing publications that users recognise and abide by the legal requirements associated with these

- Users may download and print one copy of any publication from the public portal for the purpose of private study or research.

- You may not further distribute the material or use it for any profit-making activity or commercial gain

If the publication is distributed under the terms of Article $25 \mathrm{fa}$ of the Dutch Copyright Act, indicated by the "Taverne" license above, 


\section{WIRED FOR LEARNING}

How computers can support interaction in small group learning in higher education 
ISBN 978-90-77201-35-0

(c) De Leng, Maastricht 2009

Layout: Jasper Holthuis, PrimalD

Printed by: Drukkerij Walters, Maastricht

Publisher:Mediview, Maastricht 


\section{WIRED FOR LEARNING}

How computers can support interaction in small group learning in higher education

\section{PROEFSCHRIFT}

ter verkrijgen van de graad van doctor

aan de Universiteit Maastricht,

op gezag van de Rector Magnificus,

Prof. mr. G.P.M.F. Mols

volgens het besluit van het College van Decanen,

in het openbaar te verdedigen

op dinsdag 8 december 2009 om 12.00 uur

door

Bastiaan Albert de Leng 


\title{
PROMOTOR
}

Prof. dr. C.P.M. van der Vleuten

\author{
CO-PROMOTORES \\ Dr. D.H.J.M. Dolmans \\ Dr. Ir. A.M.M. Muijtens
}

\section{BEOORDELINGSCOMMISSIE}

Prof. dr. J.J.G. van Merriënboer (voorzitter)

Prof. dr. P.A. Kirschner (Universiteit Utrecht/ Open Universiteit Nederland)

Dr. M.G.A. Oude Egbrink

Prof. dr. L. Snoeckx (Technische Universiteit Eindhoven/ Universiteit Maastricht)

Prof. dr. M. Valcke (Universiteit Gent) 


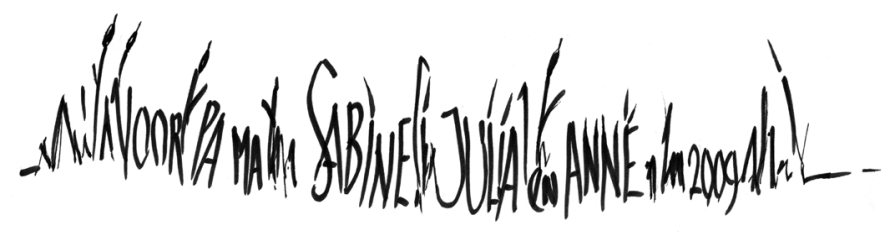




\section{Acknowledgement:}

It takes a thousand voices to tell a single story. Thanks to all those who made it possible to write this story! 


\section{Table of contents}

1 Introduction 9

2 Student perceptions of a Virtual Learning Environment for a 25 problem-based learning undergraduate medical curriculum Published in Medical Education 2006; 40 (6): 568-575

3 How video cases should be used as authentic stimuli in problem-based medical education

Published in Medical Education 2007; 41 (2): 181-188

4 The effect of face-to-face collaborative learning on the elaboration of computer-based simulated cases

Accepted for publication in Simulation in Healthcare

5 Exploration of an e-learning model to foster critical thinking on basic science concepts during work placements

Published in Computers \& Education 2009; 53 (1): 1-13

6 Instruments to explore blended learning: modifying a method to analyse online communication for the analysis of face-to-face communication

Under editorial review

7 Discussion

Summary

Samenvatting

Curriculum vitae 

Chapter 1

Introduction 
ปัँ 


\section{INTRODUCTION}

\section{Society and education}

Two societal developments of the last two to three decades have challenged many traditional approaches to education. Firstly, digital technologies, such as personal computers and the Internet have come to pervade our lives, changing not only the way we work and communicate but also the way we educate and learn. While it is important for educational institutions to adapt to technology-driven ways of learning, it is equally important for them to make sure that the choices they make in this regard are based on sound educational considerations and not dictated by technological options. Secondly, the knowledge society and globalisation have given rise to an exponential growth of information with a concomitant fall in the turn-over time of knowledge. If today's and tomorrow's knowledge workers are to cope with this deluge of information, they need to possess skills for continuous reflection on knowledge, appraisal of information and 'critical' thinking. It is the mission of higher education to deliver graduates who are equipped with this intellectual baggage.

The studies in this thesis represent our efforts to provide sound underpinnings for ways in which computers can support cognitive learning in higher education. In the introduction we first describe the concepts of learning on which our research is premised, followed by what the literature tells us about small group learning in general and with computers in particular. We identify current insights and gaps in knowledge and derive from them the central research question of this thesis, rounding off with a thesis outline, briefly sketching the issues addressed.

\section{Active learning}

Over the last three to four decades, ideas about cognitive learning have changed and evolved. Traditionally, the 'acquisition' metaphor prevailed, picturing the human mind as a container or archive in which ready-made information is accumulated until eventually knowledge emerges as the final 'product' (Sfard, 1998). In the late 1970's, Vygotsky presented his 'general genetic law of cultural development,' proposing a different take on learning and knowledge. Emphasising the social origins of a person's mental functioning, Vygotsky characterised learning by a'participation' metaphor, in which learning is located in participation in various cultural practices, which results in 'knowing' (Sfard, 1998).

In this thesis we adhere to a cognitive notion of learning, in which learners are not passive subjects acted upon by teachers, but active players, who relate new knowledge to what they already know (Ausubel, 1968). We combine this view with the constructivist notion that learners construct their own meaning from their experiences (Novak, 1993). We use the term cognitive processes to refer to the mental activities engaged in by individual learners in constructing their own knowledge.

In line with Vygotsky, we assume that social exchange is pivotal in fostering cognitive processes (Wertsch \& Smolka, 1993). From this perspective, it is important that social processes, which we call interpersonal interactions, are internalised. 
Since it is the task of higher education to promote higher order thinking, students should be enabled to engage in interpersonal interactions that foster such higher order cognitive processes.

\section{Small group learning}

Small group learning is often applied in education. Many studies on learning in classrooms showed that students learned more in collaborative conditions than in competitive or individual conditions (Johnson \& Johnson, 1989; Slavin, 1989). For instance, problem solving in pairs yielded better group performance, which subsequently transferred to better individual performance (Light, Littleton, Messer, \& Joiner, 1994). Cohen qualified this claim by showing that this effect occurred mainly in groups working on group tasks and tackling problems that did not have one clear-cut answer but invited multiple solutions (Cohen, 1994). It was in situations like these that interpersonal interaction proved profitable.

From research in secondary education we also know that different types of interpersonal interaction elicit different kinds of cognitive processes. Summarising, clarifying and predicting during reading tasks in small groups were seen to foster text comprehension and factual recall (Rosenshine \& Meister, 1994), while higher order cognitive processes, such as analytical thinking, integration of ideas, and reasoning, were promoted by activities like explaining concepts (Chi, De Leeuw, Chiu, \& Lavancher, 1994), asking thought-provoking questions (King, 1994) and resolving conceptual discrepancies (Piaget, 1985).

Finally, we know from the literature that learners are generally unlikely to interact in cognitively effective ways unless they are given some structured guidance (Kirschner, Sweller, \& Clark, 2006; Mayer, 2004). Based on this insight, many educators try to structure learners' interpersonal interactions in collaborative conditions using measures ranging from general task instructions to highly detailed instructions as to what is to be discussed and how. In secondary education, methods like Guided Strategic Problem Solving (King 1991), Ask to Think-Tell Why (King , 1997), Structured Controversy (Johnson \& Johnson, 1992) and Jigsaw Debate (Brown \& Campione, 1994) have been developed to promote and structure interpersonal interactions that foster higher order cognitive processes. In a vocational education setting, Anderson (Anderson, Howe, Soden, Halliday, \& Low, 2001) demonstrated that critical thinking skills were augmented as a result of guided peer-based dialogue. Other studies revealed (Cohen, 1994; O'Donnell, 1999) that structures imposed to promote interaction were generally profitable as long as they did not constrain the full discussion of problems. Too much structure can be counterproductive and obstruct cognitive processes by causing demotivation or cognitive overload. So the crux in structuring group interactions lies in striking the right balance: neither too little nor too much structure (Fisher, Kollar, Haake, \& Mandl, 2007).

All of the above-mentioned methods to enhance collaborative learning were developed for face-to-face learning in classroom settings, mainly in secondary education. Little is known about the validity of these methods for online collaborative settings or for higher education. Students in higher education are likely to be more experienced in collaborative and self-directed learning than 
learners in primary and secondary education, whose exposure to collaborative learning and understanding of what it means to explain, analyse and argue is limited and whose conceptions of group collaboration may be naive.

\section{Learning with computers}

When we look at the literature on learning with computers, we see a considerable body of media comparison studies, comparing online and face-to-face learning. A large and recent media comparison study (Luppicini, 2007) reported that, in general, students performed at least as well in online courses as in face-to-face courses. Many studies found that, in online discussions, learners showed less inhibition, more expression of personal viewpoints and more argumentation (Quinn, Mehan, Levin, \& Black, 1983). In addition, online contributions were shown to be more task focused and linked, and reflected more well-founded opinions (Jonassen \& Kwon, 2001; Marttunen \& Laurinen, 2001; Guiller, Dumdell, \& Ross, 2008).

The results of comparative studies on learners' perceptions of learning with computers are more ambiguous, however. In many studies, students were satisfied with their asynchronous online learning experiences (Picciano, 2001; Walker \& Arnold, 2004; Wu \& Hiltz, 2004). They perceived online discussions as more task directed and the setting conducive to deep and reflective thinking (Jonassen \& Kwon, 2001; Meyer, 2003). On the other hand, other studies showed less positive or even contrasting results. In several comparative experiments, students were less satisfied with asynchronous than with face-to-face learning (Cooper, 2001; Ocker \& Yaverbaum, 1999; Tiene, 2000) and the level of participation in computermediated communication groups was lower than in face-to-face groups (Kamin, Glicken, Hall, Quarantillo, \& Merenstein, 2001). Students also commented that asynchronous online discussions were slow (Jonassen \& Kwon, 2001; Meyer, 2003; Olaniran, Savage, \& Sorenson, 1996) and emotionless (Walther, 1996). Results of other media comparison studies showed that students deemed online discussions more exacting, making them put more thought into their comments (Jonassen \& Kwon, 2001; Kamin et al., 2001). Guernsy (Guernsey, 1998) found that students felt they had to work harder but did not perceive performance benefits to themselves.

\section{Computer mediated communication}

The above-mentioned media comparison studies can be characterised as 'justification' studies (Cook, Bordage, \& Schmidt, 2008), investigating if a new medium has comparable or superior effects on learners' performance or perceptions compared to traditional media. The focus in this thesis, however, is on 'clarification' and on how learning with computers can support interpersonal interactions that foster cognitive processes leading to knowledge construction and higher order thinking.

In educational settings where students are distributed over different but interconnected computers (in the same place or at a distance), communication among students can be fully computer mediated. In such computer-mediated communication (CMC) interpersonal interactions are conducted over the 'wires' of the computer network. That is why Crook called this type of setting an 'interaction through computers' arrangement. In computer-mediated communication, a 
distinction can be made between asynchronous, or delayed time, communication and synchronous, or real-time, communication. For asynchronous communication, such as email and discussion boards, participants do not have to interact simultaneously, whereas synchronous communication, such as chat and videoconferencing, requires simultaneous interaction.

It is evident that interpersonal interaction is prerequisite for learning in 'interaction through computers' settings. A pertinent question is whether the most active online learners are also the most successful ones. Wang (Wang, 2004) found that students who made many discussion board postings academically outperformed students who showed less asynchronous activity. By contrast, Johnson (Johnson, 2005) reported a curvilinear relationship between number of articles posted on discussion boards and final grades and speculated that excessive posting might reduce the time available for other forms of learning.

The notion that not all interactions within small groups are valuable for learning also applies to computer-mediated settings (Fauske \& Wade, 2003). Several studies on asynchronous computer-mediated communication revealed that structured communication promoted higher order cognitive activity (Aviv, Erlich, Ravid, \& Geva, 2003). On the other hand some of these studies also reported difficulties in getting learners to move beyond the level of merely exchanging and comparing information (Fahy, 2002; Garrison, Anderson, \& Archer, 2001; Järvelä \& Häkkinen, 2002; Kanuka, Rourke, \& Laflamme, 2007; McKlin, Harmon, Evans, \& Jones, 2002; Meyer, 2003; Schrire, 2004, 2006). In addition some problems of the collaboration in face-to-face settings may be augmented, others reduced in online distributed groups (Bromme, Hesse, \& Spada, 2005).

The number of published studies on asynchronous computer-mediated communication in higher education settings is quite substantial but most of these studies dealt with courses in which computer-mediated communication in itself was an intrinsic part of the content of the course, such as courses in computer science (e.g. instructional design of $\mathrm{CMC}$ ) or teacher education (e.g. training teachers to be online moderators in CMC). Studies in which computer-mediated communication was primarily used to facilitate interactions between students and had no role as the topic of study, however, are scarce. Consequently, the findings from studies of computer-mediated communication in higher education may be biased and have limited generalisability.

\section{Face-to-face discussions at computers}

The role of computers in small groups is not limited to mediating interpersonal interactions in distributed groups. Computers can also play a role when groups of students are working together face to face in one location. From a socioconstructivist point of view, the role of the computer in the latter setting is not to deliver pre-digested information to individuals but to provide opportunity and resources for social debate and discussion (Fischer \& Ostwald, 2005). Crook (Crook, 1996) characterised settings where a shared computer is used during faceto-face discussions as an 'interaction at computer' arrangement. 
Studies that evaluate the effects of small group learning with computers can focus on gains in knowledge and competence for higher order thinking. Most outcome studies on 'interaction at computer' settings were performed in primary and secondary education. This body of research did not find consistent effects of small group learning with computers on students' academic achievement (Johnson, Johnson, \& Stanne, 1986). In a meta-analysis, Lou et al. (Lou, Abrami, \& d'Apollonia, 2001) concluded that small group learning with computers impacted more favourably on student outcomes than individual learning with computers, although not all groups performed equally well and not all students learned more.

Evaluations can also focus on cognitive processes during learning activities that are prerequisite for achieving the final cognitive outcome. Studies of this kind also mainly originated from early education and indicated that cognitive processes like elaboration, reasoning, synthesis and reflection can be valuable for cognitive learning (Chi et al., 1994; Howe, Tolmie, \& Mackenzie, 1995; Johnson \& Johnson, 1979; King, 1994; Kuhn, Shaw, \& Felton, 1997; Piaget, 1985; Sharan \& Shaulov, 1990; Webb, 1989; Yackel \& Cobb, 1991).

The cognitive processes elicited by interpersonal interactions in small group learning can be seen as a first order effect, with gains in knowledge and competence in higher order thinking as secondary effects. Although the latter effect is the final goal of education, it is hard to measure because of its dependence on factors like number and duration of learning activities. Because high frequencies and long durations of learning interventions are generally outside the scope of qualitative experimental research, we will focus in this thesis on the first order effects of interpersonal interactions: the cognitive processes.

\section{Problem statement and central research question}

Based on the above considerations we argue that interpersonal interactions are a central ingredient for learning and, today, computers have an essential role to play in this respect. Previous research indicated that small group learning with computers can have added value compared to learning where students work on a computer by themselves, provided students are given group tasks with multiple potential solutions. We can also learn from the literature that effective cognitive learning requires structured guidance and careful judgement of how much and what kind of guidance is most likely to further the desired cognitive processes.

When it comes to higher education, where higher order cognitive processes like reflection and critical thinking are of central importance, the literature offers little advice on how to strike the right balance in structuring learners' interpersonal interactions in general, and in settings with computers in particular. Research of 'interaction at computer' arrangements focused mainly on methods developed for primary and secondary education, while research of 'interaction through computers' arrangements, although frequently situated in higher education, are mainly restricted to courses in which computer-mediated communication was strongly related to the topic of the course. 
The research reported in this thesis aims to remedy this gap in our knowledge by addressing the central question:

How should we structure interpersonal interactions in small groups of learners, working with computers in higher education, to optimise the chance that higher order cognitive processes are elicited and fostered? The scope of this question is limited to education settings where computers or computer communication are as such not topics for learning. The question is addressed for different social arrangements with computers:

- Face to face communication at a computer, 'interaction at computer' arrangements;

- Computer-mediated communication, 'interaction through computers' arrangements;

- Or a combination of the two.

\section{Thesis outline}

The more detailed research questions derived from the central question are formulated and addressed in the different chapters of this thesis. A synopsis of these questions, their relevance and the way they were researched is given in this thesis outline.

\section{Chapter 2}

Nowadays, higher education institutions use computer programs and webtechnology to deliver and manage their curricular material. These systems, so-called virtual learning environments, also provide tools for online communication and collaboration. There are two aspects that should be noted here. On the one hand, computer programs inherently structure the actions they enable and mediate, but they do so in close reciprocity with the characteristics of the users (Jermann, Soller, \& Lesgold, 2004). The properties of computer programs that enable specific interactions are called affordances. On the other hand, students' expectations, attitudes and behaviours in relation to computers are shaped by the technology that was available when their generation matured (Hartman, Moskal, \& Dziuban).

Based on these notions and the fact that medical education makes extensive use of virtual learning environments (Cook, 2002; Lau \& Bates, 2004; Ward, Gordon, Field, \& Lehmann, 2001), we sought medical students' perceptions of the virtual learning environment of a problem-based undergraduate curriculum, which was applied in both 'interaction at computer' and 'interaction through computers' arrangements. We conducted a cross-sectional survey and quantitatively described students' perceptions and verified if the affordances of the virtual learning environment, as perceived by the students, resulted in the type of interpersonal interactions that are commensurate with the aims of problem based learning.

\section{Chapter 3}

Building on the results of chapter 2 we 'zoom in' on the use of digital video in tutorial groups in an 'interaction at computer' arrangement for case presentations in problem-based learning. Among other things we explored which conditions students perceived to be essential for productive interpersonal interaction in 
discussing digital video cases. We conducted a focus group study to obtain qualitative information on favourable conditions for the application of digital video in tutorial groups in an undergraduate medical curriculum.

\section{Chapter 4}

In higher education, case-based learning is regularly used to support authentic activities (Bennett, 2006), aimed at encouraging learners to think like practitioners as they face cognitive challenges similar to those experienced in the work environment (Savery \& Duffy, 1995). Case materials can be used by individuals or groups as a stimulus for problem-solving activities in a particular domain. In the medical domain they are increasingly used in the format of computer-based simulated cases, generally named virtual patients (Huang, Reynolds, \& Candler, 2007). Virtual patients mostly encompass patient data as well as a professional framework (workflow of a consultation) to structure students' interactions with the patient data (Huwendiek et al., 2009) and often also a case-based learning aid to help students interpret, reflect on and apply their experiences (Kolodner, Owensby, \& Guzdial, 2004).

The focus of this study is an 'interaction at computer' arrangement in which a small group of students engaged in a virtual patient work-up on a shared computer. We investigated whether working in this arrangement had added value compared to an individual work-up of the same virtual patient. In both the group and the individual condition no other structuring was offered than the case-based learning aid developed for individual students. We performed a randomised controlled experiment to measure the effect of 'social context' on students' perceptions of the elaboration process and the time they spent on the various parts of the computer case.

\section{Chapter 5}

Building on the results of chapter 2 we 'zoom in' on the use of asynchronous computer-mediated communication in an 'interaction through computers' arrangement for undergraduate medical students on clinical work placements. Work-based learning is a pivotal educational format in higher education. However, apart from their undeniable virtues, work placements have shortcomings as well, notably the relative inability of educational institutions 'at a distance' to place important curricular themes on the agenda of the workplace as well as barriers to ongoing discussions on essential themes among peers dispersed over different locations.

In medical education, 'critical thinking' in the workplace tends to be heavily inclined towards 'clinical reasoning' (Norman, 2005) or 'critical appraisal' in Evidenced Based Medicine (Claridge \& Fabian, 2005) to the neglect of the basic science knowledge underlying diagnostic and therapeutic reasoning. Because this latter theme features explicitly in almost all vertically integrated medical curricula, we designed a method in which asynchronous computer-mediated communication facilitated discussions and critical thinking on basic science topics in distributed online learning groups during clinical work placements.

We explored how a specific procedural facilitation, embedded in the asynchronous 
learning system, structured the interpersonal interactions 'through' the computer network and we evaluated the effects of these interactions on the cognitive processes of the students. In this study, we applied a mixed method approach including content analysis of the messages.

\section{Chapter 6}

Currently, we know of no empirical studies that have examined blended learning in higher education and its impact on educational interactions. Research in this area still has a long way to go and design-based research might be used to explore how 'blends' can enhance and eventually transform current pedagogy (Garrison \& Kanuka, 2004; Graham, 2006). To succeed in this effort we need to be able to analyse face to face communication as well as computer-mediated communication.

In our search for appropriate and aligned instruments to analyse both types of communication, we examined if methods of proven value for interaction analysis, developed in the domain of Computer Supported Collaborative Learning, could be converted and used to analyse face-to-face interactions. We performed a reliability and usability study to establish whether a modified coding scheme was suitable for evaluating verbal interactions during face-to-face sessions. Because case presentations play a key role in structuring the professional learning of medical students (Lingard, Schryer, Garwood, \& Spafford, 2003), we used the modified coding scheme to analyse students' interpersonal interactions in small group sessions in which cases were presented and discussed by the students.

\section{Chapter 7}

Discusses the findings reported in the various chapters and puts them into perspective, considers the implications for the use of computers in higher education and reflects on directions for future research. A summary concludes the thesis.

Chapters 2 to 6 are based on published journal articles and can therefore be read on their own in random order.

\section{REFERENCES}

Anderson, T., Howe, C., Soden, R., Halliday, J., \& Low, J. (2001). Peer interaction and the learning of critical thinking skills in further education students. Instructional Science, 29(1), 1-32.

Ausubel, D. (1968). Educational psychology: a cognitive view. New York: Holt, Reinhart and Winston.

Aviv, R., Erlich, Z., Ravid, G., \& Geva, A. (2003). Network analysis of knowledge construction in asynchronous learning networks. Journal of asynchronous learning networks, 7(3), 1-23.

Bennett, S. (2006). Using related cases to support authentic project activities. In A. Herrington \& H. Herrington (Eds.), Authentic learning environments in higher education (pp. 120-134). London: Information science publishing. 
Bromme, R., Hesse, F., \& Spada, H. (2005). Barriers, biases and opportunities of communication and cooperation with computers: introduction and overview. In $\mathrm{R}$. Bromme, F. Hesse \& H. Spada (Eds.), Barriers and biases in computer-mediated knowledge communication: and how they may be overcome (Vol. 5, pp. 1-14): Springer Science.

Brown, A. L., \& Campione, J. C. (1994). Guided discovery in a community of learners. In K. McGilly (Ed.), Classroom lessons: integrating cognitive theory and classroom practice (pp. 229-270). Cambridge, MA: MIT Press.

Chi, M. T. H., De Leeuw, N., Chiu, M.-H., \& Lavancher, C. (1994). Eliciting selfexplanations improves understanding. Cognitive Science: A Multidisciplinary Journal, 18(3), 439 - 477.

Claridge, J. A., \& Fabian, T. C. (2005). History and development of evidence-based medicine. World Journal of Surgery, 29(5), 547-553.

Cohen, E. (1994). Restructuring the classroom: conditions for productive small groups. Review of Educational Research, 64, 1-35.

Cook, D. A., Bordage, G., \& Schmidt, H. G. (2008). Description, justification and clarification: a framework for classifying the purposes of research in medical education. Medical Education, 42(2), 128 -133.

Cook, J. (2002). The role of virtual learning environments in UK medical education. LTSN Bioscience Bulletin, 5, 10-11.

Cooper, L. (2001). A comparison of online and traditional computer application classes. Technological Horizons in Education Journal, 28(8), 52-58.

Crook, C. (1996). Computers and the collaborative experience of learning. London: Routledge.

Fahy, P. J. (2002). Assessing critical thinking processes in a computer conference [Electronic Version]. unpublished paper. Retrieved Retrieved August 2007, from http://cde.athabascau.ca/softeval/reports/mag4.pdf

Fauske, J., \& Wade, S. E. (2003). Research to Practice Online: Conditions that Foster Democracy, Community, and Critical Thinking In Computer-Mediated Discussions. Journal of Research on Technology in Education, 36(2), 137-153.

Fischer, G., \& Ostwald, J. (2005). Knowledge communication in design communities. In R. Bromme, F. Hesse \& H. Spada (Eds.), Barriers and biases in computer-mediated knowledge communication: and how they may be overcome (Vol. 5, pp. 213-239): Springer Science.

Fisher, F., Kollar, I., Haake, J., \& Mandl, H. (2007). Perspectives on collaboration scripts. In F. Fisher, I. Kollar, H. Mandl \& J. Haake (Eds.), Scripting computer-supported collaborative learning: cognitive, computational and educational perspectives (Vol. 6): Springer Science.

Garrison, D. R., Anderson, T., \& Archer, W. (2001). Critical thinking, cognitive presence and computer conferencing in distance education. The American Journal of Distance Education, 15(1), 7-23. 
Garrison, D. R., \& Kanuka, H. (2004). Blended learning: uncovering its transformative potential in higher education. Internet and Higher Education, 7, 95-105.

Graham, C. (2006). Blended learning systems: definition, current trends, and future directions. In C. Bonk \& C. Graham (Eds.), The Handbook of Blended Learning: Global Perspectives, Local Designs. San Francisco: Pfeiffer.

Guernsey, L. (1998). Distance education for the not-so-distant. Chronicle of higher education, 45(3), 29-30.

Hartman, J., Moskal, P., \& Dziuban, C. Preparing the academy of today for the learner of tomorrow. Retrieved April 10th, 2005, from http://www.educause.edu/ preparingtheacademyoftodayforthelearneroftomorrow/6062

Howe, C., Tolmie, A., \& Mackenzie, M. (1995). Computer support for the collaborative learning of physics concepts. In C. O'Malley (Ed.), Computer supported collaborative learning (Vol. 128, pp. 51-68). Berlin: Springer-Verlag.

Huang, G. M. D., Reynolds, R. M. P. A., \& Candler, C. M. D. (2007). Virtual Patient Simulation at U.S. and Canadian Medical Schools. Academic Medicine, 82(5), 446451.

Huwendiek, S., Reichert, F., Bosse, H., de Leng, B., van der Vleuten, C., Haag, M., et al. (2009). Design principles for virtual patients: a focus group study among students. Medical Education, 43(6), 580-588.

Järvelä, S., \& Häkkinen, P. (2002). Web-based cases in teaching and learning: the quality of discussion and stage of perspective taking in asynchronous communication. Interactive learning environments, 10, 179-189.

Jermann, P., Soller, A., \& Lesgold, A. (2004). Computer software support for CSCL. In J. Strijbos, P. Kirschner \& R. Martens (Eds.), What we know about CSCL: and implementing it in higher education (Vol. 3, pp. 141-166). Dordrecht, The Netherlands: Kluwer Academic Publishers.

Johnson, D., \& Johnson, R. (1979). Conflict in the classroom: controversy and learning. Review of educational research, 49, 51-70.

Johnson, D., \& Johnson, R. (1989). Cooperation and competition: theory and research. Edina: Interaction Book.

Johnson, D., \& Johnson, R. (1992). Creative controversy: intellectual challenge in the classroom. Edina: Interaction Book Company.

Johnson, G. (2005). Student alienation, academic achievement, and WebCT use. Educational technology and society, 8, 179-189.

Johnson, R., Johnson, D., \& Stanne, M. (1986). Comparison of computer assisted cooperative, competitive, and individualistic learning. American educational research journal, 23(382-392).

Jonassen, D. H., \& Kwon, H. (2001). Communication patterns in computer mediated vs face-to-face group problem solving. Educational technology research and development, 49(1), 35-51. 
Kamin, C., Glicken, A., Hall, M., Quarantillo, B., \& Merenstein, G. (2001). Evaluation of electonic discussion groups as a teaching/leaning strategy in an evidence-based medicine cours: a pilot study. Education for health, 14(21-32).

Kanuka, H., Rourke, L., \& Laflamme, E. (2007). The influence of instructional methods on the quality of online discussion. British Journal of Educational Technology, 38(2), 260-271.

King, A. (1994). Guiding knowledge construction in the classroom: effects of teaching children how to question and how to explain. American Educational Research Journal, 30, 338-368.

Kirschner, P. A., Sweller, J., \& Clark, R. E. (2006). Why Minimal Guidance During Instruction Does Not Work: An Analysis of the Failure of Constructivist, Discovery, Problem-Based, Experiential, and Inquiry-Based Teaching. Educational Psychologist, $41(2), 75-86$.

Kolodner, J. L., Owensby, J., \& Guzdial, M. (2004). Case-based learning aids. In D. $H$. Jonassen (Ed.), Handbook of research on educational communications and technology (second ed., pp. 829-861). Mahwah, New Jersey: Lawrence Erlbaum Associates.

Kuhn, D., Shaw, V., \& Felton, M. (1997). Effects of dyadic interaction on argumentative reasoning. Cognition and Instruction, 15(3), 287-315.

Lau, F., \& Bates, J. (2004). A review of e-learning practices for undergraduate medical education. Journal of Medical Systems, 28(1), 71-87.

Light, P., Littleton, K., Messer, D., \& Joiner, R. (1994). Social and communicative processes in computer-based problem solving. European Journal of Psychology of Education, 9(1), 93-109.

Lingard, L., Schryer, C., Garwood, K., \& Spafford, M. (2003). 'Talking the talk': school and workplace genre tension in clerkship case presentations. Medical Education, 37(7), 612-620.

Luppicini, R. (2007). Review of computer mediated communication research for education. Instructional Science, 35, 141-185.

Marttunen, M., \& Laurinen, L. (2001). Learning of argumentation skills in networked and face-to-face environments. Instructional Science, 29(2), 127-153.

Mayer, R. E. (2004). Should there be a three-strikes rule against pure discovery learning? American psychologist, 59(1), 14-19.

McKlin, T., Harmon, S., Evans, W., \& Jones, M. (2002). Cognitive presence in webbased learning: a content analysis of students' online discussions [Electronic Version]. Retrieved February 2007, from http://it.coe.uga.edu/itforum/index.html

Meyer, K. (2003). Face-to-face versus threaded discussions: the role of time and higherorder thinking. JALN, 7(3), 55-65.

Norman, G. R. (2005). Research in clinical reasoning: past history and current trends. Medical Education, 39(4), 418-427. 
Novak, J. (1993). Human constructivism: a unification of psychological and epistemological phenomena in meaning making. International Journal of Personal Construct Psychology, 6, 167-193.

O'Donnell, A. (1999). Structuring dyadic interaction through scripted cooperation. In A. O'Donnell \& A. King (Eds.), Cognitive perspectives on peer learning (pp. 179-197). Mahwah NJ: Lawrence Erlbaum Associates.

Ocker, R., \& Yaverbaum, G. (1999). Asynchronous computer-mediated communication versus face-to-face collaboration: results on student learning, quality and satisfaction. The journal of group decision and negotiation, 8, 427-440.

Olaniran, B., Savage, G., \& Sorenson, R. (1996). Experimental and experiential approaches to teaching face-to-face and computer-mediated group discussion. Communication education, 45(3), 244-259.

Piaget, J. (1985). The equilibration of cognitive structures: the central problem of intellectual development (T. Brown \& K. Thampy, Trans.). Chicago: University of Chicago Press.

Picciano, A. (2001). Beyond student perceptions: issues of interaction, presence and performance in an online course. Journal of asynchronous learning networks, 6(1).

Quinn, C. N., Mehan, H., Levin, J. A., \& Black, S. D. (1983). Real education in non-real time: The use of electronic message systems for instruction. Instructional Science, 11(4), 313-327.

Rosenshine, B., \& Meister, C. (1994). Reciprocal teaching: a review of the research. Review of Educational Research, 64(4), 479-530.

Savery, J., \& Duffy, T. M. (1995). Problem based learning: an instructional model and its constructivist framework. Educational technology, 35(5), 31-58.

Schrire, S. (2004). Interaction and cognition in asynchronous computer conferencing. Instructional Science, 32, 475-502.

Schrire, S. (2006). Knowledge building in asychronous discussion groups: going beyond quantitative analysis. Computers \& Education, 46, 49-70.

Sfard, A. (1998). On Two Metaphors for Learning and the Dangers of Choosing Just One. Educational Researcher, 27(2), 4-13.

Sharan, S., \& Shaulov, A. (1990). Cooperative learning, motivation to learn, and academic achievement. In S. Sharan (Ed.), Cooperative learning : theory and research (pp. 173-202). New York: Praeger.

Slavin, R. (1989). Cooperative learning and student achievement. In R. Slavin (Ed.), School and classroom organization (pp. 129-156). Hillsdale: Erlbaum.

Tiene, D. (2000). Online discussions: a survey of advantages and disadvantages compared to face-to-face discussions. Journal of educational multimedia and hypermedia, 9(4), 371-384.

Walker, R., \& Arnold, I. (2004). Introducing group-based asynchronous learning to business education: reflections on effective course design and delivery. Educational media international, 41, 253-262. 
Walther, J. B. (1996). Computer-Mediated Communication: Impersonal, Interpersonal, and Hyperpersonal Interaction. Communication Research, 23(1), 3-43.

Wang, M. (2004). Correlational analysis of student visibility and performance in online learning. Journal of asynchronous learning networks, 8(4).

Ward, J., Gordon, J., Field, M., \& Lehmann, H. (2001). Communication and Information technology in medical education. Lancet, 357, 792-796.

Webb, N. (1989). Peer interaction and learning in small groups. International Journal of Educational Research, 13, 21-40.

Wertsch, J., \& Smolka, A. (1993). Continuing the dialogue: Vygotsky, Bakhtin, and Lotman. In H. Daniels (Ed.), Charting the agenda: Educational activity after Vygotsky. (pp. 69-92). London: Routledge.

Wu, D., \& Hiltz, S. (2004). Predicting learning from asynchronous online discussion. Journal of asynchronous learning networks, 8(4).

Yackel, E., \& Cobb, P. (1991). Small-group interactions as a source of learning oppotunities in second-grade mathematics. Journal for research in mathematics education, 22, 390-408. 


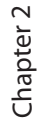


$\begin{array}{ll}\text { Chapter } 2 & 25\end{array}$

Student perceptions of a

Virtual Learning Environment

for a problem-based learning

undergraduate medical curriculum

Published in Medical Education 2006; 40 (6): 568-575

Bas A de Leng, Diana H J M Dolmans, Arno M M Muijtens \& Cees P M van der Vleuten 


\section{Abstract}

Objective

\section{Methods}

A questionnaire was administered to 355 medical students in Years 1 and 2 to ask them about the perceived usefulness of a virtual learning environment that was created with Blackboard for group interaction and the use of learning resources.

\section{Results}

The students indicated that the VLE stimulated face-to-face interaction in the preliminary discussion and in the reporting phase but not computer mediated distance interaction during the self study phase. They perceived that the use of multimedia in case presentations led to a better quality of the group discussion than when case presentations were exclusively text based. They also indicated that the information resources that were hyperlinked in the VLE stimulated the consultation of these resources during self study, but not during the reporting phase.

\section{Conclusions}

Students indicated that the use of a VLE in the tutorial room and the inclusion of multimedia in case presentations enhanced face-to-face interaction in the tutorial groups. However, if we want to exploit the full potential of asynchronous computer mediated communication to initiate in-depth discussion during the self study phase, its application will have to be selective and deliberate. Students indicated that the links in the VLE to selected information in library repositories supported their learning. 


\section{INTRODUCTION}

Web-based virtual learning environments (VLEs) are used in many medical schools (Cook, 2002; Lau \& Bates, 2004; Ward, Gordon, Field, \& Lehmann, 2001). Some schools use commercially available software, such as WebCT and Blackboard. Others use custom-made systems that they have developed individually or as partner in a consortium. Although off-the-shelf programs have the advantage of no unpredictable development costs, guaranteed compatibility with other software due to standardisation and the sharing of experiences with other users, they have an important educational drawback in that they leave users no option but to accept the consequences of the choices made by the original software developers.

Because the majority of commercially available software packages have been developed for traditional learning environments, the organisational principles and functionalities are generally tailored to an objectivist and teacher-centred educational concept. This means that the package is not tailored to the conditions of problem-based learning (PBL), where the emphasis is on self-directed learning and where students actively construct their own knowledge by working on authentic problems. Implementing software applications like Blackboard in this type of learning environment confronts educators with special challenges.

In learning environments geared to distance learning in virtual groups, online information supply and the use of computer networks for communication between students and teachers are logistical prerequisites. However, with faceto-face formats, the situation is very different, although such educational formats can also benefit from the logistic advantages of the VLE (Hoffmann \& Ritchie, 1997; Romiszowski, 2004). Current web technology offers opportunities for efficient, ondemand and just in time delivery of text, pictures and video materials. In addition, current office software suites make it easy for students to create and store digital records of group sessions. The question is, however, whether a VLE can support in a more generic way educational methods and activities in a PBL undergraduate medical curriculum where face-to-face tutorial group sessions are the predominant educational format.

The literature offers little enlightenment on this subject. Chumley-Jones et al. (Chumley-Jones, Dobbie, \& Alford, 2002) reviewed the literature on web-based learning in undergraduate, postgraduate and continuing medical, dental and nursing education. They found that many papers were confined to descriptions of e-learning programs and their usage. Only a few studies involved in-depth evaluation of e-learning in undergraduate medical education and their focus was mainly on knowledge-based software for specific courses.

In order to be effective in PBL settings, VLEs must offer generic support of active learning processes in large sections of the curriculum. AVLE in PBL must be targeted at the enhancement of discussions and group interaction (Koschmann, Myers, Feltovich, \& Barrows, 1994; Slotte, Wangel, \& Lonka, 2001). Studies addressing the effects of e-learning on interaction and communication generally focus on distance learning (Kim, Kolko, \& Greer, 2002; Stromso, Grottum, \& Hofgaard Lycke, 2004; White, Albritton, \& Rindt, 2001) and not on settings where face-to-face interaction is the prevailing format, like PBL in medical education. Even future scenarios of a 
virtual medical school place much emphasis on face-to-face activities in addition to online distance learning (Harden \& Hart, 2002). That is why, in considering the effects of a VLE in a problem based undergraduate medical education, one should preferably look at the effects on both face-to-face learning and distance interaction. Three broad phases can be distinguished in the active learning process in PBL. The first is the preliminary phase, in which students brainstorm to determine what they already know and what they need to know to tackle the problem. This phase ends by the identification of learning objectives to be pursued in the next phase, individual self study. In the third phase, the results of the self study activities are reported, critically evaluated, synthesised and applied to the problem. The process ends by reflection on the learning process. What PBL has in common with evidencebased medicine is the premise that information gathering is a key feature (Hagdrup et al., 1999; Roberts, Lawson, Newble, \& Self, 2003). In summary, an investigation of any useful effects of VLEs should address interaction and information gathering in all phases of PBL: the preliminary, self study and reporting phases.

We examined whether a VLE offered generic support for active learning processes in a PBL undergraduate medical curriculum by seeking answers to two research questions in relation to the three phases of the PBL process.

1. Does a VLE support interactions between students, and between students and teachers?

2. Does a VLE support the consultation of information resources?

We surveyed 355 medical students in Years 1 and 2 of a six-year curriculum on these questions.

\section{METHODS}

\section{Setting}

In 2002, the Maastricht University acquired the Blackboard Learning System to build a VLE for the PBL curricula of her eight faculties. The VLE was named EleUM (Electronic learning environment of the University of Maastricht). The Faculty of Medicine started to use EleUM in September 2003 in a blended construction to support educational activities in medical school settings, like tutorial group meetings, in home settings, such as self study by students, and in office settings, such as course development by teachers. Currently, EleUM is not (yet) used for skill training and online distance learning. It is used as an intranet application with access for authorised persons only.

Problems and cases are presented with EleUM in the tutorial groups in Years 1 and 2. Students meet in group rooms that accommodate some ten students. These rooms are equipped with a group computer and a beamer that projects the computer screen onto the wall of the room so that it is easily visible to all group members. The authenticity of presentations is enhanced by the use of multimedia, such as photographs and streaming audio and video. The tutorial groups' discussion boards in EleUM are used to post the minutes of group sessions and to provide opportunities for asking and answering questions outside group sessions. 


\section{Subjects}

A total of 355 medical students in Years 1 and 2 were asked to complete a questionnaire about their perceptions of the effects of EleUM. The students in Year 1 had had 4 months of experience with PBL and EleUM and the students in Year 2 approximately 16 months. The undergraduate curriculum is organised in thematic block courses that generally last six weeks. At the time of the study, the courses completed by the participating students had used EleUM for at least a year. Therefore, the teachers of these courses may be assumed to have beeen familiar with the use of EleUM.

\section{Material}

Students completed a questionnaire about the effects of the VLE, which consisted of statements to be responded to on a five-point Likert scale ( $1=$ fully disagree; $5=$ fully agree). The statements concerned qualitative and quantitative aspects of group interaction and information gathering for the three phases of the PBL process. Of the 18 statements about group interaction, 3 referred to the preliminary phase, 12 to the self study phase and 3 to the reporting phase. Of the 6 statements about information gathering, 4 referred to the self study phase and 2 to the reporting phase. The students were also asked to give a mark out of 10 for the usefulness of the VLE for group interaction and information gathering in the three PBL phases. If possible, the statements included the following 3 issues: whether the VLE stimulated the student's activity, whether it stimulated the group process, whether it enhanced the overall learning process. Finally, the questionnaire contained three open questions that invited suggestions and views regarding the educational added value of the VLE.

\section{Analysis}

Means, standard deviations and 95\% confidence intervals were calculated per item.

\section{RESULTS}

Table 1 shows the responses concerning stimulation of interaction by the VLE in the three PBL phases. The highest scores were those for stimulation during the preliminary phase (face-to-face); the lowest scores were for stimulation of interaction during the self study phase (computer-mediated). Students gave significantly positive marks for the effect in the preliminary and reporting phases (the lower boundary of the 95\% confidence intervals was $>3$ for 5 of the 6 items). In the preliminary phase the VLE stimulated both participation in and depth of the discussion. Students indicated that the use of multimedia in case presentations enhanced the quality of the discussion. Students gave a significantly negative judgement of the stimulation of the interaction during self study (the upper boundary of the $95 \% \mathrm{Cl}$ was $<3$ for all items). The discussion board did not stimulate distance discussions in between face-to-face group meetings. During the self study phase the discussion board was seldom used for asking and answering questions and for information purposes. The marks were moderate/satisfactory for the preliminary and reporting phases, but poor for the self study phase. 


Statements
A Preliminary phase
- Projecting the minutes of the group meeting on the wall of the room
makes it easier to join in the discussion than when this is not done.
- Projecting the minutes of the group meeting on the wall enhances the
depth of the group discussion.
- When multimedia is used for case/task presentation the group
discussion is better than when the case is only text based.

Responses from Year $1 \& 2(n=355)$

$\begin{array}{lll}\text { Mean } & \text { SD } \quad 95 \% \quad \mathrm{Cl}\end{array}$ discussion is better than when the case is only text based.

\section{B Self study}

- The discussion board stimulates me to give information to other students between two group sessions.

- The discussion board stimulates me to put questions to other students between two group sessions.

$\begin{array}{llll}4.11 & 0.888 & 4.02 & 4.21 \\ 3.44 & 0.871 & 3.35 & 3.54 \\ 3.70 & 0.903 & 3.61 & 3.80\end{array}$

- The discussion board stimulates me to put questions to the tutor between two group sessions.

- Other students post questions on the discussion board between two group sessions.

- Teachers post questions on the discussion board between two group sessions.

$\begin{array}{llll}2.11 & .999 & 2.01 & 2.22 \\ 1.94 & 0.924 & 1.84 & 2.03 \\ 1.87 & 0.900 & 1.77 & 1.96 \\ 1.71 & 0.899 & 1.61 & 1.80 \\ 1.70 & 0.894 & 1.61 & 1.80 \\ 1.88 & 0.989 & 1.77 & 1.98 \\ 1.68 & 0.879 & 1.58 & 1.77 \\ 1.63 & 0.831 & 1.54 & 1.71 \\ 1.94 & 0.995 & 1.83 & 2.04 \\ & & & \\ 1.93 & 0.975 & 1.83 & 2.04 \\ & & & 2.94 \\ 2.81 & 1.234 & 2.68 & \\ & & 1.92 & 2.16\end{array}$

- The discussion board is used by teachers to answer students' questions.

2.04

$\begin{array}{lll}1.125 & 1.92 \quad 2.16\end{array}$ presentations or assignments.

\section{Reporting phase}

- The projection of the minutes on the wall makes it easier to join in the discussion than when the minutes would not be projected.

- The discussion in the group after self study is stimulated when EleUM is used to present materials (such as summaries, schemas, websites).

- During self study I post questions or things that are not clear to me on the discussion board to introduce them in the group discussion during the session.

\section{Marks for stimulation of 'interaction'}

- Give a mark (1-10) for the stimulation of student interaction by EleUM during the preliminary phase.

\begin{tabular}{|c|c|c|c|c|}
\hline $\begin{array}{l}\text { Give a mark (1-10) for the stimulation of student interaction by EleUM } \\
\text { during self study. }\end{array}$ & 4.91 & 2.103 & 4.69 & 5.13 \\
\hline $\begin{array}{l}\text { Give a mark (1-10) for the stimulation of student interaction by EleUM } \\
\text { during the reporting phase. }\end{array}$ & 6.12 & 1.812 & 5.93 & 6.31 \\
\hline
\end{tabular}

Table 1. Students perceptions regarding interaction. 
Table 2 shows the responses to the statements about consulting information sources during the self study phase and reporting phases. The questionnaire contained no items about information resources with reference to the preliminary phase (face-to-face), because during this phase students focus on prior knowledge and not on external information resources. The VLE was most useful for information gathering during self study, with the lower boundary of the $95 \% \mathrm{Cl}$ being $>3$. During the reporting phase information resources were not much used and not considered of any great value to the learning process (the upper boundary of the 95\% Cl was approximately 3). The mark for stimulation by the VLE of the use of different information resources was satisfactory for self study and unsatisfactory for the reporting phase.

\begin{tabular}{|c|c|c|c|c|}
\hline \multirow[b]{2}{*}{ Statements } & \multicolumn{4}{|c|}{ Responses from Year $1 \& 2(n=355)$} \\
\hline & Mean & SD & $95 \%$ & $\mathrm{Cl}$ \\
\hline \multicolumn{5}{|l|}{ A Self study } \\
\hline $\begin{array}{l}\text { - The online information resources (websites, papers in e-readers etc.) } \\
\text { in a course stimulated me to consult many different resources. }\end{array}$ & 3.86 & 0.900 & 3.77 & 3.96 \\
\hline $\begin{array}{l}\text { - The list of course related books (with location of book and available number } \\
\text { of copies) stimulated me to actually consult these books in the library. }\end{array}$ & 4.02 & 0.959 & 3.92 & 4.12 \\
\hline $\begin{array}{l}\text { - Power Point presentations or PDF presentations which are posted on EleUM } \\
\text { prior to the lecture stimulate me to do preparatory work for the lecture. }\end{array}$ & 3.40 & 1.188 & 3.28 & 3.53 \\
\hline $\begin{array}{l}\text { - In the self study phase after a lecture I consult Power Point presentations } \\
\text { or PDF presentations that are posted in EleUM. }\end{array}$ & 4.09 & 0.941 & 3.99 & 4.19 \\
\hline \multicolumn{5}{|l|}{ B Reporting phase } \\
\hline $\begin{array}{l}\text { - Online information resources (websites, papers in e-readers) } \\
\text { mentioned in the course book are consulted in the reporting phase. }\end{array}$ & 2.74 & 1.131 & 2.62 & 2.86 \\
\hline $\begin{array}{l}\text { - I think that the online consultation of information resources } \\
\text { during the reporting phase is valuable. }\end{array}$ & 2.99 & 1.130 & 2.87 & 3.11 \\
\hline \multicolumn{5}{|l|}{ C Marks for stimulation of the consultation of information resources } \\
\hline $\begin{array}{l}\text { - Give a mark (1-10) for the stimulation by EleUM of the use of different } \\
\text { information resources during the self study phase. }\end{array}$ & 7.31 & 1.237 & 7.18 & 7.44 \\
\hline $\begin{array}{l}\text { - Give a mark (1-10) for the stimulation by EleUM of the use of different } \\
\text { information resources during the discussion in the reporting phase. }\end{array}$ & 5.76 & 1.754 & 5.57 & 5.94 \\
\hline
\end{tabular}

Table 2. Statements about the consultation of information resources.

Table 3 shows students' general marks for the value of the VLE for their learning in the three PBL phases. The highest marks were given for support of self study and the lowest marks for support of the discussions in the reporting phase.

\begin{tabular}{|c|c|c|c|c|}
\hline & \multicolumn{4}{|c|}{ Responses from Year $1 \& 2(n=355)$} \\
\hline & Mean & SD & $95 \%$ & $\mathrm{Cl}$ \\
\hline $\begin{array}{l}\text { - Give a mark (1-10) for the support by EleUM of the learning during the } \\
\text { preliminary phase. }\end{array}$ & 6.12 & 1.728 & 5.94 & 6.30 \\
\hline - Give a mark (1-10) for the support by EleUM of the learning during self study. & 7.05 & 1.438 & 6.90 & 7.21 \\
\hline $\begin{array}{l}\text { - Give a mark (1-10) for the support by EleUM of the learning during the } \\
\text { reporting phase. }\end{array}$ & 5.97 & 1.710 & 5.79 & 6.15 \\
\hline
\end{tabular}

Table 3. General marks for the value of the virtual learning environment for student learning. 
The following remarks about the discussion board are representative of the responses to the three open questions at the end of the questionnaire:

'The discussion board does not initiate discussions, but that does not matter.'

'No questions are put to tutors in between group sessions. If you have a question, I think you will have to ask them in the group session or they may be questions the tutor is unable or unwilling to answer (with a view to self study).'

'Actually, the discussion board is just not used. Any questions or comments will be discussed in the group sessions.'

'I think the discussion boards contributed least to my learning. Email is much easier to use for communication in between tasks.'

\section{DISCUSSION AND CONCLUSION}

In-depth studies of e-learning in medical education are sparse. Research on process outcomes of virtual learning environments has focused mainly on distance education, while research on learning outcomes has mostly addressed programs with specific content. Review studies, like those by Chumley-Jones (Chumley-Jones, Dobbie, \& Alford, 2002), Greenhalgh (Greenhalgh, 2001) or Lau (Lau \& Bates, 2004), but also later studies (Cook, Dupras, Thompson, \& Pankratz, 2005; Sisson, Hughes, Levine, \& Brancati, 2004; Smucny \& Epling, 2004), show that students generally have a favourable attitude towards digital learning formats. However, the effects of these formats on performance or knowledge are ambiguous. Some studies report significantly better scores on knowledge tests by users of e-learning programs compared with control groups, whereas other studies report no differences. As far as we know, no study has yet addressed the general educational effects of VLEs in face-to-face group sessions in medical problem-based learning.

This study shows that students think that a VLE built with Blackboard for use in an undergraduate medical PBL curriculum is effective in supporting face-to-face interaction in tutorial group sessions. Students showed positive views of the stimulation of interaction during the preliminary phase and moderately positive views of it during the reporting phase. Although the study design did not allow for comparison between tutorials with VLE and 'conventional' PBL without VLE, we think that the students who participated in this study had had enough experience with group discussions to notice which factors supported or impeded interaction in the group.

Students also indicated that the quality of discussions was enhanced by multimedia case presentations compared with text-based presentations. Because a lot of cases in the thematic blocks are still exclusively text-based, the students in our study were well able to compare the 2 formats. This positive, albeit subjective, view is also supported by experimental studies of process outcomes for multimedia cases. Kamin et al. (Kamin, O'Sullivan, Deterding, \& Younger, 2003) analysed the content of discussions among students for different case formats and found that video presentations in face-to-face groups led to more critical thinking processes compared with text-based presentations. 
Introducing group computers in tutorial groups, presenting cases using a VLE and projecting cases on the wall of the group room constitutes a form of learning in which group discussions and working with the computer are combined. This is the type of social configuration that Crook calls 'Interactions at computers' (Crook, 1996), in which peers work together on the same computer-assisted task. We expected that this social configuration, which consisted of multimedia case presentations and the recording of the minutes on the network to allow immediate presentation to the group, would enhance the discussion in the preliminary phase. Some teachers, however, were apprehensive that the presence of a computer might hamper discussions. This study shows that students do not regard the presence of the group computer in the room as disturbing to the group process.

Distance, computer-mediated interaction - a social configuration that Crook (Crook, 1996) refers to as 'interactions through computers' - was not stimulated by the VLE in our study. The items about stimulating discussions among students and among students and teachers by the discussion boards during self study yielded negative responses. The discussion boards were mainly used to post the minutes of group meetings and hardly for discussion. With the current VLE, use of the discussion boards is entirely up to the students and students have no explicit targets and focused tasks that might encourage full exploitation of the potential value of asynchronous communication for more in depth discussion (Wolf, 1988). The paucity of interactions and the absence of the desired 'transactive discussions' (articulation, critique and defence of ideas) with free and untargeted use of discussion boards is also described in the literature (Tolmie \& Boyle, 2000). Harasim (Harasim, Hiltz, Teles, \& Turoff, 1995) uses the metaphor of a garden to illustrate this: an on-line course requires attention to instructional design, with structures being put in place to 'hold and shape the interaction among participants'.

Many studies claim that, for productive interaction to be initiated via discussion boards, it is important that tutors actively moderate online discussions.(Warren \& Rada, 1998; Wilson \& Whitelock, 1998). However, the main factor is probably that students accept the usefulness and the necessity of computerised interaction (Hammond, 2000; Tolmie \& Boyle, 2000). Of course, the usefulness of computerised interaction is more self-evident and easier to achieve with real distance learning than in residential contexts. Students' responses to the open questions clearly reflect their lack of conviction of the usefulness of online communication via the discussion board with each other and with tutors between face-to-face meetings.

It is our opinion that in situations where students have regular face-to-face contact in tutorial group meetings, skill training sessions and other activities, the conditions for the successful implementation of discussion boards will only be met in exceptional circumstances. With subjects that students see as relevant and that are difficult to teach face-to-face, specially constructed tasks and active moderation of discussions by tutors might result in more in depth learning through online asynchronous discussion. When students have no face-to-face contact with the group for a prolonged period of time, for instance when students are doing clerkships in different locations, the use of discussion boards may seem more natural. 
In addition to the effects of the VLE on group interaction, this study addressed the effects of consultation of information resources by students. Good knowledge and good thinking are inextricably bound up (Bereiter \& Scardamalia, 1993) and students must learn to identify questions worth pursuing and explore and interrogate information in a resource-based approach (Pithers \& Soden, 2000). In our study students clearly indicated that direct access to digital information resources and an up-to-date list of the printed books in the library stimulated the use of this hybrid collection during self study. In order to guarantee lawful availability of content for large numbers of students and at the same time maintain accessibility of the growing collection for the curriculum, close collaboration between teachers and the university library in including resources in the VLE is of vital importance. In a way, the teachers who develop the tasks for the VLE fill the library systems and these resources are then linked back to the VLE. The importance of such an approach is also suggested in the literature (MacColl, 2001).

In a way, advance selection of information resources goes against the principles of $\mathrm{PBL}$, which require students to conduct information searches independently. On the other hand, nobody learns to surf in the middle of a desert and students should therefore have access to a minimal literature base to enable them to conquer the waves of the information society. Problem-based learning students are continually encouraged to look for additional information resources and offered a sufficient number of tasks in which active literature searches play a central role. Nevertheless, we must guard against the over-prescribing of literature by teachers.

Although students clearly indicated that the VLE supported face-to-face interaction during the preliminary phase of $P B L$, their general assessment of the value of the VLE for the learning process at this stage was disappointing: they rated it at just above 6 . An explanation for this disappointing mark might be that, despite students appreciation of the role of multimedia for the interaction during the preliminary discussion, so far visuals and video have been used for a limited number of cases only.

We examined the possibility of a novelty effect of the use of computers in education by comparing the perceptions of the Year 1 students, who had used the VLE for 4 months, with those of the Year 2 students, who had used the VLE for 16 months. The novelty effect refers to the phenomenon that students tend to give novel media increased effort and attention, which may result in motivational effects and achievement gains that are only temporary (Niemiec \& Walberg, 1987). The comparison showed significant differences (2-sample t-test) between the 2 groups for only 6 out of 35 propositions. Three of these differences were related to the use of information resources, with Year 2 students giving stronger indications of being stimulated by the VLE to use those resources compared with Year 1 students. Thus, these differences swing in the opposite direction to that predicted by a hypothetical novelty effect. The 3 other differences concerned the appreciation of discussion boards for distance interaction. This was already negative for both groups and only deteriorated over the year. These findings indicate that it is not very likely that the results of this study were substantially affected by a novelty effect. 
A limitation of this study is that the results are based on students' subjective perceptions of the educational value of a VLE in an undergraduate medical curriculum. More in-depth studies will be needed to gain more insight into the effects of VLEs in general and multimedia in particular on interactions in tutorial groups.

\section{REFERENCES}

Bereiter, C., \& Scardamalia, M. (1993). Surpassing ourselves: an inquiry into the nature and implications of expertise. Chicago: Open Court.

Chumley-Jones, H. S., Dobbie, A., \& Alford, C. L. (2002). Web-based learning: Sound educational method or hype? A review of the evaluation literature. Academic Medicine, 77(10), S86-S93.

Cook, D., Dupras, D., Thompson, W., \& Pankratz, V. (2005). Web-based learning in residents' continuity clinics: A randomized, controlled trial. Academic Medicine, 80(1), 90-97.

Cook, J. (2002). The role of virtual learning environments in UK medical education. LTSN Bioscience Bulletin, 5, 10-11.

Crook, C. (1996). Computers and the collaborative experience of learning. London: Routledge.

Greenhalgh, T. (2001). Computer assisted learning in undergraduate medical education. British medical journal, 322(7277), 40-44.

Hagdrup, N., Edwards, M., Carter, Y., Falshaw, M., Gray, R., \& Sheldon, M. (1999). Why? What? and How? IT provision for medical students in general practice. Medical Education, 33, 537-541.

Hammond, M. (2000). Communication within on-line forums: the opportunities, the constraints and the value of a communicative approach. Computers \& Education, 35, 251-262.

Harasim, L., Hiltz, R., Teles, L., \& Turoff, M. (1995). Learning Networks: a field guide to teaching and learning online. In (pp. 128). Cambridge, MA: MIT Press.

Harden, R. M., \& Hart, I. R. (2002). An international virtual medical school (IVIMEDS): the future for medical education? Medical Teacher, 24(3), 261-267.

Hoffmann, B., \& Ritchie, D. (1997). Using multimedia to overcome the problems with problem based learning. Instructional science, 25(2), 97-115.

Kamin, C. S., O'Sullivan, P., Deterding, R., \& Younger, M. (2003). A comparison of critical thinking in groups of third-year medical students in text, video, and virtual PBL case modalities. Academic Medicine, 78(2), 204-211.

Kim, S., Kolko, B., \& Greer, T. (2002). Web-based problem solving learning: third-year medical students' participation in end-of-life care virtual clinic. Computers in Human Behavior, 18, 761-772.

Koschmann, T. D., Myers, A. C., Feltovich, P. J., \& Barrows, H. S. (1994). Using technology to assist in realizing effective learning and instruction: a principled approach to the use of computers in collaborative learning. The journal of the learning sciences, 3(3), 227264. 
Lau, F., \& Bates, J. (2004). A review of e-learning practices for undergraduate medical education. Journal of Medical Systems, 28(1), 71-87.

MacColl, J. (2001). Virtuous learning environments: the library and the VLE. ProgramElectronic Library and Information Systems, 35(3), 227-239.

Niemiec, R., \& Walberg, H. (1987). Comparative effects of computer-assisted instruction: a synthesis of reviews. Journal of educational computing research, 3(1), 19-37.

Pithers, R. T., \& Soden, R. (2000). Critical thinking in education: a review. Educational Research, 42(3), 237-249.

Roberts, C., Lawson, M., Newble, D., \& Self, A. (2003). Managing the learning environment in undergraduate medical education: the Sheffield approach. Medical Teacher, 25(3), 282-286.

Romiszowski, A. (2004). Computer-mediated communication. In D. H. Jonassen (Ed.), Handbook of research on educational communications and technology (second edition ed., pp. 397-431). Mahwah, New Jersey: Lawrence Erlbaum Associates.

Sisson, S. D., Hughes, M. T., Levine, D., \& Brancati, F. L. (2004). Effect of an Internetbased curriculum on postgraduate education - A multicenter intervention. Journal of General Internal Medicine, 19(5), 505-509.

Slotte, V., Wangel, M., \& Lonka, K. (2001). Information technology in medicaleducation: a nationwide project on the opportunities of the new technology. Medical Education, 35, 990-995.

Smucny, J., \& Epling, J. W. (2004). A web-based approach to teaching students about diagnostic reasoning. Family Medicine, 36(9), 622-624.

Stromso, H., Grottum, P., \& Hofgaard Lycke, K. (2004). Changes in student approaches to learning with the introduction of computer-supported problem-based learning. Medical Education, 38, 390-398.

Tolmie, A., \& Boyle, J. (2000). Factors influencing the success of computer mediated communication (CMC) environments in university teaching: a review and case study. Computers \& Education, 34, 119-140.

Ward, J., Gordon, J., Field, M., \& Lehmann, H. (2001). Communication and Information technology in medical education. Lancet, 357, 792-796.

Warren, K., \& Rada, R. (1998). Sustaining computer-mediated communication in university courses. Journal of Computer Assisted Learning, 14, 71-80.

White, C., Albritton, T., \& Rindt, K. (2001). MEOW: a web site to improve consistency and communication in clerkships. Academic Medicine, 76(5), 542.

Wilson, T., \& Whitelock, D. (1998). What are the perceived benefits of participating in a computer-mediated communication (CMC) environment for distance learning computer science students? Computers \& Education, 30(3/4), 259-269.

Wolf, D. (1988). The quality of interaction: domain knowledge, social interchange, and computer learning. In G. Forman \& P. Pufall (Eds.), Constructivism in the computer age (pp. 203-217). Hillsdale, NJ: Lawrence Erlbaum. 


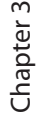


Chapter 3

How video cases should be used as authentic stimuli in problem-based medical education

Published in Medical Education 2007; 41 (2): 181-188

Bas A de Leng, Diana H J M Dolmans, Margje W J van de Wiel, Arno M M Muijtens \& Cees P M van der Vleuten 


\section{ABSTRACT}

\section{Purpose}

To examine problem-based learning ( $\mathrm{PBL}$ ) students' views on the added value of video cases compared to text-based cases in the pre-clinical phase of undergraduate medical education and on the conditions for productive use of video in tutorial group discussions.

\section{Method}

Participants were 2nd-year students who had completed a PBL programme featuring video cases. Three groups of 6-8 randomly selected students participated in focus-group interviews guided by a moderator using a 'questioning route'. The interviews were audiotaped, transcribed and analysed. The summary reports were approved by the students.

\section{Results}

According to the students, the video cases enabled them to create realistic mental pictures of disorders, provided integrated pictures of patients as people, which challenged them to elaborate the cases seriously and were more memorable than text-based cases. Cases that students perceived as fostering the productive use of video were neither too directive nor too complete, tailored to students' prior knowledge, short, varied in design and complementary to other materials. The cases should be viewed in a structured, purposeful manner, with cues, instructions and prompts to focus attention on essential issues.

\section{Conclusion}

The video cases were generally perceived as a valuable stimulus for group discussions in PBL. However, productive use depended on specific conditions. Many of the advantages and conditions mentioned are supported by earlier non-empirical claims in the literature or can be explained by theory and empirical studies on symbol systems. Future observational studies should address the effects of specific attributes of video as a medium. 


\section{INTRODUCTION}

In problem-based learning ( $\mathrm{PBL}$ ), students learn by solving problems derived from real practice. In medical education, the problems are patient cases. Patient cases enable integration of different aspects of a problem, including behavioural and psychosocial factors, treatment and prevention. In the pre-clinical years, the cases are generally constructed to'trigger' elaboration of basic science knowledge within

a clinical context. Cases are mainly written texts and may contain descriptions as well as dialogue.

Many medical schools adopt PBL in the expectation that learning from authentic cases early in the curriculum will prepare students better for clinical training than the traditional lecture-based curriculum. Unfortunately, many schools have discovered that despite experience with patient cases, the transition from pre-clinical to clinical training remains problematic. A way to address this problem is to increase the authenticity of cases. Different aspects of authenticity can be distinguished: real-world authenticity (materials and activities reflect real practice), personal authenticity (students accept the activities as 'real or genuine') and disciplinary authenticity (problem solving builds on the intellectual tradition of a discipline) (Shaffer \& Resnick, 1999). The possibilities for increasing case authenticity in the pre-clinical years are limited, because pedagogical, ethical and logistic restraints limit the use of real and simulated patients. This is where video cases are useful as a way of enhancing the authenticity of patient cases (Bromke, Byers, \& Ceglowski, 1997; Keppell, Kennedy, Elliott, \& Harris, 2001; McMahon, Hafler, \& Dluhy, 2003).

In the medical education literature, several pedagogical advantages of the use of video cases over written texts have been described.

- Videos can give a more holistic picture of a patient problem. Written texts have often undergone some sort of preparation and use verbal labels that frequently reveal the output of an expert's pattern recognition process. With videos, it is not the expert but the students themselves who translate the images and sounds relating to the patient into a medically meaningful story (Albanese, 2005). This is advantageous to students because it enables them to develop their pattern recognition skills instead of learning to diagnose on the basis of verbal labels, a skill that will be of little use to them in practice (Bransford, Sherwood, \& Hasselbring, 1990).

- Video gives students freedom to observe events in their own way, not filtered through a doctor's perspective. The structure and language of verbal cases tend to grant primacy to professionals' observations and interpretation of diagnostic tests, while playing down the patient's interpretation of reality (Kenny \& Beagan, 2004).

- Video can convey emotion, body language and other non-verbal cues directly and vividly. Because most text-based cases lack this possibility, their use may induce emotional detachment in students, thereby obstructing the development of a caring and empathic attitude. 
- A fringe benefit of video use may be that students of the so-called Generation $\mathrm{X}$ or MTV generation are more familiar with this medium. They have grown up in a world that is constantly 'pumping' images at them and may have difficulty focusing on static text-based cases (Brown \& Fritz, 2001).

Few empirical studies have investigated the effects of video cases on learning and, as stated by Richard Clark, 'media comparison' studies are often of limited use, because the effect of the medium is frequently confounded by the effects of the instructional method, design effort invested and content (Clark, 1985). 'Media comparison' studies worth mentioning are those by Kamin (Kamin, O'Sullivan, Deterding, \& Younger, 2003) and Balslev (Balslev, de Grave, Muijtjens, \& Scherpbier, 2005), who compared the use of video cases with the use of text-based cases in medical PBL, taking care to keep independent variables as constant as possible. These studies demonstrated that video actually enhanced cognitive activities in PBL groups.

In studying the educational effects of video use, one should take account of the diversity of this medium, just as written text can present a wide range of forms of communication (Shephard, 2003). In the context of the tutorial room, video can tell a story (narrative), provide access to real events (original material), give background information (documentaries, interviews), convey emotion, etc. Furthermore, the media carrying video recordings have evolved and the possibilities for using video in education have expanded dramatically. While with films, television and videotape the use of 'moving images' was restricted mainly to linear teacherdirected use, CD-ROMs and DVDs have opened the door to more interactive, 'on demand', student-centred use of video. Today, video is 'streamed' via a network of computers (intranet and internet) and can be integrated with other resources.

Given the increased possibilities and the dearth of studies about the effectiveness of video in medical education (Balslev, de Grave, Muijtjens, \& Scherpbier, 2005; Ber \& Alroy, 2001; Bromke, Byers, \& Ceglowski, 1997; Kamin, O'Sullivan, Deterding, \& Younger, 2003; Parkin \& Dogra, 2000), we decided to design a study to examine whether and how students use and learn from video cases. We conducted a focusgroup study to seek students' perceptions of the effects of video in tutorial groups in a PBL curriculum. The aim of our study was to examine:

- what medical students perceive to be the added value of the use of video cases as compared to text-based cases; and

- what conditions medical students perceive to be essential for the productive use of video cases in tutorial group discussions. 


\section{METHODS}

\section{Setting}

Since September 2000, Maastricht Medical School has replaced some paper cases by video cases to trigger the discussion in the tutorial group. 'Streaming' video is used and the video cases are delivered to the tutorial group rooms through an intranet by a 'virtual learning environment' (de Leng, Dolmans, Muijtjens, \& van der Vleuten, 2006). In the first 2 years of the curriculum, 12-15 video cases of 3-20 minutes' duration are used. They show either simulated or real patients and differ considerably in content, e.g. a strong emotional appeal from a patient who is in a great deal of pain, a registration of an advanced trauma life support (ATLS) procedure after a motorcycle accident, 3 patients with similar symptoms and complaints (chest pain) but with different underlying pathophysiology, a complete consultation (history taking, physical examination and evaluation) of patients with arthrosis by an orthopaedic surgeon, an epileptic insult, etc. In June 2005, we performed a focus-group study among 2 nd-year students who had completed the programme featuring the video cases to seek their views on how they had worked with and learned from these cases.

\section{Focus groups}

We conducted focus-group interviews because this qualitative approach is inductive and naturalistic, and therefore appropriate for collecting different opinions and experiences (Krueger \& Casey, 2000). Focused discussions in peer groups provide a relatively safe environment in which the imbalance of power between researcher and subject is toned down. Additionally, group interaction fosters deeper analysis of the views on a topic and may even refine or modify them. This is a strong point of the focus-group method compared with individual questionnaires and interviews.

A potential drawback of focus groups is that during the discussions, talkative individuals or those who consider themselves experts dominate the shy and quiet participants in the group. In addition, the social pressure of peers or the responses of the moderator can influence the honesty of the contributions in the group. We tried to counteract these limitations by using an experienced moderator who solicited everyone's input actively, repeatedly stressed the value of both positive and negative experiences and asked the participants to write down some catchwords before a topic was discussed in the group.

\section{Subjects}

Second-year undergraduate medical students who had just completed their last regular thematic block participated in a group discussion about the use of video in tutorial groups. In order to select a stratified random sample, we divided the total of about 300 2nd-year students into 30 strata on the basis of the composition of the tutorial groups in the last block of the 2 nd year. Thirty students were selected randomly from these strata and $70 \%$ of these students participated in the study, of whom 9 were male and 12 female. Three groups of 6-8 students were interviewed and all received a small financial incentive. 


\section{Material}

Consistency across the groups in the way questions were asked was enhanced by using a 'questioning route', i.e. a sequence of questions in complete sentences (Table 1) that guides the interviews (Krueger \& Casey, 2000). These questions also supported the leading moderator (MvdW), who was highly experienced in focusgroup interviews but had no direct involvement in the courses under discussion.

\section{Procedure}

All 3 focus-group sessions lasted 2 hours and were held on 1 day. One of the authors (MvdW) moderated the discussions. The principal investigator (BdL) was assistant moderator and took comprehensive notes of the discussions. Moderators and students sat around a table, with paper and pen available for everyone to enable the students to write down some notes before discussing their answers to the questions in the group. The sessions were audio-recorded and transcribed literally. A summary report of the discussion was mailed to the students for approval.

\section{Question 1 (30 minutes):}

We would like you to look back at the videos that were used in the tutorials during the past two years. Select one case in which you thought the use of video was particularly effective in the discussion in the tutorial group. Give a step by step description of the discussion about that case (ask the students to write this down).

\section{Question 2 (15 minutes):}

When does the use of video add to the value of the discussion? You might try and determine this by comparing the effective case with video that we just discussed with another effective case that was only text based. (ask the students to write their answers down). Can you give any differences in the course of the discussion in the group between the text-based case and the video case we just discussed? Were these differences due to the formats, i.e. text versus video?

\section{Question 3 (30 minutes):}

Think of a video case where you thought the use of video was not effective for the discussion in the group. Describe what did not go well. When you compare this video case with the effective video cases discussed earlier, can you identify any factors within the case or in the context that determined the effectiveness? (ask the students to write their answers down)

\section{Question 4 (10 minutes):}

So far we have looked at the way you used video during the discussions in the group and how it affected the learning process. Obviously, we first and foremost want to establish whether the use of video improves your learning. Looking back at the past two years, do you think you learned more from cases with video than from cases without video?

\section{Question 5 (5-10 minutes):}

Are there any aspects relating to the use of video in the discussions in the tutorial group that have not been brought up in the discussion so far and that you think are relevant?

Table 1. The sequence of questions ('questioning route') used by the moderators to guide the focused discussions. The time in parentheses is an indication of the time allocated for each question. 


\section{Analysis}

The transcripts of the discussions in the 3 focus groups were analysed by the principal investigator ( $\mathrm{BdL}$ ), who read through the transcripts, identifying and marking themes in the discussion. Themes often recurred during a discussion and were not necessarily confined to the answers to a particular question of the 'questioning route'. Subsequently, the transcripts were thematically reordered and summarised. The categorisation was discussed critically with the moderator and adjusted whenever necessary. Each student received a report of his or her own group discussion, in which the students' opinions were described and illustrated with characteristic quotations (with students' initials in parentheses). If possible the intensity of an opinion and the extent of support from the group were indicated as well. The summary reports were approved by all the students.

\section{RESULTS}

The students' stories and opinions were assigned by the investigators to 1 of 2 themes: (1) the added value of video cases to the PBL process and (2) the conditions for productive use of video cases in PBL. The following section will summarise the students' opinions. For each opinion category a few characteristic quotations from the focus-group discussions are presented in Table 2 and Table 3. Numbers indicating focus group and student, respectively, are given in parentheses.

\section{Added value of video cases in PBL}

\section{Video cases are more authentic and illustrative}

A video presentation gives a better picture of diseases and examinations than a written text. For instance, students may have difficulty picturing certain neurological or psychiatric disorders and may be unsure whether the picture in their mind corresponds with reality. Watching a video of a patient gives them a more faithful representation of reality (Table 2 ).

\section{Video cases present a comprehensive view}

Video presentations give an integrated picture of the situation of a patient and at the same time the richness of the information in the video makes it possible to focus on the details of a clinical picture. Video offers students role models by showing them doctors who are dealing with problems in real practice. In this way they can observe early in their study how communication skills are used, how standard examination techniques taught in skills training are adapted to real practice and how a doctor-patient relationship is established (Table 2).

\section{Video cases are motivating and challenging}

A video presentation motivates students to work on a case and can sometimes make it easier for students to imagine themselves in a certain situation or identify with people. Some written cases may also enable this, because the description in itself is very evocative or because a student or the tutor adds an example or a personal experience. However, these additions are dependent on personal contributions and not inherent in the material. Moreover, compared with a text, a 


\section{Video cases are more authentic and illustrative}

"You read long descriptions of psychiatric disorders for instance, and with a video you can link a picture to the text." $(3,3)$

"A physician uses his eyes first, doesn't he. He sees signs and symptoms and detects certain clinical pictures. We read about them in books and sometimes have little idea of how to visualize them. That is why a video is much more true to life and efficient." $(3,2)$

\section{Video cases present a comprehensive view}

"Video gives you an overall picture with all aspects that figure in the real world. You are confronted with more aspects than when it is only written down." $(1,4)$

"In a video about shock. We had to compare three patients ... What was good was that we started to pay attention to details. What is pale skin, what is red skin? In a text you just read red skin, it is a given." $(3,2)$

"In year 1 there was a video of a car accident and the emergency care in that situation. We watched it together and that led to a good discussion in the group. We discussed the care that was given, what happened and why.' $(3,1)$ "And what you would do as a professional in that situation." $(3,5)$

\section{Video cases are motivating and challenging}

"With a video you can rub people's noses in it and show them the consequences of a certain disease or strategy." $(1,1)$

"A video about behavioral disorders in children showed a child that was just sitting there crying and did not want to eat and you did not know what was going on. You want to know what is wrong with that child. The image is challenging of itself; it really moves you" $(1,2)$

\section{Video cases are better retained in memory}

"Yes, the image, like that epileptic patient, I can still see it in my mind" $(3,5)$ "That was such a long time ago and still everybody remembers it as we are talking about it now." $(3,7)$

"This interview clearly shows that it is much easier for us to recall a case that was presented with a good video than a good case without a video." $(1,8)$

"When you are learning skills such movies are very good, because when you are performing the skill yourself, you just play the movie in your head. You have a better idea of where something starts and ends and how it proceeds". $(1,7)^{\prime \prime}$

Table 2. Added value of video cases in PBL. Categories of students' perceptions followed by exemplar quotations from the focus group discussions.

The numbers in parentheses indicate the focus group and student, respectively.

video can confront students with a situation more forcefully and make a stronger impression thus challenging students to tackle the problem actively (Table 2).

\section{Video cases are better retained in memory}

A video presentation enhances retention in longterm memory. As a result students are better able to remember actions and procedures they have watched on video and apply them in practice (Table 2).

\section{Conditions for the productive use of video cases in PBL}

The contents of video cases should not be too complete or directive

Some things should remain unclear or be omitted altogether, in order to leave some things for students to explore and investigate. The diagnosis should not be 


\section{The contents of video cases should not be too complete or directive}

"Everything you could see was quite clear, things were explained and the video did not engage your curiosity, it raised no questions." $(1,5)$

"You have videos that give information and videos that make you want to take action. You need to make that distinction, and the informative videos should not be used for the preliminary discussion in PBL." $(3,6)$

\section{The content of the video cases should present an appropriate degree of difficulty}

"It should be somewhat clear, but also a bit challenging. Like, yes I do want to learn more about that. It should not be childish, you should feel that you are being taken seriously, it may even be somewhat too challenging." $(3,6)$

"Seeing an endoscopy or an abdominal operation after having learned about the anatomy of the bowel and then being asked what do you see here and what do you see there, now that would seem really interesting to me." $(3,2)$

\section{The video cases should be watched in a structured fashion}

"It depends on the tutor what happens during the preliminary discussion and how the video is actually used. We had a rehabilitation specialist who kept asking questions. He was motivated to get at the story behind the clinical presentation, what a disease means to a patient and to which aspects you should pay attention. " $(3,7)$

"With the video on epilepsy, we were instructed to first watch the patient and then what the girl was doing. Such instructions are very important." $(1,5)$

"In the block about shock, we had to compare and describe three patients with similar symptoms. Next we had to find out who had had an infarction. That was a different way of watching a video and paying attention to it. You are motivated and made to think." $(3,1)$

"You could divide the group, like: you two are the patient's partner and you two are the orthopedic surgeon treating the patient. Obviously, that would make for a good discussion." $(1,7)$ "Everybody will be advocating their own interests!" $(1,2)$

\section{The video cases should be short and unique}

"With the arthrosis cases, the second video was structured in exactly the same way, only with the questions about the hip instead of the knee. That video we just did not watch at all." $(3,5)$ "All findings from the examination were written down in detail, that does not challenge you to take a really good look at the patient's symptoms. You should use video or text, not both." $(3,6)$

Table 3. Essential conditions for productive use of video cases in tutorial group discussions. Categories of students' opinions followed by exemplar quotations from the focus group discussions. The numbers in parentheses indicate the focus group and student, respectively.

given, because students enjoy the challenge of making a differential diagnosis themselves (Table 3).

\section{The content of the video cases should present an appropriate degree of difficulty}

The degree of difficulty of the case should be appropriate for what students already know at that point in the curriculum. Students also say that correct timing of the use of video in the PBL process is important. For instance, a certain anatomical or physiological subject should not be included in a video case before students have acquired the relevant knowledge (Table 3).

\section{The video cases should be watched in a structured fashion}

A structured approach to watching a video case is perceived as essential. Many students see an important role for the tutor in this respect. Some students suggested 
that the procedure should be standardised by including focused questions in the tutor instructions or in the video. Cues in the video or in accompanying materials could also direct students' attention to particular aspects. For instance, students could watch symptoms on a video on the basis of medical reports (for instance a referral letter) or a list of laboratory results (Table 3 ).

Observation can also be guided by having students compare items or examine a topic from different angles (Table 3).

\section{The video cases should be short and unique}

The video should not be too long; they should not be identical in structure, nor should they repeat a message already stated in the text (Table 3).

\section{DISCUSSION AND CONCLUSION}

In this study, we examined what medical students perceive to be the added value of video cases in PBL and what they perceive to be essential conditions for the productive use of video cases in their tutorial group discussions. In general, students saw video cases as a valuable stimulus for group discussions and learning in PBL.

They said that the depictive quality of video cases helped them to create realistic mental pictures of disorders. In addition students stated that video cases give an integrated picture of the patient as a person appealing to multiple senses of the students and motivating them to work seriously on elaborating cases. Finally, the students indicated that video cases were more memorable.

With regard to the conditions video cases should meet to promote productive tutorial group discussions students said that:

- the content of the video case should be suitable for elaboration and neither too directive nor too complete and detailed;

- the content of the video case should be in line with their previous knowledge;

- the video case should be viewed in a structured, purposeful manner, with cues, instructions and prompts to focus attention on essential issues; and

- the video cases should be short, complement other materials and vary in design.

Some of the advantages of video cases mentioned by the students in this study are related closely to the pedagogical advantages described in the literature and mentioned in the introduction, i.e. video cases present a more holistic picture and can convey emotion. These findings are supported by Salomon's theories on symbol systems (Salomon, 1994). He claims that visuals convey more dimensions of information (high repleteness) than passages of text and we assume that it is due to this high repleteness that video is a better medium than text for conveying multifaceted aspects of human behaviour, which in turn makes it more effective in touching students' emotions.

Salomon also noted that visuals in videos fully resemble their referents in real life (high resemblance) while being non-notational (open to ambiguity) and transient. 
Kozma, elaborating on Salomons' work (Kozma, 1991), suggested that the high resemblance and repleteness of video might help students with little previous knowledge to connect mental representations to the real world in a way that they find hard to accomplish with text. This is exactly what 2 nd-year students with no clinical experience told us that video enabled them to do: visualising disorders they had never encountered. Baggett (Baggett, 1989) inferred that the repleteness of video would present more pegs which could be used to associate new information with information already in long-term memory. This might explain why students say that video cases enhance the retention of case material in long-term memory.

The strong need for viewing the video cases in a structured and focused fashion that emerged from the interviews may be related to a drawback of visuals mentioned by Kozma (Kozma, 1991). He stated that information in visuals is more ambiguous than that in text, and if learners are not given directions they may ignore important elements or attach too much significance to extraneous elements of the image. In addition, he cautioned against learners assuming that video needs little mental effort, because this is a misconception that may cause shallow information processing. We expect that instructions, cues and prompts can help students to watch video cases in an active, focused and structured fashion.

Some of the conditions for productive use of video cases mentioned by the students also relate to the principles of effective case design; in PBL, as described by Dolmans et al. (Dolmans, Snellen-Balendong, Wolfhagen, \& van der Vleuten, 1997), a case should be tailored to students' previous knowledge, contain several cues that stimulate elaboration and match one or more of the curricular objectives. They also cautioned, however, against too many cues and too much structure, as that might hamper elaboration and self-directed learning. This might be equally applicable to video cases.

The present study has some limitations. A focus-group study was performed to obtain a global view of the use of video and how it affects the learning process in tutorial groups. Such a self-reporting method is inherently biased and we would like to obtain a more objective view through observational studies in future research. Secondly, our research question about the added value of video cases has a'media comparison' component: students are asked to compare video with text-based cases. In the future 'media attributes' studies are needed that focus on specific attributes of video as a medium (Wetzel, Radtke, \& Stern, 1994). In conjunction with instructional methods that take advantage of these attributes, this may offer us a better specified set of conditions for effective use of video cases as an authentic context for learning in medicine. 


\section{REFERENCES}

Albanese, M. A. (2005). Coming to a medical school near you: full motion video medical education. Medical Education, 39(11), 1081-1082.

Baggett, P. (1989). Understanding visual and verbal messages. In H. Mandl \& J. Levin (Eds.), Knowledge acquisition from text and pictures. Amsterdam, The Netherlands: Elsevier.

Balslev, T., de Grave, W. S., Muijtjens, A. M. M., \& Scherpbier, A. J. J. A. (2005). Comparison of text and video cases in a postgraduate problem-based learning format. Medical Education, 39(11), 1086-1092.

Ber, R., \& Alroy, G. (2001). Twenty Years of Experience Using Trigger Films as a Teaching Tool. Academic Medicine, 76(6), 656-658.

Bransford, J. D., Sherwood, R. D., \& Hasselbring, T. S. (1990). Anchored instruction: Why we need it and how technology can help. In D. Nix \& R. J. Spiro (Eds.), Cognition, education, and multimedia: Exploring ideas in high technology (pp. 115-141). Hillsdale, NJ: Lawrence Erlbaum.

Bromke, B. J., Byers, S. E., \& Ceglowski, W. S. (1997). Video case programs for PBL: integration of microbiology and medicine. Teaching and learning in medicine, 9(3), 233-237.

Brown, L. H., \& Fritz, K. O. (2001). The X factor: teaching strategies for Generation X. The Michigan community college journal(spring), 53-66.

Clark, R. E. (1985). Confounding in educational computing research. Journal of educational computing research, 1(2), 137-148.

de Leng, B. A., Dolmans, D. H. J. M., Muijtjens, A. M. M., \& van der Vleuten, C. P. M. (2006). Student perceptions of a virtual learning environment for a PBL undergraduate medical curriculum. Medical Education, 40(6), 568-575.

Dolmans, D. H. J. M., Snellen-Balendong, H., Wolfhagen, I. H. A. P., \& van der Vleuten, C. P. M. (1997). Seven principles of effective case design for a problem-based curriculum. Medical Teacher, 19(3), 185-189.

Kamin, C. S., O'Sullivan, P., Deterding, R., \& Younger, M. (2003). A comparison of critical thinking in groups of third-year medical students in text, video, and virtual PBL case modalities. Academic Medicine, 78(2), 204-211.

Kenny, N. P., \& Beagan, B. L. (2004). The patient as text: a challenge for problem-based learning. Medical Education, 38(10), 1071-1079.

Keppell, M., Kennedy, G., Elliott, K., \& Harris, P. (2001). Transforming traditional curricula: enhancing medical education through problem-based learning, multimedia and web-based resources [Electronic Version]. Interactive Multimedia Electronic Journal of Computer-Enhanced Learning, 3 from http://www.imej.wfu.edu/ articles/2001/1/index.asp.

Kozma, R. B. (1991). Learning with media. Review of educational research, 61(2), $179-211$.

Krueger, R. A., \& Casey, M. A. (2000). Focus groups: a practical guide for applied research (3 ed.). London: Sage Publications, Inc. 
McMahon, G. T., Hafler, J. P., \& Dluhy, R. G. (2003). Development and implementation of the VISUAL Project (Video for Structured Understanding and Learning). Boston: Harvard: Macy Institute Program for Physician Educators.

Parkin, A., \& Dogra, N. (2000). Making videos for medical undergraduate teaching in child psychiatry: the development, use and perceived effectiveness of structured videotapes of clinical material for use by medical students in child psychiatry. Medical Teacher, 22(6), 568-571.

Salomon, G. (1994). Interaction of media, cognition, and learning: an exploration of how symbolic forms cultivate mental skills and affect knowledge acquisition. Hillsdale, New Jersey: Lawrence Erlbaum Associates.

Shaffer, D. W., \& Resnick, M. (1999). "Thick" Authenticity: New Media and Authentic Learning. Jl. of Interactive Learning Research, 10(2), 195-215.

Shephard, K. (2003). Questioning, promoting and evaluating, the use of streaming video to support student, learning. British Journal of Educational Technology, 34(3), 295-308.

Wetzel, C. D., Radtke, P. H., \& Stern, H. W. (1994). Instructional effectiveness of video media. Hillsdale, New Jersey: Lawrence Erlbaum Associates. 
$\frac{\square}{\frac{1}{4}}$ 
Chapter 4

\section{The effect of face-to-face collaborative learning on the elaboration of computer-based simulated cases}

Accepted for publication in Simulation in Healthcare

Bas A de Leng, Arno M M Muijtens \& Cees P M van der Vleuten 


\section{ABSTRACT}

\section{Objective}

This study investigates the effects of working face to face in small groups on the processes that occur when students elaborate on computer-based simulated cases.

\section{Methods}

We performed a randomized controlled experiment that was designed to measure the effect of 'social context' (triads versus individuals) on students' perceptions of the elaboration process and on the time spent on the different parts of the computer case. We sought students' perceptions using a questionnaire that was administered to all participating students $(\mathrm{N}=47)$ and we examined the actions of the students working in triads $(\mathrm{N}=12)$ and individually $(\mathrm{N}=11)$ by analyzing the log-files of the computer case.

\section{Results}

The results demonstrated no significant effect of social context on the degree of elaboration of the computer case.

\section{Conclusions}

Working with computer-based simulated cases in small groups as opposed to individually in itself is not enough to increase the scope and depth of the elaboration of computer cases. 


\section{INTRODUCTION}

Collaborative work is widely used in education to intensify or elicit processes that promote learning and cognitive development. Results from field and laboratory studies have led to a growing consensus among researchers that cooperative and collaborative conditions can be helpful for learning (Slavin, 1995), although benefits are not guaranteed (Rogoff, 1990) and various contexts may have differential effects on the effectiveness of small group learning (Cohen, 1994; Hyun, 2005; Light, Littleton, Messer, \& Joiner, 1994). Different theories have been put forward to explain the potential positive effect of collaborative learning as follows:

- The mechanism of "conflict and controversy," in which coordination of points of view gives rise to learning (Dillenbourg, Baker, Blay, \& O'Malley, 1995; Howe, Tolmie, \& Mackenzie, 1995; Johnson \& Johnson, 1979; Piaget, 1985). The responsibility to declare and justify one's ideas to a collaborator induces selfreflective processes (declarative aspect).

- Peers who are giving "elaborated" help to others have to elaborate on their own cognitive structures in a social context (Webb, 1989; Yackel \& Cobb, 1991). Collaborating students can take each other further by complementing insights and offering new ones (interactive aspect).

- Social-emotional processes can increase the motivation to learn (Sharan \& Shaulov, 1990).

With these potential benefits of collaborative learning in mind, we wanted to explore whether collaborative learning would enhance students' learning from computer-based simulated cases. A meta-analysis of studies on learning with computer technology (CT) by Lou et al (Lou, Abrami, \& d'Apollonia, 2001) showed that students working in groups with $\mathrm{CT}$ showed greater gains in individual knowledge than students working individually and that group products generated from work with CT were better than the products of individual students. However, these findings were heterogeneous: not all groups performed equally well and not all students in small groups learned more than students learning individually. To understand this heterogeneity, the researchers looked for contextual factors in the studies included in the meta-analysis that could moderate the effects of the social context (individual versus group) and thus account for the variability in the findings. On the basis of their results, they warned to be careful in situations where no specific cooperative strategies are used, group size exceeds two members, and programs involve exploratory learning.

From a theoretical point of view, it is to be expected that after completing computer cases aimed at improving clinical reasoning and medical problem solving skills, students who worked in small groups will have better learning outcomes than those who worked individually. A case can be a "social catalyst" by eliciting discussion, leading to deeper elaboration and better learning. In the presence of a human tutor, a group of students may experience social pressure to answer quickly, which may be a disincentive to discussing their response extensively before answering. However, when a computer is waiting upon their 
answer, students may feel free to discuss their response as extensively as they find necessary (Wegerif, 2004). However, such a situation would meet the three critical conditions warned against by Lou et al (Lou, Abrami, \& d'Apollonia, 2001): computer cases are exploratory environments, more than two people work on the cases, and no specific cooperative strategies are used. Arguments against the applicability of conclusions by Lou et al to the situation we want to investigate are the following: in the meta-analysis the category "exploratory environments" was coarse grained including microworlds, simulations, hypertext-based learning environments, and even productivity tools, such as word-processing software; about $60 \%$ of the studies in the meta-analysis concerned learners at precollege levels; the metaanalysis included more than 20 different contextual factors concerning technology, tasks, grouping, and learners, which could interact and have different effects on cognitive, process, and affective outcomes. So, the study by Lou et al (Lou, Abrami, \& d'Apollonia, 2001) allows only general conclusions to be drawn, and it is not clear whether the results are applicable to our study question. That is why we designed a study involving computer cases, small groups of university students, and process outcomes. We did not address individual learning outcomes, because we did not expect the completion of only a few clinical cases to result in substantial cognitive development. Moreover, a valid and reliable assessment of individual learning effects would be difficult to perform. Assuming that academic achievement is the result of many factors in the learning process, we decided to measure the following process factors: the time students spent performing the tasks, the intensity of the interaction with the learning material, and the kind of processes that occurred.

The aim of this study was to investigate the effect of working face to face in small groups on the processes that occur when students elaborate on computer cases. To this end, we designed an experiment to measure the effect of the independent variable "social context" (small groups versus individuals) on the dependent variable "elaboration" within a medical education context. Elaboration was operationalized as students' individual perceptions of the working process, the degree of interaction with the computer program, and the time students spent on the different parts of the computer program. Each part of the program was associated with one of three types of activity: inquiry, interpretation, or reflection. We hypothesized that elaboration triggered by computer-based simulated cases would be more intensive in small groups than for students working individually.

\section{METHODS}

\section{Participants}

Forty-seven volunteers ( 36 women, 11 men) were recruited from a total of 2504 thyear undergraduate students at the medical school of Maastricht University, The Netherlands. They were randomly allocated to the experimental condition (small groups; $n=36$ ) or to the control condition (working individually; $n=11$ ). All the students had ample experience with problem-based learning in tutorial groups of 10 students and were enrolled in a regular problem-based learning course. None of the students had worked with the computer program or the computer cases under study before. The language of the course and of the computer case was English to enable participation of international students. For group size we chose triads to 
ensure both access to the keyboard and enough "volume" for a discussion in which participants can take positions (King, 2002). Because of the relatively small number of male students and the attendance of some international students, we took care that the triads were heterogeneous for gender and nationality.

\section{Procedure}

Both triads and individual students were asked to explore the same clinical case in the computer program CAMPUS (Riedel et al., 2001) and perform any diagnostic and therapeutic action they deemed appropriate. Working on the case was selfpaced, but it typically took about 45 minutes to complete the case. The work station and the presentation of the computer case were identical for individuals and triads. However, in the experimental condition, the monitor was replaced by a digital projector presenting the computer case on a screen to allow each student in a triad a good view of the computer screen and to enable better observation of the discussion by the researchers. The individual students used a computer with a monitor. Immediately before the experiment, all participants, in groups of 10 , took part in a session in which they received instructions and some handson experience with a computer- based simulated case that had been specially designed to illustrate all the features of the computer program ( 25 minutes). After this session, the students were assigned to the experimental or control condition and distributed over different rooms to work on the clinical computer case. Each triad and each individual student were placed in a separate room. After completing the computer-based simulated case, all students individually filled out a questionnaire.

To reduce systematic inequalities in participation and the influence of status (Cohen, 1994) in the triads, we rotated keyboard control among the students according to the three phases of the computer program. We also tried to avoid a division of labor between "thinkers" and "typist" by assigning the role of "discussion leader" to the student at the keyboard. The students were familiar with the role of discussion leader, because it is also used in the regular tutorial groups.

Agreeing with Crook (Crook, 1996) that the enthusiasm with which students work on computer tasks can be misleading and that detailed recording of what students are actually doing is needed to monitor their engagement in learning processes, we used the log files of the keyboard actions to infer students' learning activities. For this reason, both individual students and triads were asked to log into the program before starting work on the case.

\section{MATERIALS}

\section{Clinical Case}

The patient case used in the study is a linear presentation, which unfolds as it is being actively explored. The program does not allow students to go forward in the program without entering an enquiry nor to alter earlier decisions. However, the students can revisit previous enquiries and actions, as well as the information they have gathered in the patient record. The diagnostic and therapeutic actions are selected from comprehensive lists. The workflow consists of three phases 
each with several possible actions: (1) an exploratory examination consisting of history taking, physical examination, and initial differential diagnosis; (2) a specific examination consisting of physical examination, technical examination, laboratory tests, and working diagnosis; and finally (3) therapy and monitoring loops with management plan, follow-up, and the possibility to change the diagnosis. Thus, the computer program imposes a specific structure on the working process. After each phase in the program, students' actions and choices are automatically compared with the approach of the attending clinician. This means that the feedback students receive is not of the "true/false" format with explanation of "golden rules" but of a "matching" format in which the actions of the students are compared with those of an expert with all the inherent idiosyncrasies.

This kind of feedback is more conducive to reflection and interaction in the group (Crook, 1991). The English-language clinical case was built and presented in the computer program CAMPUS (Riedel et al., 2001), a crossplatform and webbased (Java-applets and Oracle database) program developed at the University of Heidelberg (Germany). The program was translated into English in close collaboration with the Medical Informatics School of Technology in Heilbronn (Germany). The diagnoses incorporated in the program were from the Dutch version of the International Classification of Diseases version 10 (ICD-10) with matching thesaurus, provided by the Department of General Medicine of the Academic Medical Center, Amsterdam, The Netherlands.

\section{Instruments}

Elaboration was investigated by analyzing the information in the log files on the frequency of students' interactions with the computer and the time spent on the different parts of the program. The different parts of the program were associated with one of three types of activity: inquiry, interpretation, or reflection (see appendix 1).

Elaboration was also examined by a questionnaire about students' perceptions of the working process consisting of six statements concerning activities related to inquiry, interpretation, and reflection, because we considered exploration of information, pursuit of meaning, and reflection important manifestations of elaboration (Table 2). Students were asked to respond to the statements on a 5 -point scale ( 1 = "fully disagree"; 5 = "fully agree"). Reliability analysis of the questionnaire resulted in a Cronbach a of 0.57.

\section{Data analysis}

We primarily balanced the number of elements in the experimental ( 12 triads) and the control (11 individuals) condition to enable comparison of the logged actions in the computer-based simulated case. Because the triads in the experimental group used one data entry point, we analyzed keyboard and mouse actions at triad level $(\mathrm{N}=12)$, whereas the data of the control group were analyzed at student level $(\mathrm{N}=11)$.

Students' perceptions of the working process were measured and analyzed at individual student level for both the experimental group $(\mathrm{N}=36)$ and the control 
group $(\mathrm{N}=11)$. For each statement in the questionnaire, the mean scores and standard deviations were calculated across individual students in the experimental group and the control group, respectively. In addition, we analyzed the total scores across the six statements as an overall indicator of the degree of elaboration. We used a Mann-Whitney $\mathrm{U}$ test to compare the results between the groups with $\mathrm{P}=$ 0.05 as the (two tailed) significance level.

The frequency and duration of the activities related to inquiry, interpretation, and reflection were inferred by summation of the counts and minutes recorded in the log files for the different actions. The "degree of inquiry into the case" was derived from the combination of the "number of requests" and the "time spent on inquiry." The "degree of interpretation of information" was derived from the "time spent viewing substantial information" and the "average time spent viewing information." The "degree of reflection" was calculated by summing the totals of all reflectionrelated activities. Finally, the means and standard deviations were calculated. We established the differences between the groups using a Mann-Whitney $U$ test, with $\mathrm{P}=0.05$ as the (two tailed) significance level.

In addition to the statistical significance testing for the differences between the experimental and control group, we calculated the effect sizes (ESs), because this index is independent of the size of the sample and of the original scale of the variables (Hojat \& Xu, 2004). So, the ES might enable us to spot tendencies in the small sample size of this study and enable other researchers to use our findings in meta-analysis studies on computer-based simulated cases.

\section{RESULTS}

Table 1 shows the responses to the six propositions given by the students in the control group $(N=11)$ and the experimental group $(N=36)$. The fifth column presents the " $\mathrm{P}$ " values for a two-tailed test, so the probability that the difference occurs by chance. The last column shows the ESs for the differences between the two groups based on the pooled within group standard deviation. The bottom row shows the mean total scores across the propositions. Most differences were in favor of the experimental group, but none were significant. The responses of both groups indicated that the computer case stimulated active inquiry and that reflection (weighing alternative interpretations, checking ideas, and comparing approaches) did take place.

Table 2 presents the duration (minutes) and frequency of the "condensed" activities of individuals and triads calculated from the log files. Because for both groups one log file was corrupt, $\mathrm{N}=10$ for the control group and $\mathrm{N}=11$ for the experimental group. The fifth column presents the $\mathrm{P}$ value for a two-tailed test, and the last column shows the ESs for the differences between the two groups based on the pooled within group standard deviation.

None of the differences between the experimental and the control group were significant. Although the number of requests was slightly higher for the triads, this was not significant because of the large standard deviations. The triads spent well 


\begin{tabular}{|c|c|c|c|c|c|c|}
\hline \multirow[b]{3}{*}{ Propositions } & \multicolumn{6}{|c|}{ Responses* } \\
\hline & \multicolumn{2}{|c|}{$\begin{array}{c}\text { Individuals } \\
\text { (control group) } \\
\mathrm{N}=11\end{array}$} & \multicolumn{2}{|c|}{$\begin{array}{l}\text { Triads } \\
\text { (experimental } \\
\text { group) } \\
\mathrm{N}=36\end{array}$} & \multirow[b]{2}{*}{$P$} & \multirow[b]{2}{*}{ ESt } \\
\hline & Mean & SD & Mean & SD & & \\
\hline $\begin{array}{l}\text { 1. Only when we felt quite sure about a question } \\
\text { or test did we enter it into the computer program. }\end{array}$ & 2.18 & 0.98 & 2.33 & 0.79 & 0.45 & 0.18 \\
\hline $\begin{array}{l}\text { 2. The computer case stimulated us to ask useful } \\
\text { questions on the topic at hand. }\end{array}$ & 3.36 & 1.03 & 3.61 & 0.84 & 0.51 & 0.28 \\
\hline $\begin{array}{l}\text { 3. During the elaboration of the case we checked } \\
\text { the quality of our ideas. }\end{array}$ & 3.91 & 0.54 & 3.83 & 0.66 & 0.89 & -0.13 \\
\hline $\begin{array}{l}\text { 4. When looking at the findings (answers of the } \\
\text { patient, test results), we considered various } \\
\text { alternative interpretations. }\end{array}$ & 3.45 & 0.69 & 3.92 & 0.73 & 0.11 & 0.65 \\
\hline $\begin{array}{l}\text { 5. The analysis of the findings after the questions } \\
\text { or tests often resulted in entering new questions } \\
\text { and tests into the computer program. }\end{array}$ & 3.09 & 1.04 & 3.42 & 0.84 & 0.33 & 0.37 \\
\hline $\begin{array}{l}\text { 6. The overview presented after each differential } \\
\text { diagnosis with both our own approach and the } \\
\text { author's actions, gave rise to a lot of reflection. }\end{array}$ & 4.45 & 0.69 & 4.14 & 0.64 & 0.19 & -0.48 \\
\hline Mean total score & 3.41 & 0.34 & 3.54 & 0.46 & 0.43 & 0.30 \\
\hline
\end{tabular}

Table 1. The responses to the questionnaire by the students in the control group (individuals) and the experimental group (triads).

over 6 minutes longer on the inquiry, but the time spent on the answers to their requests (history question, physical, and technical examination) was comparable with that of the control group. The amount of time spent by the students on substantial information (such as viewing laboratory results and $\mathrm{x}$-rays or listening to heart sounds) and on reflection (such as comparing their inquiry and findings with those of the attending clinician) did not differ much between the two groups.

To provide amore complete picture of the activities in the experimental group, we analyzed the field notes of the discussions within the triads with the lowest and highest level of inquiry and within the triads with the lowest and highest level of reflection as logged in the computer-based simulated case.

We found that there was considerable variation between the triads in the amount of discussion. The group with the highest inquiry action as logged in the computer also had the highest number of questions, responses, and statements in the discussion, whereas the triad with the lowest inquiry action in the computer had the lowest interaction in their discussion. So in this experiment, the degree of inquiry in the computer reflected the intensity of the discussion in the group. 


\begin{tabular}{|c|c|c|c|c|c|c|}
\hline \multirow[b]{3}{*}{ Categories with their subordinated activities } & \multicolumn{6}{|c|}{ Duration (min) and Frequency } \\
\hline & \multicolumn{2}{|c|}{$\begin{array}{l}\text { Individuals } \\
\text { (control group) } \\
\mathrm{N}=10^{*}\end{array}$} & \multicolumn{2}{|c|}{$\begin{array}{l}\text { Triads } \\
\text { (experimental } \\
\text { group) } \\
\mathrm{N}=11 \dagger\end{array}$} & \multirow[b]{2}{*}{$P$} & \multirow[b]{2}{*}{ ES‡ } \\
\hline & Mean & SD & Mean & SD & & \\
\hline \multicolumn{7}{|l|}{ Degree of inquiry } \\
\hline Number of requests & 67.40 & 30.38 & 76.00 & 30.18 & 0.71 & 0.28 \\
\hline Time spent on inquiry (min) & 21.34 & 7.98 & 27.81 & 4.64 & 0.07 & 1.00 \\
\hline \multicolumn{7}{|l|}{ Degree of interpretation of information } \\
\hline Time spent viewing substantial information (min) & 5.69 & 3.60 & 5.65 & 2.20 & 0.92 & -0.01 \\
\hline Average time spent viewing information (min) & 1.30 & 0.46 & 1.50 & 0.52 & 0.86 & 0.41 \\
\hline \multicolumn{7}{|l|}{ Degree of reflection } \\
\hline Time spent on reflection (min) & 17.04 & 7.39 & 17.88 & 4.11 & 0.61 & 0.14 \\
\hline $\begin{array}{l}\text { * One of the } 11 \text { log files was corrupt. } \\
\text { † One of the } 12 \log \text { files was corrupt. } \\
\text { ‡ Effect size based on the pooled within group standard }\end{array}$ & iiation. & & & & & \\
\hline
\end{tabular}

Table 2. Duration and frequency of different types of activities calculated for the control group (individuals) and the experimental group (triads).

The amount of reasoning and elaborative answers in the peer discussions showed little difference between the triads. In fact the group with the lowest reflective action had the highest reflective activity in their peer discussion. So in this experiment, the depth of the discussion in the group was not reflected by the same kind of activity in the computer.

\section{DISCUSSION}

The results of this experiment demonstrated no significant $(P<0.05)$ effects of working face to face in small groups compared with working individually on the elaboration of computer-based simulated cases. The questionnaire revealed a moderate $(E S=0.30)$ difference between the experimental group (triads) and the control group (individuals) in the perceived working processes. The log files showed that the triads requested more information $(E S=0.28)$ and spent more time on inquiry $(E S=1.00)$. However, this increase in exploration did not result in a substantial increase in recorded interpretative or reflective activities.

The triads scored lower than the individuals on two (numbers 3 and 6) propositions in the questionnaire that were designed to probe for reflective activities. An explanation for this might be that the proposition on checking the quality of ideas was interpreted by the students in the control group (individuals) as an intrapersonal activity (did you reflect on this by yourself), whereas the students in the experimental group (triads) interpreted it as an interpersonal question (did you discuss personal reflections in the group). So, the students within the triads may have reflected on ideas by themselves without expressing these ideas in the group. The aforementioned unexpected results on two questionnaire items were not paralleled by the log files of the computer actions, which showed that the 
experimental groups (triads) spent more time on reflection. The explanation we suggested earlier that the students in the triads may not have discussed their intrapersonal reflections in the group is at odds with the longer time on reflection logged in the triads' work-up of the computer-based case simulation. Here, the longer time spent on inquiry might be an explanation. The fact that the triads did not discuss all their personal reflections in the group may have been compensated by the higher level of inquiry in the triads with more information to reflect on.

Overall, the results did not confirm our expectation that group work would induce more elaboration compared with individual work. An explanation may be found in the notion that students working with simulations tend to concentrate on the manipulation of objects without generating a deeper understanding of the model or of the principles underlying observed behavior (Pilkington \& ParkerJones, 1996).

When we look at the results of the few studies by Lou et al meta-analysis (Lou, Abrami, \& d'Apollonia, 2001) that reported directly on working processes and compare them with the findings of our study, we see similarities and differences. The results of the meta-analysis showed that learners in groups were more perseverant and took longer to complete tasks. The results of our study showed a similar, albeit not significant, effect. A difference between the studies in the meta-analysis and our study is that the studies in the meta-analysis showed that individuals on average interacted more with the computer programs than did the groups, whereas we found the reverse, although the difference did not reach significance.

The results of our study are consistent with findings reported by others (Novak, 1998; Perkins, 1992) that many students are not inclined to move toward meaningful learning strategies. Educational incentives (grades or teacher approval) and instructional measures (cooperative or scaffolding strategies) may stimulate the use of such desired learning strategies (Reid, Zhang, \& Chen, 2003).

The small sample sizes in our experiment may have affected the results. The differences between the experimental group (triads) and the control group (individuals) showed small to medium ESs for perceptions of the working process and interaction with the computer in favor of the experimental group. This may indicate that the sample size in our study was too small to demonstrate any differences.

An alternative explanation for the absence of differences may be that the instruments to measure the dependent variables were not sensitive enough. Barron (Barron, 2000) found large differences between two triads in what they accomplished in their discussion and what they recorded on paper, with one triad recording $100 \%$ and the other triad recording only $25 \%$ of the correct solutions they generated. Although the case study by Barron included only two specially selected contrasting triads, we cannot rule out that a similar phenomenon affected the results of our study.

In summary, we conclude that working with computer-based simulated cases in small groups as opposed to individually in itself is not enough to increase 
the scope and depth of the elaboration of computer cases. To achieve our goal of using computer-based simulated cases as "social catalysts," we will probably need to introduce additional cooperative learning strategies, such as positive interdependence and individual accountability 13 or scaffolding strategies, such as "question prompts" and "guided peer interaction" (Ge \& Land, 2003).

\section{REFERENCES}

Barron, B. (2000). Achieving coordination in collaborative problem-solving groups. Journal of the Learning Sciences, 9(4), 403-436.

Cohen, E. (1994). Restructuring the classroom: conditions for productive small groups. Review of Educational Research, 64, 1-35.

Crook, C. (1991). Computers in the zone of proximal development: implications for evaluation. Computers in Education, 18(1), 32-42.

Crook, C. (1996). Computers and the collaborative experience of learning. London: Routledge.

Dillenbourg, P., Baker, M., Blay, A., \& O'Malley, C. (1995). The evolution of research on collaborative learning. In H. Spada \& P. Reimann (Eds.), Learning in humans and machines. Towards an interdisciplinary learning science (pp. 189-211). Oxford: Pergamon.

Ge, X., \& Land, S. M. (2003). Scaffolding students' problem-solving processes in an ill-structured task using question prompts and peer interactions. Etr\&D-Educational Technology Research and Development, 51(1), 21-38.

Hojat, M., \& Xu, G. (2004). A visitor's guide to effect sizes. Advances in health sciences education, 9, 241-249.

Howe, C., Tolmie, A., \& Mackenzie, M. (1995). Computer support for the collaborative learning of physics concepts. In C. O'Malley (Ed.), Computer supported collaborative learning (Vol. 128, pp. 51-68). Berlin: Springer-Verlag.

Hyun, E. (2005). A study of 5- to 6-year-old children's peer dynamics and dialectical learning in a computer-based technology-rich classroom environment. Computers \& Education, 44(1), 69-91.

Johnson, D., \& Johnson, R. (1979). Conflict in the classroom: controversy and learning. Review of educational research, 49, 51-70.

King, A. (2002). Structuring peer interaction to promote high-level cognitive processing. Theory into Practice, 41(1), 33-39.

Light, P., Littleton, K., Messer, D., \& Joiner, R. (1994). Social and communicative processes in computer-based problem solving. European Journal of Psychology of Education, 9(1), 93-109.

Lou, Y. P., Abrami, P. C., \& d'Apollonia, S. (2001). Small group and individual learning with technology: A meta- analysis. Review of Educational Research, 71(3), 449-521.

Novak, J. (1998). Learning, creating, and using knowledge. Mahwah, New Jersey: Lawrence Erlbaum Associates. 
Perkins, D. N. (1992). Smart schools: better thinking and learning for every child. New York: The Free Press.

Piaget, J. (1985). The equilibration of cognitive structures: the central problem of intellectual development (T. Brown \& K. Thampy, Trans.). Chicago: University of Chicago Press.

Pilkington, R., \& ParkerJones, C. (1996). Interacting with computer-based simulation: The role of dialogue. Computers \& Education, 27(1), 1-14.

Reid, D., Zhang, J., \& Chen, Q. (2003). Supporting scientific discovery learning in a simulation environment. Journal of Computer Assisted Learning, 19(1), 9-20.

Riedel, J., Singer, R., Heid, J., Leven, F., Schnabel, K., Tönshoff, B., et al. (2001). CAMPUS: A Simulative, Flexible, Case-oriented Web-based Training System for MultiPurpose Use in PBL-Curricula. In S. Stensaas, M. Fischer, M. Batschkus \& J. Dietrich (Eds.), Multimedia in Health Sciences Education (pp. 267-277). Berlin: Logos Verlag.

Rogoff, B. (1990). Apprenticeship in Thinking: cognitive development in social context. New York: Oxford University Press.

Sharan, S., \& Shaulov, A. (1990). Cooperative learning, motivation to learn, and academic achievement. In S. Sharan (Ed.), Cooperative learning : theory and research (pp. 173-202). New York: Praeger.

Slavin, R. E. (1995). Cooperative learning : theory, research, and practice (2nd ed.). Boston: Allyn and Bacon.

Webb, N. (1989). Peer interaction and learning in small groups. International Journal of Educational Research, 13, 21-40.

Wegerif, R. (2004). The role of educational software as a support for teaching and learning conversations. Computers \& Education, 43(1-2), 179-191.

Yackel, E., \& Cobb, P. (1991). Small-group interactions as a source of learning oppotunities in second-grade mathematics. Journal for research in mathematics education, 22, 390-408. 
$\frac{1}{d}$
$\frac{1}{0}$
$\frac{0}{0}$
$\frac{c}{\cup}$ 
Chapter 5

\section{Exploration of an e-learning model to foster critical thinking on basic science concepts during work placements}

Published in Computers \& Education 2009; 53 (1): 1-13

Bas A de Leng, Diana H J M Dolmans, Rijn Jöbsis,

Arno M M Muijtens \& Cees P M van der Vleuten 
Abstract

We designed an e-learning model to promote critical thinking about basic science topics in online communities of students during work placements in higher education. To determine the effectiveness and efficiency of the model we explored the online discussions in two case studies. We evaluated the quantity of the interactions by looking at quantitative data of the discussion 'threads' and we evaluated the quality of the discussion by content analysis of the individual messages. Both the procedural facilitation of the discussion and the instrument for content analysis were based on Garrison's 'Practical Inquiry model of Cognitive Presence.' Furthermore, we explored the experiences of the students and moderators by interviewing them and we organised their perceptions using the framework of an activity system. On the basis of the quantitative and qualitative data we conclude that the e-learning model was successful in establishing a dialogue among a group of students and an expert during work placements at different locations. The 'Practical Inquiry model' was useful in facilitating a sustained on-topic discourse involving critical thinking. Although the amount of critical thinking was moderate, the results suggest ways to increase integration and resolution activities in the online discussions. 


\section{INTRODUCTION}

Work-based or apprenticeship learning is a powerful educational format in higher education. It can be regarded as situated learning in which practice is not conceived of as independent of learning, and meaning is not conceived of as separate from the contexts in which it is negotiated (Barab \& Duffy, 2000). In designing a situated learning environment one may adopt a 'schooling' perspective, focusing on the learning objectives of a curriculum and situating specific content within a context of authentic activities. The emphasis of such a design will be on learning activities and how they are related to a wider practice (Mayes \& de Freitas, 2004). Taking an 'anthropological' perspective, one might create a design focused on possibilities for community building and experiences of learners as members of a community. In this type of design, the main emphasis will be on the relationship between an individual and members of an occupational group with its own identity and role in society.

'Practice fields' are environments that are designed from the'schooling' perspective. They engage learners in authentic tasks requiring the use of specific concepts and skills. The practices in which learners engage are'school'tasks, which are abstracted from the real world, and the learning environment is separated from 'real' practice in time, setting and activity (Barab \& Duffy, 2000). 'Communities of practice' on the other hand are environments designed from an 'anthropological' perspective. In 'communities of practice' groups of individuals share mutually defined practices, beliefs, and understandings over an extended time frame in the pursuit of a shared enterprise (Wenger, 1998). Here, individuals contribute to the construction of their own identity in relation to the community of practice and, reciprocally, to the construction and development of the community of practice of which they are a part (Brown \& Duguid, 1991).

This study explores an e-learning model designed to be a practice field for a work placement. It is a contrived context, in which students discuss and apply wellestablished concepts from basic sciences, such as physiology, chemistry, biology, in resolving problems which they encounter in the course of their personal experiences in work-based learning. The e-learning model is not intended as a community of practice in which the participants, as legitimate members of an occupational group, contribute to the maintenance and expansion of the group's knowledge base.

Schools of engineering and medical schools aim to deliver graduates who are competent in general and professional skills, who understand what they are doing in their professional work and can justify why they are doing it. Consequently, it is important for students during work placements to have regular opportunities for reflecting on basic science concepts and for discussing their reasoning with others. For instance, when medical students are diagnosing a patient or developing a patient management plan, they may need to revisit what they learned about physiology and biochemistry earlier in the curriculum, but the demands of day-today practice with its main orientation to procedural and management knowledge do not facilitate reflection on and discussion about basic science knowledge. 
A learning environment that fosters reflection on basic sciences from the perspective of a professional practitioner is a 'cognitive apprenticeship', a specific 'practice field' in which students learn at the 'elbows' of experts who coach and model the desired cognitive activity (Collins, Brown, \& Newman, 1989).

Not only the type of work but also the distributed nature of work placements makes it difficult for students to discuss basic science issues. During work placements students are frequently dispersed over different locations in which each individual is not only involved in different activities but also has different time schedules. Thus the opportunities for interacting with peers and group mentoring by experts are few and may depend on the use of technology.

Although distance in place and time can be bridged by two-way delayed feedback technologies, such as asynchronous computer-mediated communication, both distance education and computer supported collaborative learning (CSCL) have their specific problems.

- In distance education, where learners and teachers are separated geographically, a psychological and communication space has to be crossed, a space of potential misunderstanding between input from instructors and learners (Moore, 1993). This gap in understanding and communication between learners and teachers, the so-called 'transactional distance', can be bridged when interaction is facilitated by a well thought-out instructional design (Moore \& Kearsley, 2005). This requires a type of interaction that is purposeful, constructive and valued by all parties concerned. This type of interaction is referred to as dialogue and in educational relationships the objective of the dialogue is to improve students understanding.

- In CSCL sustained on-topic discourse can be impeded by participants'reluctance to take part in online discussions and the difficulty of formulating meaningful contributions (Luppicini, 2007). Procedural facilitation can be used to counter these inhibiting factors and was found to be useful in encouraging discussion and in enhancing the quality of discussions (Saab, van Joolingen, \& van HoutWolters, 2007; Scardamalia \& Bereiter, 1991). In a CSCL environment, procedural facilitation may take the form of online feedback provided by a teacher or supervisor (interaction) but also of features embedded in the CSCL program itself (structure). Examples of 'structure' features are: types or classifications that students can use to classify their contributions, sample phrases that are useful when composing a note of a certain type, or 'anchors' that facilitate the decision to participate in the discussion (Guzdial \& Turns, 2000). 'Anchors' are texts, pictures etc., which capture the attention of participants in a discussion forum because they are separate from the discussion and present topics which are assumed to be of interest to participants (Fig. 1).

So a certain amount of interaction and structure is required in CSCL for sustained on-topic discourse. Both interaction and structure need special qualities to be functional in a distance education setting. Because personal feedback in CSCL often takes up a lot of scarce and expensive faculty time, a successful e-learning model 


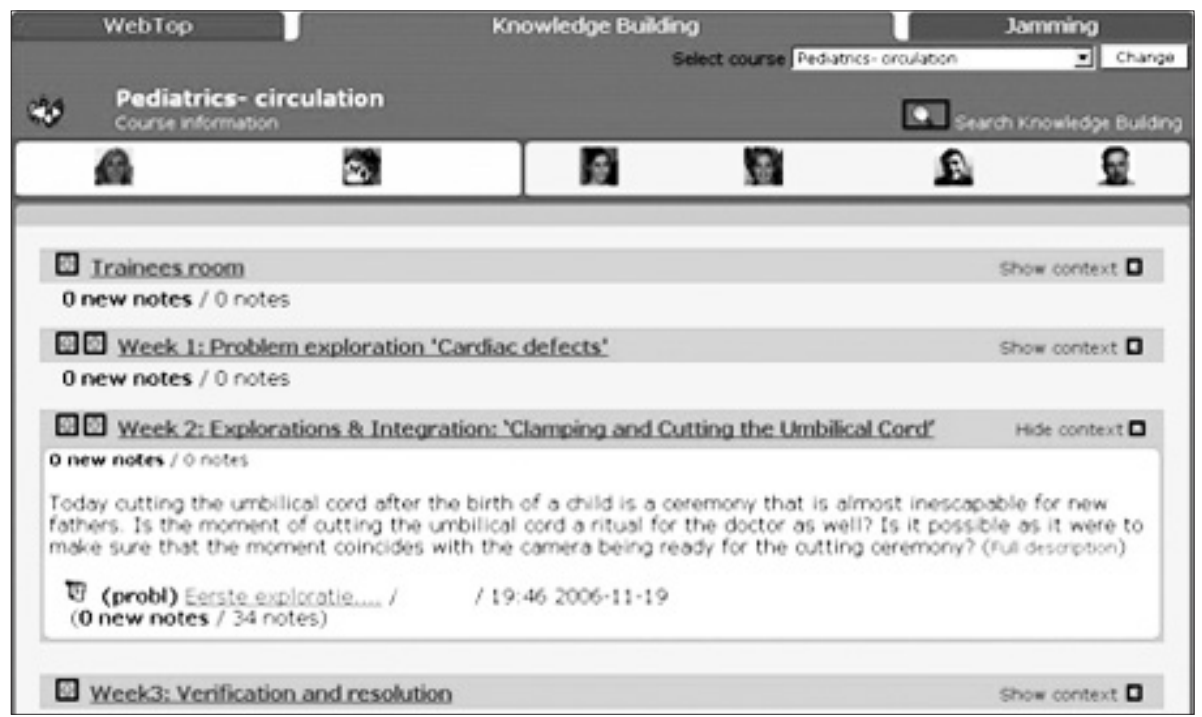

Fig. 1. A short text used as an 'anchor' at the start of the second week to tease students to address the problem definition they chose at the end of the first week.

for supporting discourse at a distance should strike an effective balance between procedural facilitation by a person and by a CSCL program. It should be noted, however, that measures to facilitate discourse, which are embedded in the CSCL program carry the inherent risk of an undesirable increase in the 'transactional distance', when the structure that is added does not meet any real need of the learners (Moore, 1993).

In order to address all these demands, we designed an e-learning model to promote dialogue and discussion about basic science concepts in small groups of peer students dispersed over different locations during work placements. The aim of the discussions is to foster critical thinking, address topics that puzzled students during their work and improve students' understanding of basic science concepts.

The first aim of this study is to explore different aspects of the interactions and cognitions in small groups of learners who are using this e-learning model in the setting of a work placement. More specifically, we want to evaluate:

- the quantity and quality of interactions between participants using the e-learning model during a work placement;

- the quality of the discussion by examining if the discussions within the e-learning model attest to critical thinking.

We have framed the quantitative analysis of interactions and cognitions within the holistic context of two qualitative case studies so as to avoid the flaws which Mason described for isolated quantitative or qualitative studies of computer conferencing (Mason, 1992). The second aim of this study is to evaluate the experiences of students and moderators with this e-learning model. We do so by seeking answers to the following questions: 
- How do students perceive the learner-learner, learner-instructor and learner-interface interactions and how do they value these interactions? Are the interactions perceived as purposeful in the sense that they foster critical thinking and understanding of basic science concepts? Do the students find the e-learning model responsive to their needs?

- Do teachers perceive the e-learning model as enabling them to moderate online peer groups effectively and efficiently? Do they think the e-learning model stimulates critical thinking and improves students' understanding of basic science concepts?

\section{METHODS AND MATERIALS}

\section{Setting and research design}

In years 5 and 6 of the undergraduate curriculum of Maastricht Medical School, the Netherlands, students disperse over different locations for 12 mandatory and two elective clerkships. For this study, we formed two 'virtual groups' which were randomly selected from a group of students scheduled for elective clerkships in the same discipline but in different hospitals during the same period. Both groups consisted of four students, one from each of four hospitals. Participation was voluntary and all students consented to take part in our experiment. We interconnected the students via the Internet and a CSCL program. In these 'virtual groups' the students used asynchronous computer- mediated communication to discuss pathophysiological concepts in a paediatric workplace setting.

We used a quasi-experimental design in which both quantitative and qualitative data were collected to explore the effects of the implementation of the e-learning model on the following broad constructs: interaction (Wagner, 1994; Yacci, 2000), critical thinking (Duffy, 1998; Pithers \& Soden, 2000), and transactional distance (Moore, 1993) within a small group of distributed peers. A pre-test with the California Critical Thinking Disposition Inventory (Facione, Facione, \& Sanchez, 1994) showed that the groups were comparable with regard to attitude towards critical thinking.

\section{E-Learning model}

The two virtual groups were asked to use the same e-learning model halfway through an 18-week clerkship in November 2006 and March 2007, respectively. During a three-week period, in which the highly demanding regular training programme continued as usual, the distributed peers engaged in distance conversations on pathophysiological topics relating to preselected themes (cardiovascular and respiratory physiology) and originating from their personal experiences in the hospitals. The conversations were enabled by asynchronous computer-mediated communication and were moderated online by an expert (paediatrician). Each group was moderated by a different paediatrician with expertise in the relevant pathophysiological topics. The two moderators did not supervise the students during their work placements. They had no previous experience with online moderation but were experienced tutors in problem-based learning. 
Because we agree with Duffy that critical thinking is an effortful, often difficult process, which can benefit from support to help students stay focused on the process and structure of an inquiry (Duffy, 1998), we used the Practical Inquiry model of Cognitive Presence (Garrison, Anderson, \& Archer, 2001) as the framework for the discussions. In this model, the process of critical thinking is defined as cognitive activities geared to four consecutive phases: triggering event, exploration, integration, and resolution. Students' authentic questions and previous knowledge of the phenomena under consideration are used as starting points for the process of deepening understanding, which involves finding evidence in scientific sources, building consensus on a hypothesis and applying newly acquired knowledge in thought experiments or in real practice. Table 1 shows how we operationalised the Practical Inquiry model in the online support features of the CSCL program.

\section{Procedures}

The three-week experiment started with a face-to-face introductory session in which the students and the paediatricians were introduced to each other, the CSCL program, and the Practical Inquiry model. After this session, the participants did not meet face-to-face again and communicated exclusively online via the CSCL environment.

The student roles in the 'virtual' groups during the asynchronous conversations were distributed in such a way that all students acted as starters of a triggering event by introducing an issue they had personally encountered in real practice and found puzzling. In the first week of the online discussion each triggering event was expected to result in a well-defined problem. Only one of these problem definitions was then selected by the group as a topic for in-depth discussion during the second week. In this discussion each student was both inquirer and hypothesis builder. In the third and final week each student contributed to the underpinnings of the hypothesis which the group until then had been developing mainly based on prior knowledge. To support their hypothesis and fill important gaps in their knowledge the students consulted non-prescribed external resources, such as books, articles and/or experts.

The paediatricians acted as moderators and tried to keep the conversation alive, in-depth and focused on the generated questions and hypothesis. The moderators strove to transfer the responsibility for the discussion to the students and act as meta-level process organisers and evaluators rather than equal participants in the process (co-inquirer). In accordance with the literature on feedback (Kulhavy \& Wager, 1993), the moderators tried to restrict feedback that contained new information to situations relating to persisting misconceptions. In the last week, the moderators stressed the importance of underpinning the hypothesis developed by the 'virtual' groups with evidence from various sources.

It was important for the topics to be limited to cardiovascular or respiratory themes and for the students to focus the discussion on pathophysiological issues. That is why, each week, the discussion started with an 'anchor' to frame the potential problems, hypotheses, and resolutions to be addressed. Fig. 1 shows an example 
of an anchor at the start of week two. So in our e-learning model we tried to find a balance between learner autonomy and pedagogic guidance in topic selection and moderating the conversations.

\begin{tabular}{|ll}
\hline KT & Checklist \\
1. Problem & - Are you contributing experiences that are salient to \\
definition & you and that you would like to examine in depth? \\
& - Are you trying to describe the matter that is puzzling \\
& you in such a way that it is gradually becoming \\
& clearer what the core problem is? \\
- Are you gradually moving to a problem definition? & - Are you trying to formulate the problem in such a \\
& way that it will be interesting for the group to pursue \\
& in the discussion?
\end{tabular}

2. Exploration - Do you ask questions to analyse the problem and map it out clearly?

- Are you using your current knowledge to come up with as many explanations of the problem as possible?

- Are you trying to express your thoughts (interpretations, hypotheses, and theories) as clearly as possible so that others can understand them?

3. Integration - Are you using your currently available knowledge to think logically about the explanations suggested and are you trying to generate arguments in favour and against every explanation? Are you trying to explain all this to the group in your own words?

- Are you trying to ascertain the relevance of the suggested ideas for resolving or explaining the problem under discussion? And do you make suggestions for theories on which the group should be concentrating?

- Are you looking for connections between theories by comparing ideas?

- Is the group trying to determine which knowledge is 'completely missing' (gaps) or in need of 'sound underpinnings'?

4. Verification - Are you searching for'evidence based' theories and and are you trying to explain the evidence as concretely as resolution possible to the other group members?

- Are you comparing different'scientific' theories and do you give your opinion as to which theory you think is superior?

- Are you applying newly gained insights to the problem and does that lead to resolutions, predictions, or conclusions?

\section{Description}

- In this contribution you introduce experiences relating to biomedical features which you find confusing and difficult to understand or which you would like to have explained for different reasons. Your contribution is intended as an appeal to the other group members to help you clarify your problem and to discover whether your problem can be described in such a way that others understand and recognise it and consider it a relevant topic for discussion.

- You can also use your contribution to follow-up on a problem that has already passed through a round of critical discussion but which has raised specific issues that are new to you and which you would like to elucidate. In this way your contribution can be the starting point for deepening and refining knowledge obtained in an earlier discussion cycle.

- In this contribution you ask the group questions to explore the problem. You also give your interpretation of the problem, your explanations, and hypotheses. The aim is to activate prior knowledge and to use the group's joint knowledge to resolve or clarify the problem by logical reasoning.

- In this contribution you respond critically to explanations that have been suggested at an earlier stage. You express you own arguments against or in favour of the theories put forward so far and you indicate how useful you think the proposed theories are for resolving or explaining the problem. You also try to identify connections between different ideas and describe which aspects are overlapping, complementary, or contradictory. The group also identifies for which aspects no explanations have been put forward yet (gaps). Finally, the group determines which relevant explanations and gaps require recourse to the literature for further verification and investigation.

- In this contribution you introduce information from the literature to support or refute explanations suggested in the previous phase. The aim is to supply scientific underpinnings for'personal' theories. You also try to use the literature to close 'gaps' in the group's collective knowledge to come to a better understanding of the whole issue. Finally, you examine whether the new insights offer useful explanations of situations and events in real practice.

Table 1. The 'Knowledge Types' (KTs) in the CSCL program are in line with the Practical Inquiry model. The checklists and descriptions support the students in the use of these 'Knowledge Types.' 


\section{CSCL environment}

We created a CSCL environment using Future Learning Environment (FLE3), an 'open source' and free software program released under the GNU General Public Licence (Muukkonen, Hakkarainen, \& Lakkala, 1999). The program has sophisticated discussion management features supporting both students and moderators in keeping track of the discussion. Moreover, FLE3 has customisable facilitation features which enable users to flesh out the 'procedural facilitation'.

Before participants write a message in FLE3 they are required to select a'knowledge type' that reflects the purpose of their contribution. These 'knowledge types' have two functions: they guide the composer of the message in writing notes in line with their expressed purpose and later on they afford participants an overview of a threaded discussion because each contribution is assigned to a 'metalevel' (example in Fig. 2). We defined for the students the following 'knowledge types' in line with the Practical Inquiry model (Garrison et al., 2001): problem definition, exploration, integration, verification and resolution, and other (Table 1). The checklists and general thought-provoking questions accompanying each knowledge type are based on literature on discourse and inquiry learning (King, 1995, 1999; Pilkington, 1999).

FLE3 also provides features of social presence by allowing students to create their own homepages with information on their personal background, interests etc. Photographs of the students in the group are always displayed at the top of the collaboration window and highlighted when students are online (Fig. 1). A sense of being part of a community is vital for students to sustain on-topic discussion in CSCL and this may be fostered by such features of social presence (van Aalst, 2006).

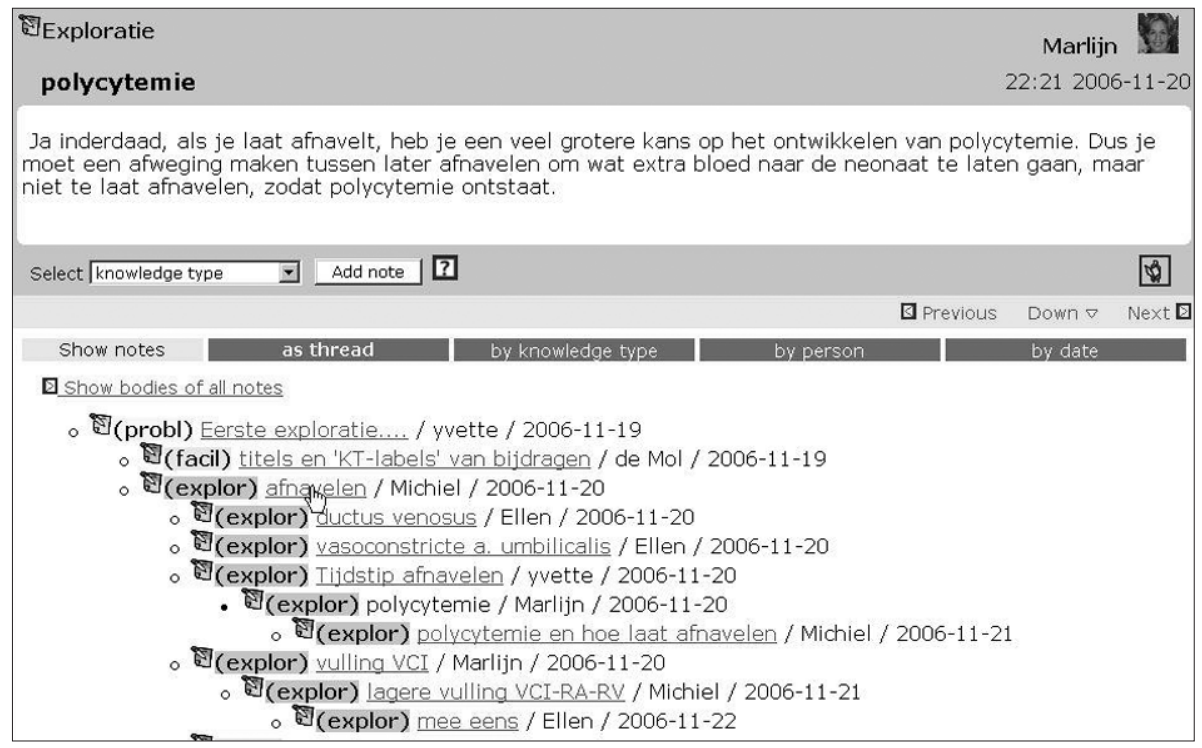

Fig. 2. In lower window: discussion thread in FLE3 with 'meta-level' labels in front of each message assigned by the sender. In upper window: the content of the selected message (message with filled dot in front of it) with time stamp of posting and name and picture of the sender. 


\section{Data collection and analysis}

Data for this study were extracted from two resources: the logged postings in the CSCL environment and recorded individual interviews with all the students and moderators.

\section{Logged postings}

To gain an impression of participants' behaviour in the CSCL environment we analysed the logged postings quantitatively and qualitatively on the levels of threads and messages. We assessed the quantity of the interactions between the participants (students and moderators) by looking at the 'threads', the sequences of responses to an initial posting. We collected several types of quantitative data: the number of postings (or messages) in the discussion threads, the number of times students viewed messages posted by other students or the moderator and the number of students posting two or more messages in the same thread. Long threads (exceeding five messages), high viewing rates and repeated postings by students in the same thread suggest that students are genuinely engaged in social activity (Kay, 2006).

We assessed the quality of the discussion by a content analysis of the verbal interactions using a coding scheme developed by Garrison (Garrison et al., 2001) based on the Practical Inquiry model of Cognitive Presence. The unit of analysis is the complete message of a posting. Based on 'descriptors' (general attitude) and 'indicators' (examples) of socio-cognitive processes, messages are assigned to one of four categories: triggering event, exploration, integration and resolution (Garrison et al., 2001). This means that both the procedural facilitation of the discussion and the instrument for content analysis of the online texts are based on Garrison's model.

We used Garrison's coding scheme because the granularity of the categories makes it suitable for general educators who can use it after limited training. Another reason for using this scheme is the availability of reported interrater reliabilities, with Cohen's kappas ranging from 0.57 to 0.74, (Fahy, 2002; Garrison et al., 2001; Kanuka, Rourke, \& Laflamme, 2007; McKlin, Harmon, Evans, \& Jones, 2002; Meyer, 2003; Schrire, 2004, 2006), whereas there are many other coding schemes for which this information is not avialable. (de Wever, Schellens, Valcke, \& van Keer, 2006). Furthermore, the complete message as the unit of analysis in this coding scheme provides an authentic subdivision of texts, preventing discussions among researchers about how to parse the text.

Several researchers (Kanuka et al., 2007; Schrire, 2004) have indicated that the last two of the four phases of Cognitive Presence (triggering event, exploration, integration and resolution) represent critical thinking. Exploration is an antecedent of these higher levels of Cognitive Presence but cannot itself be seen as critical thinking. This is plausible because brainstorming, which is ubiquitous in the exploration phase, is characterised by postponement of critique.

Because the e-learning model under study is based on a student centred approach, the analyses focused on the texts produced by the students. The messages posted by the students during the three-week period were analysed for each week 
separately (timeline analysis). Because the categories of the labels which the students attached to their messages before submission in the CSCL environment were the same as those of the coding scheme (problem definition, exploration, integration, verification and resolution, and other), we masked the labels for the coders. The messages ( $n=92$ ) of the second group were classified by two coders, which enabled us to determine the interrater reliability of the coding scheme: a Cohen's kappa of 0.65 , a value interpreted by Landis and Koch as substantial interrater agreement (Landis \& Kock, 1977).

\section{Recorded interviews}

In the week following the three-week period of online discussions, we conducted individual telephone interviews with all the students to explore their perceptions of the discussions. In the same week we conducted individual structured interviews with the two moderators to explore their perceptions. All interviews were recorded and transcribed. The semi-structured interviews addressed many different interrelated aspects of the e-learning model within the context of workplace learning. Because we wanted others to be able to check the representativeness and validity of the data while also aiming for a structured presentation of the data, we organised the data according to the framework of an activity system developed by Engeström (1987). This framework was demonstrated to be effective in describing the experiences of students and teachers using technology in higher education (Issroff \& Scanlon, 2002) and work-based activities (Collis \& Margaryan, 2004).

An activity system is a framework placing human action in a meaningful context. The three main elements of the framework are: the subject (actor in the activity), the object (product acted on by the subject) and the community (social cultural context in which the activity takes place) (Engeström, 1987). In this study, the e-learning model is seen as the activity system in which the students and moderators are the subjects, the pathophysiological problems they encounter the objects and the virtual group during the work placement the community.

Subject, object and community are interrelated by three other elements: tools, rules and division of labour (Engeström, 1987). The tools (in this study the CSCL program) mediate the relation between the subjects (students and moderators) and the objects of activity (pathophysiological problems), the rules (in this study the Practical Inquiry model and labelling messages) mediate the relation between the subjects and the community (virtual group during a work placement) and the division of labour mediates the relation between the community and the objects (not explicitly used in this study).

Finally, an activity is motivated by the need to transform the object into an outcome. In this study, the main objective of the activity system is acquisition and application of basic science knowledge. Fig. 3 shows how an activity system is often depicted as a triangle containing the seven aforementioned elements. 


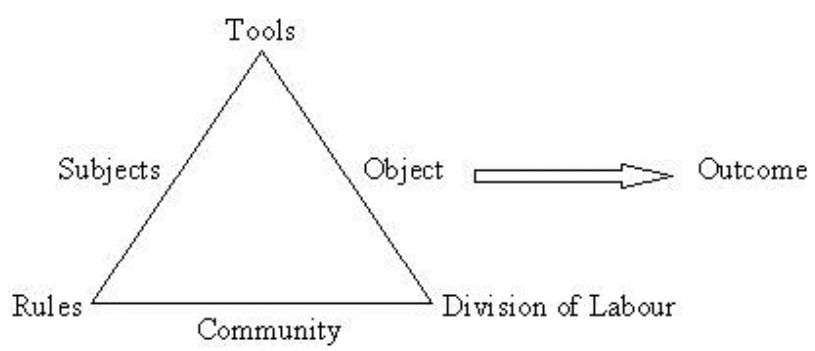

Figure 3 An activity system representation.

\section{RESULTS}

\section{The quantity of the interaction between participants}

Over the three-week study period, the virtual groups of four students and a moderator posted a total of 88 (group 1) and 110 (group 2) messages. The students posted $76 \%$ of the messages in the first group and $84 \%$ of the messages in the second group. Fig. 4 shows the number of messages in the threads during the three -week period for both groups. The median values (thick horizontal lines in the tinted boxes) range from 2.5 messages in group 1 in the first week to 14.5 messages in group 2 in the second week. Because there were only two threads in the discussion in group 2 in week two, one with 26 messages and one with three messages, the interquartile range (tinted box) in this week is very large. The percentage of threads containing 5 or more messages (indication of student engagement in social activity) was $40 \%$ in group 1 and $75 \%$ in group 2 .

Fig. 5 presents, for both groups separately, the number of times messages posted by one student were viewed by other students. Fig. 6 shows how many times students viewed messages posted by the moderator. For the interpretation of the values in Figs. 5 and 6, it is important to bear in mind that a student's posting can be read by a maximum of three students, while a moderator's posting can be read by all four students in the group. In group 1, student postings were viewed an average of 1.9 times per potential viewer and moderator postings were viewed an average of 1.6 times per potential viewer. The corresponding figures in group 2 were the same for student and moderator postings, namely 1.8 times per potential viewer. The lowest viewing rate of a student posting (bottom horizontal line in plots) in group 1 was 2 (in weeks two and three), but this concerned only three of the total of 67 messages. The lowest viewing rate of a student posting in group 2 was three, which is equivalent to the total number of potential viewers. So in this group every participant in the online discussion viewed all the postings of the other participants at least once. Nearly all of the outliers in Fig. 5 (asterisks in the plots) concerned the first posting at the start of a new week.

In addition to intensively reading each others messages all students also posted frequently messages in the discussion. So there were no 'lurkers', students reading messages of others without contributing with postings themselves. In group 1 the average number of postings per students during the three weeks was 16.8 messages, with a range from 13 to 21 messages. For group 2 the average number 


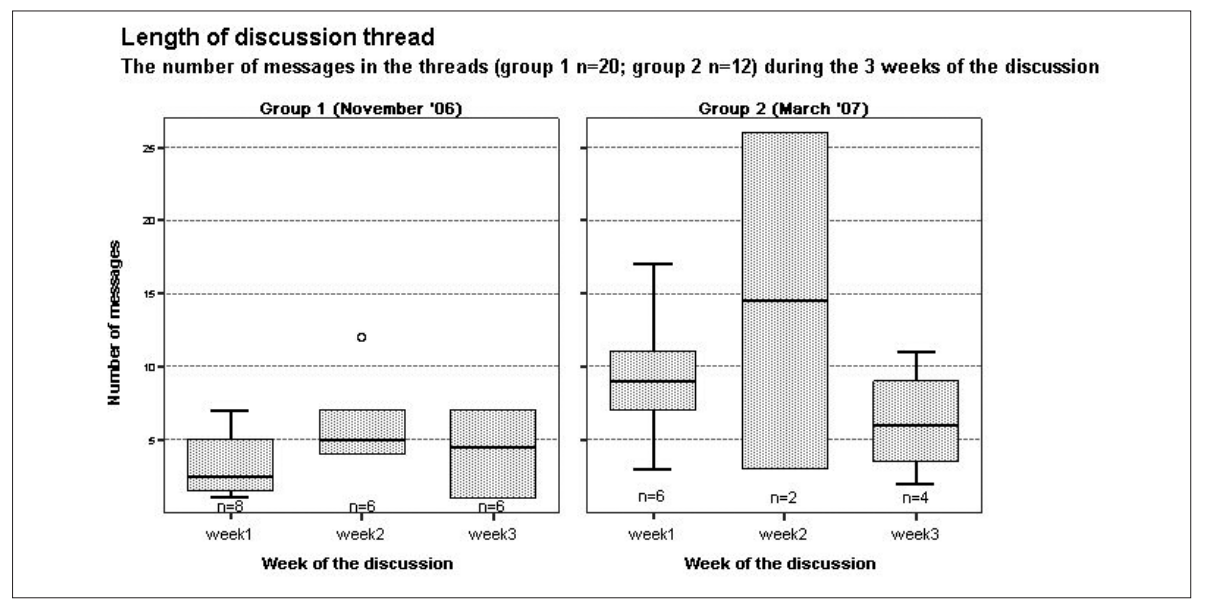

Figure 4. Length of discussion threads.

Viewing rate of messages posted by a student

The number of times messages (group $1 n=67$; group $2 n=92$ ) are viewed by other students ( $n=3$ ) over the 3 weeks
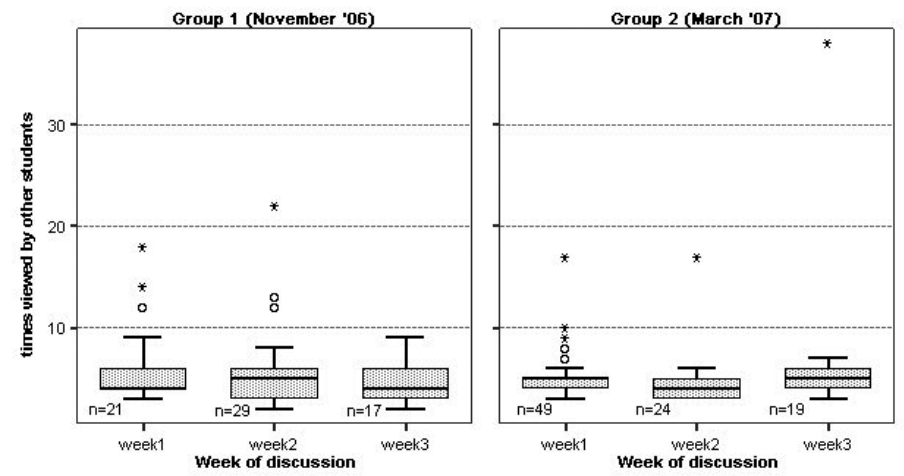

Figure 5. Viewing rate of messages posted by a student.

\section{Viewing rate of messages posted by a moderator}

The number of times messages (group1 $n=21$; group $2 n=18$ ) are viewed by students (n=4) over the 3 weeks
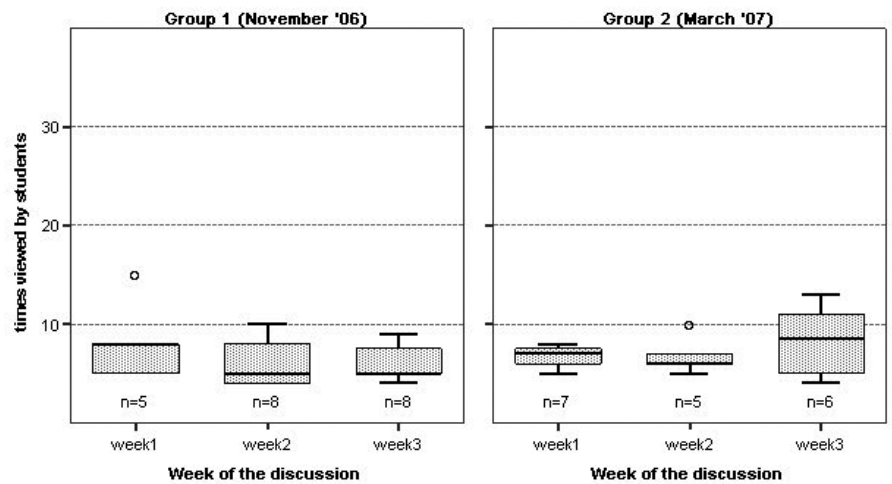

Figure 6. Viewing rate of messages posted by a moderator. 
was 23.0 with a range from 20 to 26 messages. Fig. 7 presents the number of students posting two or more messages in the same discussion thread. In all weeks, the interquartile ranges were larger for the second group than for the first group.

\section{Quality of peer interaction}

We performed content analysis of the texts of all student messages using Garrison's coding scheme (Garrison et al., 2001) in order to explore whether the discussions in the e-learning model attest to critical thinking. The following three messages illustrate how the researchers applied Garrison's coding scheme to the student postings.

\section{(1) 'Exploration' message:}

"Before birth the partial oxygen pressure of blood in the umbilical vein is a little below $5 \mathrm{kPa}(35 \mathrm{~mm} \mathrm{Hg})$. After mixing with venous blood in the $\mathrm{VCl}$ the pressure decreases to $3 \mathrm{kPa}(22 \mathrm{~mm} \mathrm{Hg}$ ). Foetal oxygen saturation in the ascending aorta is $60 \%$." This text reflects the socio-cognitive process 'Information exchange' which belongs to Garrison's 'exploration' phase.

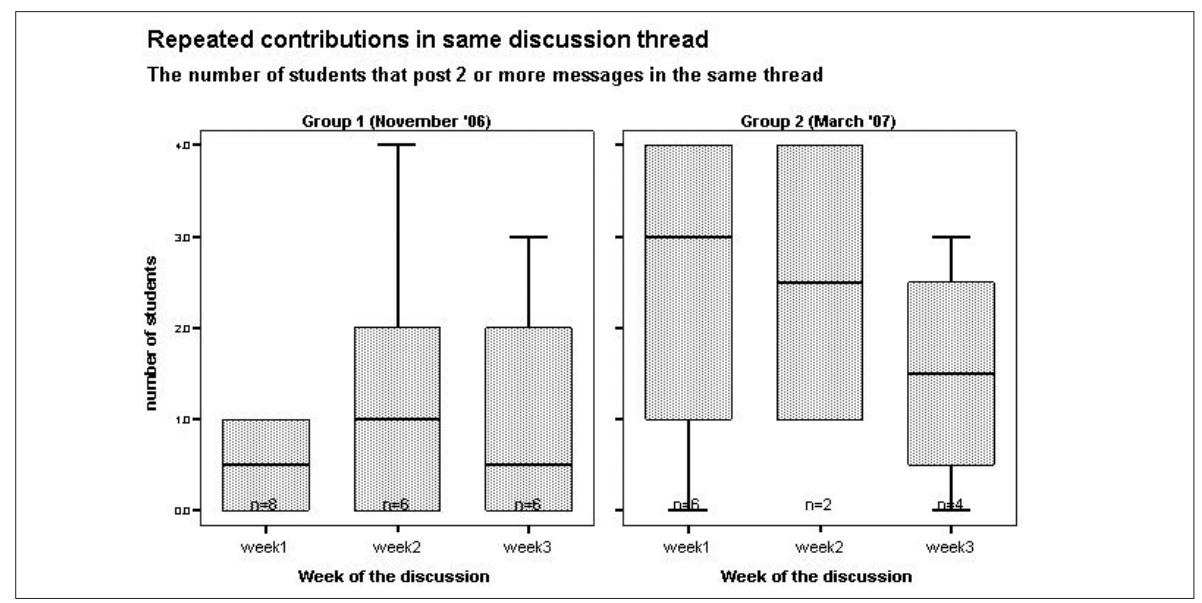

Figure 6 Repeated contibutions in the same discussion thread

\section{(2) 'Integration' message:}

"I think this is quite accurate. I don't know exactly how much blood flows from RV to the lungs and then ends up in LV. But it is a very small portion I think. This fits with what you see in ECGs of infants. For, I think, the axis of the heart shows a relative rotation towards the right at first and later this is compensated for by a stronger development of LV." This text reflects the socio-cognitive processes 'convergence among group members' and 'connecting ideas, synthesis'. Both processes belong to Garrison's 'integration' phase.

\section{(3) 'Resolution' message:}

"The transitional circulation of the preterm differs from the term infant. Higher risk of hypotension and low syst blood flow due to failure or delay in the normal 
transitional circulation processes. The maintenance of normal tissue oxygenation requires maintenance of syst blood flow and normal blood oxygen levels. Reduction in either of these can result in organ damage: IVH, longer term neurodevelopmental disability. - Kluckow M. Low systemic blood flow and pathophysiology of the preterm transitional circulation. Early Hum Dev. 2005 May;81(5):429-37. So postponing clamping can provide a bigger blood volume and a higher blood flow and less hypotension, and is therefore certainly advisable for preterm infants."

This text reflects the socio-cognitive processes of 'testing solutions' and 'defending solutions' for which an external scientific resource is used. Both processes belong to Garrison's 'resolution' phase.

Table 2 presents the distribution of student messages in the three-week discussion over the categories: triggering event, exploration, integration and resolution. The last column, labelled 'other', contains messages that were not content-related but merely procedural or social in nature. The students posted a total of 159 messages over the three-week period (Table 2 bottom row). Of these messages, $91.8 \%$ was content-related: $40.9 \%$ was categorised as exploration, $27 \%$ as integration and $7.5 \%$ as resolution. The remaining $8.2 \%$ concerned social talk or comments on the collaborative process or the use of the computer program and was categorised as 'other'.

\begin{tabular}{|c|c|c|c|c|c|c|}
\hline & \multirow[t]{2}{*}{ Number of student messages } & \multicolumn{5}{|c|}{ Distribution over categories (\%) } \\
\hline & & Trigger & Exploration & Integration & Resolution & 0ther \\
\hline \multicolumn{7}{|l|}{ Group 1} \\
\hline Week 1 & 21 & 71.4 & 9.5 & 0.0 & 0.0 & 19.0 \\
\hline Week 2 & 29 & 6.9 & 51.7 & 34.5 & 0.0 & 6.9 \\
\hline Week 3 & 17 & 0.0 & 52.9 & 23.5 & 23.5 & 0.0 \\
\hline Total & 67 & 25.4 & 38.8 & 20.9 & 6.0 & 9.0 \\
\hline \multicolumn{7}{|l|}{ Group 2} \\
\hline Week 1 & 49 & 18.4 & 49.0 & 18.4 & 0.0 & 14.3 \\
\hline Week 2 & 24 & 0.0 & 50.0 & 50.0 & 0.0 & 0.0 \\
\hline Week 3 & 19 & 0.0 & 15.8 & 42.1 & 42.1 & 0.0 \\
\hline Total & 92 & 9.8 & 42.4 & 31.5 & 8.7 & 7.6 \\
\hline \multicolumn{7}{|c|}{ Group $1 \& 2$} \\
\hline Week 1-3 & 159 & 16.4 & 40.9 & 27.0 & 7.5 & 8.2 \\
\hline
\end{tabular}

Table 2. Number of messages posted by students in groups 1 and 2 during the three weeks of the discussion and the distribution of these messages (in percentages) over Garrison's categories.

\section{Students' perceptions}

This section presents quotations from the individual interviews with all students $(n=8)$ participating in the study which we conducted after the three-week study period. When opposite perceptions were revealed we tried to include illustrative quotes for both perspectives. The quotations are clustered under six elements of an activity system (Engeström, 1987): subject, object, community, tools, rules and outcome. The letters and numbers at the end of each quote refer to student (St1-4) and group (Gr1-2). 


\section{(1) Subject (actors in activity: students and moderators)}

Students said they highly valued the input of their peers in the discussion, although some were disappointed by the low frequency of postings. Opinions varied with regard to the quantity and quality of the moderator postings.

My fellow students asked questions that were just as useful as those posed by the moderator. The questions posed by students are often more practical, questions that you might ask yourself: I saw a patient who had this, how come? Or: you may say this but in clinic I saw that, how come? The moderator's questions were more theoretical, creating depth. You need both. (Gr2, St2)

At first I participated very enthusiastically but when not everybody is posting frequently, you find that it tends to come last in an overloaded programme and that in itself is a shame. This would not happen if it was an obligatory component of the curriculum. (Gr1, St3)

The moderator could challenge us for he is a role model for us obviously, being a paediatrician, and I think most of us wish to be one as well. (Gr2, St1)

The moderator's comments might have been not so much more frequent but more pertinent. Not just in the discussion like: this does not make sense, you should look a bit further..... (Gr1, St1)

\section{(2) Object (products acted on by subjects: pathophysiological problems)}

According to the students, the online discussion increased their interest in pathophysiology and deepened the elaboration of this topic.

The online discussions have increased my interest in pathophysiology. The clerkship is just super busy. You may quickly look up this or that but you just don't take time for serious studying. Now you are compelled to go back and study the basics of something. Because I polished up on that I found that I enjoyed the clinical work more. That I start paying attention to saturation levels of all those children with pneumonia on the ward and that it is exciting to understand how it works. (Gr2, St1)

You study the material in more depth. When you are reading things by yourselfyou often just accept things. When you talk about it in this way you think: well what I thought was so simple, may be not so simple after all. Because you see other perspectives, how others may think about the same topic. (Gr1, St4)

\section{(3) Community (social cultural context in which the activity takes place: virtual group during work placement)}

Most of the students said that they felt part of a community in the virtual group and felt safe to share their thoughts within this community.

I did feel that we were working together on something. We are all in the same situation, a clerkship and apart from that working together on something different. That was a really good feeling I think. That you are really part of a group. (Gr1, St4)

l appreciated the openness of the online discussion. Especially in the exploration phase everyone was able to say what they thought and I felt free to think aloud. Maybe even 
more than during live brainstorming. Then everybody reacts and your words and train of thought get interrupted much more quickly. $(G r 2, S t 1)$

During the online discussion you were really free to write what you wanted and there was no disapproval from the others, you really felt that. Yet sometimes I felt inhibited to write my thoughts down. Maybe because I think that I should have known it already and because it is really final when you write something down. When you say something in a normal discussion and it is not correct, it is somehow easier .... (Gr1, St4)

\section{(4) Tools (online environment that mediates the activity: CSCL program)}

Several students said that the CSCL program (FLE3) had failed to give them a good overview of the unfolding discussion.

I felt that in the program the structure of the discussion got lost after a while. When there were many postings and I opened the context of a week, you got a whole list of comments and I lost track of what it was about and what I had yet to respond to. (GrI, St2)

I thought it was awkward that when I was posting a message I could not really get an overview of what all the others had said. You can view the posting you are responding to but not the postings before it. It would be useful when you could look back as you are typing and that was not possible. (Gr1, St1)

Furthermore, some students found the timing of the asynchronous discussion troublesome. With response times (the time between posting and response) exceeding $24 \mathrm{~h}$ for $47 \%$ and $57 \%$ of the responses to student postings in groups 1 and 2, respectively, students who were in the habit of checking the discussion board several times a day were annoyed that they had to wait so long for the others to respond. The variability of response times caused another timing problem as well: participants missed the opportunity to join in the 'forefront' of the discussion.

Unfortunately, I was unable to look that evening and the next morning was too busy and then there was no chance until the end of the following day. At that point there had been a whole discussion about your point in which you had been unable to participate. I really hated that. (Gr2, St1)

\section{(5) Rules (rules that constrain the activity: Practical Inquiry model, labelling messages)}

Almost all students said that the Practical Inquiry model provided a valuable structure to the online discussion and that this structure was responsive to their needs.

This structure makes you go into topics more deeply. What I also rather liked is the method of the good old 'seven jump' which was somehow evident from the different phases. You were not expected to come with literature references immediately and you had to see the verification week as the real solution week. (Gr1, St3)

Students' opinions about the value of the labels and the ease of assigning them to messages were more diverse. This also became apparent when we compared the students' labelling with the labels assigned by the researchers. The agreement 
percentage declined from $77 \%$ in the first week, via $55 \%$ in the second week to only $39 \%$ in the last week. Students often used the name of the phase in which a message was posted as the label for their message. Although this may be appropriate for most messages in the 'problem definition' phase, it is not so for the other phases.

During the introduction it was immediately clear to me what was expected for the labels. I got the picture and that was enough. I thought the system was also quite logically constructed. (Gr1, St3)

Getting used to assigning labels took a bit longer. It was difficult for me to determine what sort of contribution I was making. One time I indicated 'exploration' and the moderator said later: that is a good illustration of an integration. By looking at such examples I found out the precise meaning of the labels. I think I have got it now. (Gr1, St1)

(6) Outcome (transformation of the objects; the overall intention of the e-learning model)

Students said the online discussion was time consuming but most of them found the time investment worthwhile.

The efficiency of the time investment is a bit ambiguous: by yourself you would be able to do much more than say the two chapters we discussed, but because we did it this way they have become much more interesting, things stick in your memory much better and we studied things in much greater depth. (Gr2, St3)

\section{Moderators' perceptions}

This section presents quotations from the interviews with the two moderators. When opposite views were revealed we have tried to give an illustrative quote for both perspectives. The quotations are clustered under six elements of an activity system (Engeström, 1987).

\section{(1) Subject (actors in activity: students and moderators)}

Both moderators said they had to get used to the different dynamics of asynchronous online discussion. They perceived both advantages and disadvantages compared to face-to-face discussions.

Online the group process is different: everybody is working with the material on their own and at different times. I have the feeling that students are less inclined to simply repeat what the others have said in the discussion than they are in a f2f tutorial. (Gr2, M2)

I am the kind of person who enjoys entering into an oral conversation with others. In $f 2 f$ discussions I generally maintain a good overview of everything that is being said in group and I can give responses that are to the point. I missed that overview in the online discussions. (Gr1, M1)

\section{(2) Object (products acted on by the subjects: pathophysiological problems)}

One of the moderators said that addressing pathophysiological theory during clerkship was valuable for both students and supervisors. 
Online discussion about pathophysiology is valuable both for me and the students. For me because I notice that a student takes the initiative to go back to topics and notes from Year 3, which enables me to add that she might also have a look at Year 1 where respiratory physiology was first addressed. And now it recurs in the clerkship: the curriculum is not an incoherent jumble after all. (Gr2, M2)

For students it is particularly valuable that they are much more encouraged to think about the underpinnings of certain treatments. When you do that when you are treating a patient, you have a better understanding of why you do certain things and refrain from doing others. (Gr2, M2)

\section{(3) Community (social cultural context in which the activity takes place: virtual group during work placement)}

One of the moderators said he felt part of a community during the online discussion. Like the students he stressed that for the e-learning model to be feasible it is of the essence that the online discussion must be recognised by the organisation as a legitimate learning activity and integrated into the regular schedule of work placements.

I felt a very strong involvement with the group. You make a commitment to these students and that is why you feel responsible. Another type of commitment arises later and more from the group process: you see students making an effort, often in the evenings. Most of them are committed. It is quite evident, however, that one student is doing more in one week and another student in another week. That is probably due to workload and schedules. (Gr2, M2)

This time the hours I spent on the online discussion were mostly in evenings and weekends. These are extra and they are hidden hours: the department head does not know about it, as a matter of fact nobody does. If you would want to implement this structurally in an acceptable manner it should be given much greater visibility. (Gr2, M2)

\section{(4) Tools (online environment that mediates the activity: CSCL program)}

Both moderators experienced navigation problems with the CSCL program and said they felt that the overview of the threaded discussion should be improved. They expressed different opinions regarding the overall efficiency of the CSCL program for discussing basic science concepts. One moderator said it was 'not at all' efficient and the other one said 'yes', it was efficient but less so for wrapping up the discussion and for reaching consensus about organisational matters.

Wrapping up an online discussion is tricky. In a f2f discussion you spend the last 10 minutes answering different questions. You say: there are probably some loose ends left, ask away. Online you miss that sort of wrapping up. There you end with a summarisation, but the discussion thread often has multiple branches and there are loose ends in many different places. Those are not easy to combine in one summarisation. (Gr2, M2)

Apart from reading the postings, working with the program took up a great deal of time. I spent a lot of time searching and had to do a lot of up and down clicking and scrolling. Altogether it took up far too much time and it was not efficient at all. (Gr1, M1) 


\section{(5) Rules (rules that constrain activity: Practical Inquiry model, labelling messages)}

One of the moderators observed that implementation of the e-learning model and incorporating it into clinicians' normal working schedules would require more central planning from the moderator.

What I have now done mostly in my free time, I might also schedule within an average working week. For instance, I might schedule 30 minutes at a fixed time to look in the system. In a similar way in which I deal with my email now. This does require more central direction, however, about which you would have to make arrangements with the group in advance. (Gr2, M2)

\section{(6) Outcome (transformation of the objects: the overall intention of the learning activity)}

Both moderators (although to different degrees) said they thought the e-learning model improved students' understanding of basic science concepts, more particularly the transfer of this knowledge to clinical practice.

Apart from awareness that pathophysiology knowledge does have a function, they also gain knowledge from the discussions, which to my mind will be retained longer. They are getting away from mindless rote learning and I feel that what they learn will be much more firmly embedded in their clinical reasoning and actions. (Gr2, M2)

Physiological knowledge does not really gain more depth as a result of the discussion. They are using basic physiology which they learned in the first three years. But they do use this knowledge now for practical purposes and that does raise it to a higher level. $(G r 2, M 2)$

\section{DISCUSSION AND CONCLUSION}

\section{Quantity and quality of the interaction}

Despite the fact that the e-learning model was added to students' considerable workload in a demanding work placement and participation was voluntary conditions that would seem unlikely to favour strong involvement (Oliver \& Shaw, 2003) - the students'input in the online discussions was satisfactory: eight students posted 159 messages over the course of three weeks. This is 6.6 messages per participant per week. When we calculate similar figures for studies referred to in the methods section which reported sufficiently detailed information (Garrison et al., 2001; Kanuka et al., 2007; Schrire, 2006) we find between 0.6 and 4.8 messages per participant per week.

More important than the absolute number of students' contributions are quantitative indications for engagement in social activity: long threads, high viewing rates and repeated postings by the same students in the same thread (Kay, 2006). The number of postings in most threads exceeded five messages; $98 \%$ of student postings were viewed by all other students in the group and students posted two or more messages in many of the threads. In addition the students generated $80 \%$ of all postings and peers read these messages as often as they did the moderator's postings. In all, the quantitative data point to substantial social activity on the discussion board (Kay, 2006). 
Data from the student interviews support this impression of substantial social activity. Most students valued the input of their peers highly and thought the number of messages sufficient, although the timing of postings was often problematic. Some students were annoyed when they found themselves checking in vain for updates when response times were long; others were frustrated because they missed the 'forefront' of the discussion. These two effects emphasize that the delay in communication characteristic of asynchronous media can be both a strength and a weakness (Hammond, 2000). A feature in the CSCL program, which automatically alerts the poster of a message to incoming responses might easily alleviate some of the aggravation induced by delay in responses.

\section{Quality of the discussion}

The occurrence of a social activity, even if it is appreciated by peers, is in itself no guarantee that higher order thinking or knowledgebuilding will take place (Crook, 1996; Fauske \& Wade, 2003). The content analysis of the student messages with Garrison's coding scheme (Garrison et al., 2001) enabled us to reflect on the quality of the discussion.

Table 2 shows that $91.8 \%$ of student messages in the CSCL environment were content-related. This percentage is quite high compared to percentages reported in other studies using the same coding scheme (Fahy, 2002; Garrison et al., 2001; Kanuka et al., 2007; McKlin et al., 2002; Meyer, 2003; Schrire, 2004, 2006). A finding that is similar to the results of these other studies is that the bulk of the messages was categorised as exploration (40.9\%) while the percentages of integration (27\%) and resolution $(7.5 \%)$ were low.

Our results appear less disappointing when we compare them it to figures from the aforementioned studies, although the percentage of higher order thinking activities generated by our e-learning model (34.5\%) is lower than we had hoped, Our $34.5 \%$ is higher than the $20.2 \%$ (14.7\% integration and $5.5 \%$ resolution) reported by Kanuka et al. (2007), who studied instructional methods specifically developed to help learners move to higher levels of learning. Furthermore, unlike most of the other studies, the setting of our study was outside the domain of educational or computer science studies. In the latter settings, computer-mediated communication will be an important topic of study in itself and populations may be expected to be biased in favour of online learning.

The percentages we found for integration and resolution messages are in line with those reported by Meyer (2003) (22\% integration, 7\% resolution) and Schrire (2004, 2006) (33\% integration, $9 \%$ resolution), but unlike our results, these percentages included moderator postings. Because summarising and wrapping up are often seen as important tasks for the moderator, inclusion of moderator postings may have elevated the numbers of integration and resolution messages in those studies.

A very remarkable finding is that the timeline analysis shows that it is possible to steer the type of contribution by dedicating a certain week to a specific phase of the Practical Inquiry model. The third week of our online discussion was dedicated to 'verification and resolution' and the students in groups 1 and 2 together generated 
on average $33.3 \%$ integration and $33.3 \%$ resolution messages in this week. If we look at the groups separately, we see that these proportions may even increase as a result of the moderator's approach. Group 2, whose moderator appeared to be somewhat more inspiring, generated $42 \%$ for integration and another $42 \%$ for resolution messages in the last week (Table 2), although both groups had comparable scores on attitude towards critical thinking in the pre-test.

Garrison et al. (2001) suggested some explanations for the relatively small numbers of integration and resolution postings. One of these explanations is that composing an integration message requires more time for reflection and synthesis, which is generally considered to discourage participants from posting such messages. Another take on this might be that the inductive process involved in writing an integrative message causes participants to produce relatively few messages presenting an elaborated synthesis rather than numerous messages presenting disjointed items. So it may be a characteristic of integration messages that their number is relatively small compared to that of exploratory messages.

This inherent condensed nature could also apply for resolution postings. Moreover, before posting a resolution message participants will have to search and read the literature to find arguments underpinning the resolution message. With a limited timeframe of one week it seems only to be expected that there are only few messages per participant. Because many students said in the interviews that the 'problem definition', 'exploration and integration' phases were somewhat long compared to the 'verification and resolution' phase, extending the latter phase to 1.5 weeks at the expense of the other phases might be a good option to increase the number of resolution postings.

\section{Experiences of students and moderators with the e-learning model}

The students found that the e-learning model increased their interest in pathophysiology and that the online discussions guided by the Practical Inquiry model resulted in deep elaboration of pathophysiological topics which they encountered in practice. In addition the elearning model was sufficiently responsive to give the participants a sense of belonging to a community in which they could pursue shared and personal goals.

Both moderators (although to different degrees) said the e-learning model improved students' understanding of basic science concepts, especially the transfer of knowledge to practice. However, they expressed opposing views regarding the efficiency of the e-learning model. One moderator said he would not adhere to the e-learning model because of its inefficiency, the other moderator said it was very feasible but suggested that it should be complemented by synchronous communication. He thought a scheduled and collective meeting via videoconferencing (a sort of 'beeper' moment), integrated in the existing asynchronous communication, might solve the problems he had experienced with wrapping up the discussion and reaching consensus on organisational matters.

Students and moderators experienced navigation problems with the CSCL program (FLE3) and lost their overview of the threads in the course of the discussion. 
Improving the interface of the CSCL program by inline editing and more integration of the features to sort, nest and filter messages in the threaded discussion, might address this apparent shortcoming of the e-learning model.

A striking finding is that students as well as moderators advocated that the medical school should show recognition of the value of online discussion on basic science topics by integrating this format in the regular schedule of work placements. They claimed that formal recognition by the institution was essential for the feasibility of the e-learning model.

A limitation of this study is the small number of participants, and replication studies with more groups of students would be needed to enable statistically valuable conclusions.

In summary, we conclude that Garrison's 'Practical Inquiry' model appears to be a viable instrument for procedural facilitation of online discussions about basic science concepts among small groups of students engaged in busy work placements at different training sites. An e-learning model integrating this'Practical Inquiry' model in concerted facilitation by a human moderator and a program for asynchronous communication appeared to be successful in establishing a dialogue among an expert and a group of students. The structure of the e-learning model was useful in facilitating a sustained on-topic discourse involving critical thinking in a group of peers. Despite the moderate amount of critical thinking, the results suggest ways to increase integration and resolution activities. This might be achieved by changing the amount of time allocated to the different phases of Practical Inquiry in the CSCL program. Adding a synchronous component to the e-learning model might be another modification worth considering.

\section{REFERENCES}

Barab, S. A., \& Duffy, T. M. (2000). From practice fields to communities of practice. In D. Jonassen \& S. Land (Eds.), Theoretical foundations of learning environments (pp. 25-55). Mahwah, NJ: Lawrence Erlbaum.

Brown, J., \& Duguid, P. (1991). Organizational learning and communities of practice: Toward a unifying view of working, learning, and innovation. In M. Cohen \& L. Sproull (Eds.), Organizational learning (pp. 59-82).

Collins, A., Brown, J. S., \& Newman, S. (1989). Cognitive apprenticeship: Teaching the craft of reading, writing and mathematics. In L. B. Resnick (Ed.), Knowing, learning and instruction: Essays in honor of Robert Glaser (pp. 453-494). Hillsdale, NJ: Lawrence Erlbaum Associates, Inc.

Collis, B., \& Margaryan, A. (2004). Applying activity theory to computer supported collaborative learning and work-based activities in corporate settings. Etr\&DEducational Technology Research and Development, 52(4), 38-52.

Crook, C. (1996). Computers and the collaborative experience of learning. London: Routledge. 
de Wever, B., Schellens, T., Valcke, M., \& van Keer, H. (2006). Content analysis schemes to analyze transcripts of online asynchronous discussion groups: A review. Computers and Education, 46, 6-28.

Duffy, T. M. (1998). Critical thinking in a distributed environment: A pedagogical base for the design of conferencing systems. In C. Bonk \& K. King (Eds.), Electronic collaborators: Learner centered technologies of literacy, apprenticeship and discourse (pp. 51-78). Mahwah New Jersey: Lawrence Erlbaum Associates.

Engeström, Y. (1987). Learning by expanding: An activity theoretical approach to developmental research. Helsinki: Orienta-Konsultit.

Facione, N., Facione, P., \& Sanchez, C. (1994). Critical thinking disposition as a measure of competent clinical judgment: The development of California critical thinking disposition inventory. Journal of Nursing Education, 33(8), 345-350.

Fahy, P. (2002). Assessing critical thinking processes in a computer conference [Electronic Version]. Athabasca University, Centre for Distance Education. Retrieved August 2007 from <http://cde.athabascau.ca/softeval/reports/mag4.pdf>.

Fauske, J., \& Wade, S. E. (2003). Research to practice online: Conditions that Foster democracy, community, and critical thinking in computer-mediated discussions. Journal of Research on Technology in Education, 36(2), 137-153.

Garrison, D. R., Anderson, T., \& Archer, W. (2001). Critical thinking, cognitive presence and computer conferencing in distance education. The American Journal of Distance Education, 15(1), 7-23.

Guzdial, M., \& Turns, J. (2000). Effective discussion through a computer-mediated anchored forum. The journal of the learning sciences, 9(4), 437-469.

Hammond, M. (2000). Communication within on-line forums: The opportunities, the constraints and the value of a communicative approach. Computers and Education, $35,251-262$.

Issroff, K., \& Scanlon, E. (2002). Using technology in higher education: An activity theory perspective. Journal of Computer Assisted Learning, 18(1), 77-83.

Kanuka, H., Rourke, L., \& Laflamme, E. (2007). The influence of instructional methods on the quality of online discussion. British Journal of Educational Technology, 38(2), 260-271.

Kay, R. H. (2006). Developing a comprehensive metric for assessing discussion board effectiveness. British Journal of Educational Technology, 37(5), 761-783.

King, A. (1995). Designing the instructional process to enhance critical thinking across the curriculum. Inquiring minds really do want to know - using questioning to teach critical thinking. Teaching of Psychology, 22(1), 13-17.

King, A. (1999). Discourse Patterns for mediating peer learning. In A. O'Donnell \& A. King (Eds.), Cognitive perspectives on peer learning (pp. 87-115). London: Lawrence Erlbaum.

Kulhavy, R., \& Wager, W. (1993). Feedback in programmed instruction: Historical context and implications for practice. In J. Dempsey \& G. Sales (Eds.), Interactive instruction and feedback. Englewood Cliffs: Educational Technology Publications. 
Landis, J., \& Kock, G. (1977). The measurement of observer agreement for categorical data. Biometrics, 33, 159-174.

Luppicini, R. (2007). Review of computer mediated communication research for education. Instructional Science, 35, 141-185.

Mason, R. (1992). Evaluation methodologies for computer conferencing applications. In A. Kaye (Ed.), Collaborative learning through computer conferencing (pp. 105116). Berlin: Springer.

Mayes, T., \& de Freitas, S. (2004). Review of e-learning theories, frameworks and models (No. Work Package 1b, JISC e-learning models desk study). London: The Joint Information Systems Committee. Retrieved December 2007 from <http:// www.jisc.ac.uk/elp_outcomes.html>.

McKlin, T., Harmon, S., Evans, W., \& Jones, M. (2002). Cognitive presence in web-based learning: a content analysis of students' online discussions. University of Georgia, Instructional Technology Forum. Retrieved February 2007 from <http://it.coe.uga. edu/itforum/index.html>.

Meyer, K. (2003). Face-to-face versus threaded discussions: The role of time and higherorder thinking. JALN, 7(3), 55-65.

Moore, M. (1993). Theory of transactional distance. In D. Keegan (Ed.), Theoretical principles of distance education (2nd ed.). New York: Routledge.

Moore, M., \& Kearsley, G. (2005). Distance education: A systems view (2nd ed.). London: Thomson Wadsworth.

Muukkonen, H., Hakkarainen, K., \& Lakkala, M. (1999). Collaborative technology for facilitating progressive inquiry: Future learning environment tools. Paper presented at the CSCL 1999, Palo Alto, California.

Oliver, M., \& Shaw, G. (2003). Asynchronous discussion in support of medical education. Journal of Asynchronous Learning Networks, 7(1), 56-67.

Pilkington, R. (1999). Analysing educational discourse: The DISCOUNT scheme (No. CBLU Technical Report 99/2). Leeds: Computer based learning unit, The University of Leeds.

Pithers, R. T., \& Soden, R. (2000). Critical thinking in education: A review. Educational Research, 42(3), 237-249.

Saab, N., van Joolingen, W., \& van Hout-Wolters, B. (2007). Supporting communication in a collaborative discovery learning environment: The effect of instruction. Instructional Science, 35(1), 73-98.

Scardamalia, M., \& Bereiter, C. (1991). Higher levels of agency for children in knowledge building: A challenge for the design of new knowledge media. The Journal of the Learning Sciences, 1, 37-68.

Schrire, S. (2004). Interaction and cognition in asynchronous computer conferencing. Instructional Science, 32, 475-502.

Schrire, S. (2006). Knowledge building in asynchronous discussion groups: Going beyond quantitative analysis. Computers and Education, 46, 49-70. 
van Aalst, J. (2006). Rethinking the nature of online work in asynchronous learning networks. British Journal of Educational Technology, 37(2), 279-288.

Wagner, E. (1994). In support of a functional definition of interaction. The American Journal of Distance Education, 8(2), 6-29.

Wenger, E. (1998). Communities of practice: Learning, meaning, and identity. Cambridge, MA: Cambridge University Press.

Yacci, M. (2000). Interactivity demystified: A structural definition for distance education and intelligent computer-based instruction. Educational Technology, 40(4), 5-16. 
0
$\frac{0}{4}$
$\frac{0}{0}$
$\frac{0}{U}$ 
Chapter 6

Instruments to explore blended learning: modifying a method to analyse online communication for the analysis of face-to-face communication

Under editorial review

Bas A de Leng, Diana H J M Dolmans, H. (Jeroen) H L M Donkers, Arno M M Muijtens \& Cees P M van der Vleuten 


\section{Abstract}

In the complex practice of today's blended learning, educators need to evaluate both online and face-to-face communications to get the full picture of what is really going on in the blended learning scenarios they arrange. To enable such a comprehensive analysis we tried to provide a practical instrument for the analysis of face-to-face communication that is aligned with tools for the analysis of online communication. For this we determined if an existing coding scheme for online communication, the Transcript Analysis Tool (TAT), could be modified to evaluate face-to-face communication. In order to do so we assessed the reliability, validity and usability of a modified version of the TAT in analysing communication in small-group sessions with presentations and discussion. We found that the modified TAT was effective in obtaining a detailed description of the participation and focus during small group sessions and that the evaluations were most efficient with direct video analysis compared to an analysis of a video transcript. The direct analysis took about 2 hours for 20 minutes of video recording and had an inter-rater reliability of $\mathrm{K}=$ 0.56 . We conclude that the modified TAT is an effective and efficient instrument to analyse face-to-face communication in small group sessions with presentations and discussions. Its combined use with an evaluation instrument for online learning may create a powerful evaluation instrument for blended learning. Further studies are needed to establish the value of such an instrument. 


\section{INTRODUCTION}

Although blended learning, which we define as the combination of face-to-face and online learning, is increasingly being used in education (Garrison \& Vaughan, 2008; Graham, 2006), empirical studies on this subject are rather scarce. As a consequence, there is a need for design-based research to explore which 'blends' may enhance and perhaps transform current pedagogy (Garrison \& Kanuka, 2004).

For such research to be successful, valid instruments are required to analyse both face-to-face communication and computer-mediated communication. Instruments for analysing either face-to-face or online communication exist in many forms. However, there is a paucity of instruments that are not only suitable for analysing face-to-face communication but are also in alignment with instruments to analyse online communication. In this study we examine whether an instrument developed in the domain of Computer Supported Collaborative Learning for analysing online communication can be modified and applied to face-to-face interaction.

During discussions, either face-to-face or online, students interact with their environment (communicative events) and express their thoughts and knowledge (communication of cognition). Depending on the focus of analysis, the literature on discourse research follows one of two strands: 'conversation' (or 'interaction') analysis and 'content' analysis. The term 'conversation' analysis is used when the focus is on the more observable, surface elements in the discussion (e.g. speaker allocation, speech act, elicitation-response patterns). When the focus is more on the latent variables of cognitive processes (e.g. critical thinking), which have to be inferred from manifest indicators in texts, the term 'content analysis' is used (Mazur, 2004).

In the last decade, content analysis has been widely used to analyse the quality of online discussions and to infer cognitive processes like critical thinking (Bullen, 1998; Fahy et al., 2000; Garrison, Anderson, \& Archer, 2001; Henri, 1992; Newman, Webb, \& Cochrane, 1995). Although many different coding schemes for online discussions have been developed over the years, a substantial number of them lacks a solid theoretical foundation (De Wever, Schellens, Valcke, \& van Keer, 2006; Rourke, Anderson, Garrison, \& Archer, 2001), which raises doubts regarding their validity (Gunawardena, Carabajal, \& Lowe, 2001). For several of the coding schemes insufficient information on inter-rater reliability is available. Moreover, the comprehensiveness and wealth of detail of many coding schemes can make it difficult for raters to keep all the specific categories in mind and interpret the results of the analysis (Marra, Moore, \& Klimczak, 2004). This motivated Henri's (1992) statement that 'if content analysis is to become a workable tool for educators who are not trained as scientists, progress must be made at the conceptual level, where methods must be further refined and at the technical level, where the analytical tools must be made more user friendly."

With their strong focus on observable, surface elements in the discussion, such as speaker allocation, speech act, and elicitation-response patterns, coding schemes for interaction analysis are better geared to capture the transient characteristics of face-to-face discussions and are thus more suitable for direct analysis of videotaped 
discussion sessions. After reviewing various interaction-directed coding schemes (Boxtel van, 2000; Fahy, Crawford, \& Ally, 2001; Fahy et al., 2000; Gunawardena, Lowe, \& Anderson, 1997; Hmelo-Silver, 2003; Howell-Richardson \& Mellar, 1996; Mercer, 1996; Veerman, Andriessen, \& Kanselaar, 2000; Yagelski \& Grabill, 1998), we selected Fahy's Transcript Analysis Tool (TAT) because it offers a useful mixture of an interaction and a content-analysis coding scheme (Fahy, Crawford, \& Ally, 2001).

The intermediate position of the TAT, between an interaction and a content analysis coding scheme, makes it very suitable for analysing communicative events directly from video. The main categories of the TAT, questioning, statements and quotations, refer to speech acts that are easy to identify by non-specialist raters. The duration of these speech acts is often sufficiently long for raters to identify, before the next speech act begins, not only the participant executing the speech act but also the type of content addressed. Moreover it will also be feasible, in most cases, to identify subcategories enabling more detailed characterisation of the type of question or statement within the duration of the speech act, thereby enabling raters to conduct real-time coding from video. In addition, researchers have already reported moderate inter-rater reliabilities for the TAT with Cohen kappa's ranging from 0.45 to 0.65 (Fahy, Crawford, \& Ally, 2001).

Applying TAT in analysing face-to-face discussions is nevertheless no straightforward matter. Although there are indications that the coding scheme is well-suited to face-to-face discussions, it was originally developed for online texts with 'sentences' as the unit of analysis. However, in face-to-face discussions, the majority of sentences is likely to have no or no clear boundaries: sentences tend to be incomplete or merge with other ones. In addition, the 'sentence' may be too fine grained a unit for the kind of formative evaluation of face-to-face discussions we are after. Therefore, we expect that a more practical unit of analysis for the major coding categories of the TAT (questions, statements, reflections and external references) would be the 'utterance,' i.e. a message unit of one speaker with a singular communicative function. This unit combines the right granularity for making in-depth interpretations with boundaries that are relatively easy to observe.

The purpose of our current study is to determine if Fahy's TAT, modified to analyse verbal interactions in face-to-face communication, is an efficient and effective instrument for the analysis of small group sessions with presentations and discussion. However, before we can establish the efficiency and effectiveness of the modified TAT, we need to investigate its reliability and validity for the intended purpose. The modified TAT should enable us to identify and quantify different types and content of interactions during small group sessions with face-to-face presentations and discussion. 
These objectives led to the following research questions:

1. Is the modified TAT a reliable instrument for the description of face-to-face communication?

- What is the inter-rater reliability of the modified TAT for direct analysis of video-recordings of face-to-face communication?

- What is the inter-rater reliability of the modified TAT for the analysis of transcripts of video-recordings of face-to-face communication?

2. Is the modified TAT, applied in direct video analysis, an efficient instrument for the description of face-to-face communication?

- When the modified TAT is used for direct video analysis of face-to-face communication and also for the analysis of the transcripts of these videorecordings, do the results of these analyses correlate?

- How does the time needed for the direct video analysis of face-to-face communication with the modified TAT compare to the time needed to analyse the transcripts of these video-recordings with the modified TAT?

3. What are the benefits of using the modified TAT in direct video analysis of face-to-face communication in small group sessions with presentation and discussion?

\section{METHODS}

\section{Subjects and setting}

The study was conducted during the clinical phase of a six-year undergraduate medical curriculum. Each clerkship rotation in Years 4 and 5 is followed by a wrap-up week when students return to the medical school setting for various educational activities. One of these activities are small group sessions of 8-10 students facilitated by a clinician in which students present and discuss patient cases. The students presenting a case prepare a Powerpoint slide show and the group discusses the presented case. We chose this setting because in medical education case presentations play a key role in structuring students' clinical and professional learning (Lingard, Schryer, Garwood, \& Spafford, 2003).

A group of eight students (4 males, 4 females; age range $22-27$ years) and a group of nine students ( 4 males, 5 females; age range $22-28$ years) took part in the study during the wrap-up week of the paediatric clerkship in May and June of 2007, respectively. We studied group sessions in which the explicit goal was to discuss basic science topics underlying the presented paediatric cases. These sessions were a compulsory component of the paediatric clerkship and the discussion was guided by a paediatrician and a physiologist. These sessions typically take about 3 hours, during which a total of three cases is presented by individual students or pairs or triads of students. Students as well as teachers gave informed consent for their participation in the study.

\section{Procedure}

At the start of their paediatric rotation we informed the participating students of both groups and the tutors of the presentation sessions that we were going to videotape a specific small group session in the wrap-up week and that we wanted to do this as unobtrusively as possible. We used two digital wide-angle 
cameras to record the case presentations and the group discussion, one to record the presenting student and the two tutors and one to record the audience of 7-8 students. The screen on which the slides were projected was also included in the recording. Special microphones were mounted on the ceiling to secure high quality recording of the verbal interactions. All recordings were directly saved to a hard disk.

We used the video recording of a presentation on 'cow's milk allergy' from the second group of students (June 2007) to test inter-rater reliability. The digital video of this presentation was analysed by two raters, BdL and JD, and the transcript of the same video was analysed by BdL and another rater, MU. So, the principal researcher $(\mathrm{BdL})$ took part in both inter-rater reliability studies, each time with a different person as the second rater. Next, BdL performed a walk-through analysis of the video recording of a presentation on 'neonatal jaundice' in the first group of students (May 2007) to judge the merits of the modified TAT in describing case presentations.

\section{Transcript Analysis Tool}

We used a modified version of Fahy's Transcript Analysis Tool (TAT) to describe quantitatively the quality of the verbal interactions during face-to-face communication. Utterances were identified and coded by assigning them to one of four primary categories and, if applicable, to secondary subcategories (appendix, table 5): (1) questions (vertical or horizontal), (2) statements (non-referential, referential answer or referential comment), (3) reflections, and (4) references (unverifiable or verifiable). The TAT used in our study differed from the original TAT in that the category 'scaffolding/ engaging' was omitted, because our focus was on cognitive presence and not on teaching or social presence, and some of the original categories were refined or consolidated to improve user friendliness.

The primary and secondary categories of the original TAT were supplemented by an additional category specifying the content of interactions in order to achieve a rich description of the verbal interactions during the presentation and discussion in a face-to-face small group session. The content description allowed two levels of detail (appendix, table 6). With a high level of detail content was specified, based on the knowledge domain of the topic, as basic science (= pathophysiology) content or clinical content. With a low level of detail the only differentiation was between process (= no-content) and content without further specification of the content.

Initially developed to analyse online texts, the original TAT uses the 'sentence' as the unit of analysis. However, we deemed that an 'utterance' would be a more appropriate unit of analysis for face-to-face communication during the presentation and discussion sessions. We defined an 'utterance' as an individual message unit that: a) was expressed by one subject (e.g. student, paediatrician, physiologist) and had one single communicative function, i.e. transmitting a single message or expectation (e.g. question, statement, reflection or reference). The length of an utterance could range from one word to many sentences.

In two training sessions the raters of the transcripts of the video recordings were 
instructed how to apply the modified TAT. One session was devoted to segmenting transcribed speech into units of analysis (two hours) and another one session to assigning TAT categories to the units of analysis (four hours). For the direct coding of digital video, the modified TAT coding scheme was entered into the software program ObserverXT 7.0 (Noldus, 2007). The raters of the direct video analysis were trained in using the observation software (two days) and the modified TAT coding scheme in analysing 'utterances' (four hours).

\section{Data selection and analysis}

In order to establish the inter-rater reliability of the direct video analysis of faceto-face communication, two raters analysed a 20 minute fragment of a 50 minute session on 'cow's milk allergy'. Using Observer XT, they independently coded the digital video fragment according to the modified TAT. The coding process was not preceded by a segmentation process, because observation of an 'utterance' automatically defined the segment that needed to be coded.

The inter-rater reliability of the analysis of transcripts of videotaped face-toface communication was established by comparing the analyses of two raters of the transcript, produced by a research assistant, of the video fragment used for the direct analysis. The raters first independently segmented the transcript into 'utterances' as the unit of analysis, based on the definition described earlier. Subsequently, the raters discussed the way they had segmented the transcript until consensus was reached on the final segmentation, which was then used for coding. Finally, the raters independently assigned the categories of the modified TAT to the 'utterances'.

Cohen's kappa was used as a measure of inter-rater reliability, because it accounts for the percentage of agreement as well as the percentage of agreement expected by chance. Because the modified TAT describes the content of interactions at two levels of detail (differentiated by topic or no differentiation), we calculated Cohen's kappa for both levels of detail.

\section{RESULTS}

\section{The inter-rater reliability of the use of the modified TAT for direct video analysis of face-to-face communication}

The two raters identified a total of 96 'utterances' during the selected 20 minutes of digital video. During the direct analysis with ObserverXT, communication changes identified by the raters, marking the boundaries of 'utterances', were electronically marked in seconds. Because the changes were not marked in perfect synchrony, we manually aligned the raters' chronological lists of changes at those boundaries that were unmistakeably identical based on considerations of the speaker of the utterance. Next the two lists were merged. If one large utterance identified by one rater overlapped two or more utterances identified by the other rater, the large utterance was split to arrive at the same number of utterances. New utterances resulting from the splitting kept the same TAT category as the larger utterance from which they originated. With this procedure we ended up with 96 'utterances.' 
Table 1 shows Cohen's kappas for direct video coding using the categories of the modified TAT for the content categories with and without differentiation by topic, separately.

\begin{tabular}{lcc}
\hline Assigned TAT code (\# utterances=96) & K & Agreement \\
\hline - content category not differentiated & 0.62 & 61 \\
- content category differentiated & 0.56 & 55 \\
\hline
\end{tabular}

Table 1. Cohen's kappa for direct TAT coding of two videos by two raters.

The inter-rater reliability of the modified TAT for the analysis of transcripts of video recordings of face-to-face discussions.

The two raters identified a total of 89 'utterances' in the transcript of the 20 minute video. Because 11 of these 'utterances' were missed by one of the raters, the percentage of agreement for the segmentation process was $88 \%$. After comparing and discussing the differences in segmentation, the raters reached consensus on 82 'utterances'. Subsequent coding of these 82 'utterances' by the two raters resulted in the Cohen's kappas presented in Table 2.

\begin{tabular}{|lcc|}
\hline Assigned TAT code (\# utterances=82) & K & Agreement \\
\hline - content category not differentiated & 0.67 & 56 \\
- content category differentiated & 0.59 & 49 \\
\hline
\end{tabular}

Table 2. Cohen's kappa for TAT coding of the transcripts by two raters.

The correlation between the direct video analysis and the transcript analysis with the modified TAT

One of the raters identified 86 'utterances' using the direct analysis of 20 minutes of video and assigned TAT codes to these 'utterances'. The same rater also assigned TAT codes to the 82 'utterances' of the transcript of this video fragment on which the raters had agreed. When we merged the observed changes in the communication in both analyses on the basis of the speaker responsible for these changes, we ended up with 97 'utterances'. Table 3 shows Cohen's kappas for these two analyses for the content categories with and without differentiation by topic, respectively.

\begin{tabular}{llc|}
\hline Assigned TAT code (\# utterances = 97) & K & Agreement \\
\hline - content category not differentiated & 0.51 & 51 \\
- content category differentiated & 0.47 & 47 \\
\hline
\end{tabular}

Table 3. Cohen's kappa for TAT codes assigned by one rater directly to video and to transcript of this video. 
Table 4 shows the amount of time it took the raters to learn how to use and to actually use the modified TAT to categorise the video and the transcript of the video. The raters of the transcripts had to learn the segmentation process and the coding process separately. In all, this took approximately six hours. Direct analysis of the video did not require the raters to learn how to segment the verbal interaction and four hours of training sufficed. Coding the twenty-minute fragment using direct video analysis took two hours, while segmenting and coding the transcripts took 5.5 hours. Only the principal researcher $(\mathrm{BdL})$ attended the training sessions for both methods, starting with direct video analysis. With each of the methods, the second rater was a different person (JD and MU).

\begin{tabular}{|c|c|c|c|c|c|c|}
\hline \multirow[b]{2}{*}{ Coding method } & \multicolumn{3}{|c|}{ Training time (hours) } & \multicolumn{3}{|c|}{ Analysis time (hours) } \\
\hline & Segmentation & Coding & Total & Segmentation & Coding & Total \\
\hline Directly from video & - & 4 & 4 & - & 2 & 2 \\
\hline Via transcript & 2 & 4 & 6 & 0.5 & 5 & 5.5 \\
\hline
\end{tabular}

Table 4. Total time for learning and applying the coding method.

\section{The description of small group sessions with face-to-face oral presentations and discussion in an undergraduate medical education setting}

Using ObserverXT, we produced a chart in which the twenty minutes of interaction during the presentation of the 'neonatal jaundice' case were plotted against elapsed time. Figure 1 shows the coding of the 'utterances' in a timeframe of about three minutes (question, statement, reflection and external reference).

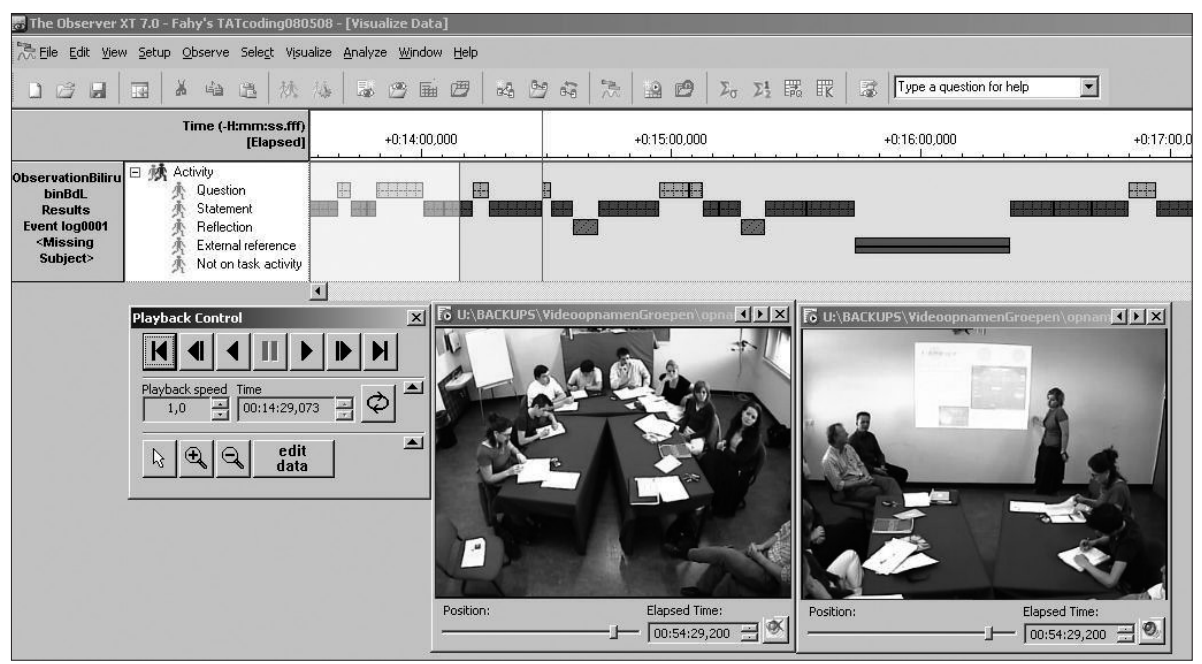

Figure 1. Playing back a video fragment (bottom windows) based on a selection made on the chart with coded interactions plotted against a time axis. 
The content of the verbal interaction during about fifteen seconds of case presentation is presented below (the categories are given within brackets)

Student: Can it also help for some adults to put them underneath the lamp? [Question, student08, clinical content, vertical]

Paediatrician: This is done with some diseases. I just have to, I can't think of the name just now. But in my opinion those, there is also a number of hereditary conjugation disorders. And those children have chronic ...

[Statement, paediatrician, content-clinical, referential answer]

Student: bia....(inaudible) patients, or something?

[Question, student02, content-clinical, vertical]

Paediatrician: ... bili's of 500 , you usually put them underneath the lamp at night.

[Statement, paediatrician, clinical content, referential comment]

Student: And in adults and older children it is of course much more often post hepatic than ... and hepatic, let's say. So then the pathology is different.

[Reflection, student 04, content-physiology]

Paediatrician: Yes, but. The rare disorder I am referring to, those hereditary conjugation disorders, the mechanisms are actually similar.

[Statement, paediatrician, content-physiology, referential comment]

In addition, we calculated the frequencies and duration of the primary, secondary and content categories of the modified TAT. In order to get an impression of the participation in the discussion (symmetry, student or teacher centeredness) we constructed charts with frequencies and duration of coded categories for the different types of participants (Figure 2 and 3). An impression of the focus (clinical or basic science) of the discussion was obtained by presenting the duration of different types of content (Figure 3).

Figure 2 shows the frequency distribution of the 'utterances' during the twentyminute case presentation over theTAT categories for the three types of participants: student, physiologist and paediatrician. We see that: a) the two most frequent 'utterances' are statements of the type referential comments and referential answers, b) the vertical questions are twice as frequent as the horizontal questions and c) students contribute most of the 'utterances', the paediatrician comes second and the physiologist has the fewest utterances.

Figure 3 shows the total time of the contributions of each participant during the twenty minutes of the case presentation and small group discussion categorised by three types of content: process (=no-content), physiology and clinical. We see that: a) nearly all of the time was devoted to content-related issues, b) physiology topics were addressed the most, c) the presenting student (student02) was responsible for nearly half and the paediatrician for about a quarter of the 'airtime', leaving the remaining quarter of 'airtime' for the other participants, whose contributions lasted less than one minute. 


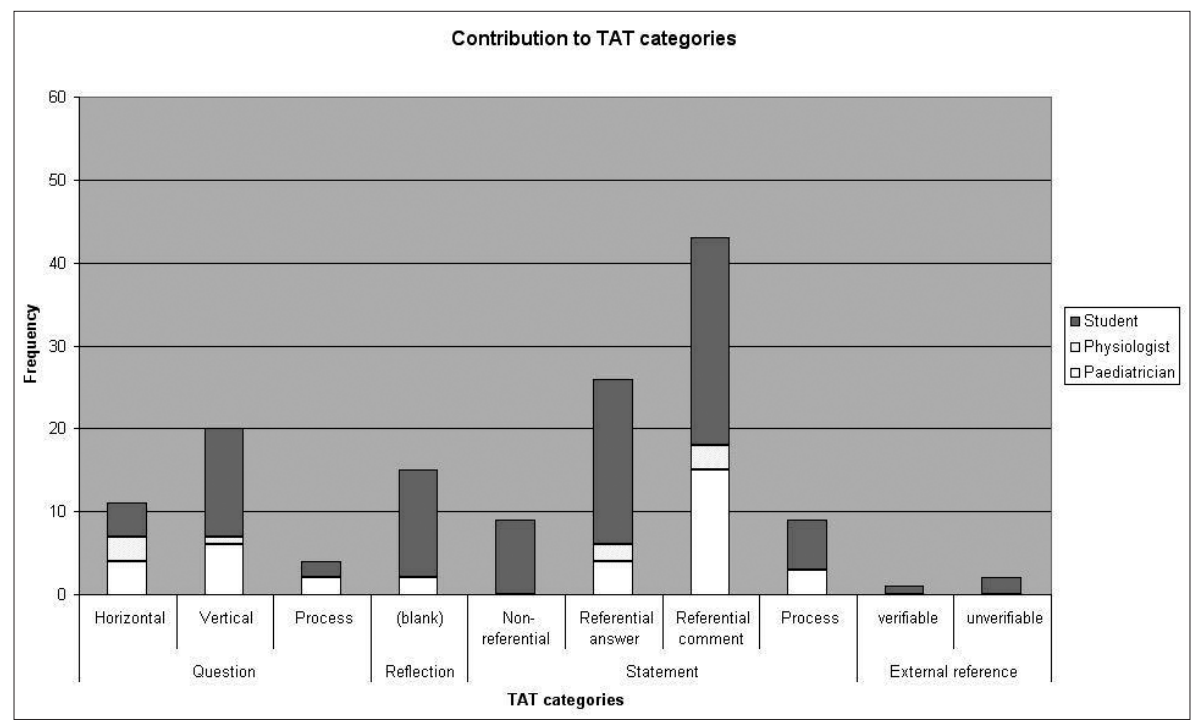

Figure 2. Frequency of 'utterances' per TAT category.

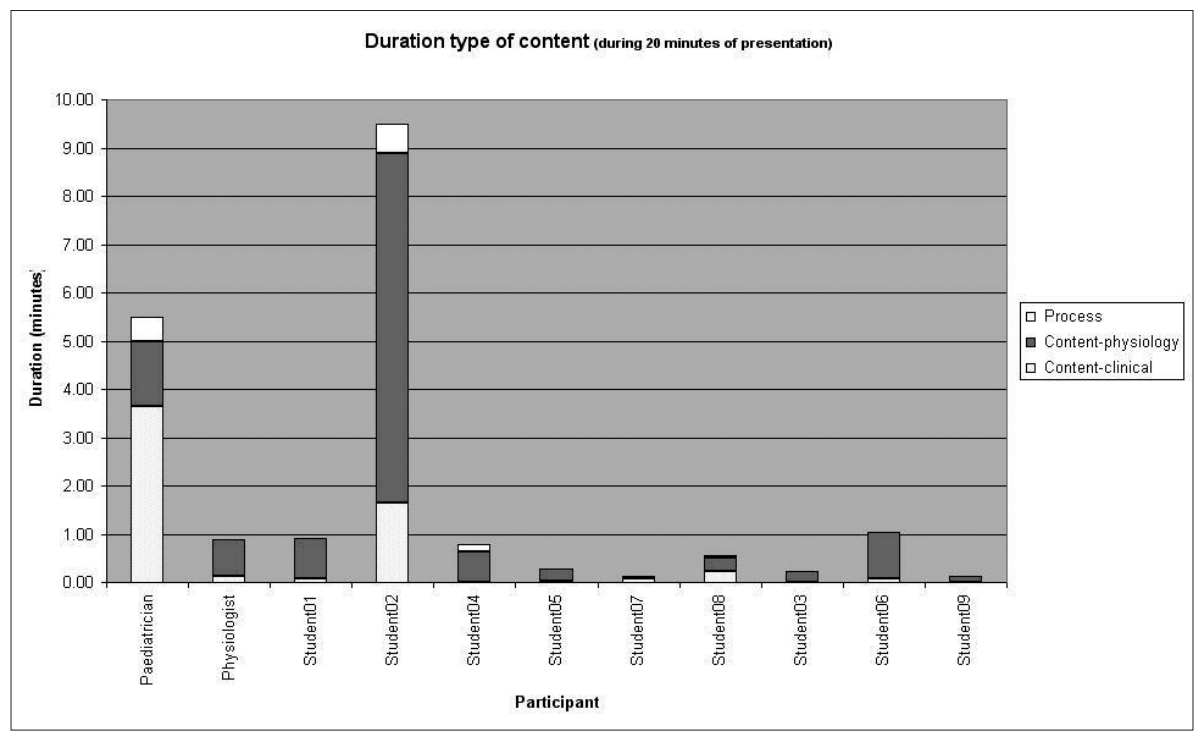

Figure 3. Duration of type of content for each participant.

In addition we see that the presenting student (student02) spent most of the time on physiology issues, while for the paediatrician clinical issues predominated.

\section{DISCUSSION AND CONCLUSION}

In this study we have shown that Fahy's Transcript Analysis Tool (TAT), modified for analysing verbal interactions during face-to-face communication, is an efficient and effective instrument for analysing small group sessions with oral presentations and discussion. In a direct analysis of video recordings of face-to-face communication, it proved feasible to use the modified TAT to code'utterances', as the unit of analysis. The inter-rater reliability of the modified TAT in categorising direct video recordings 
of face-to-face communication at the highest level of detail was acceptable, with Cohen's kappa of 0.56, which can be interpreted as moderate (Landis \& Koch, 1977). The obtained value lies between the kappa values of 0.45 and 0.65 , reported by Fahy (Fahy, Crawford, \& Ally, 2001) for the original TAT categories with online texts. The changes we made to the TAT to improve its applicability for the analysis of face-to-face oral presentations introduced some potential threats to inter-rater reliability. Using the 'utterance' as the unit of analysis necessitated a rater-dependent segmentation process and we had to add categories to describe content. Fortunately, these adjustments do not seem to have reduced the interrater agreement.

When we applied the modified TAT to 'utterances' in transcripts of video recorded face-to-face communication, Cohen's kappa was only slightly higher than that for the direct video analysis: 0.59 versus 0.56 . However, if we had taken account of the $12 \%$ disagreement in the segmentation of the transcripts, the difference in interrater reliability might have disappeared and even changed in favour of the direct video analysis.

The intra-rater reliability suggests that the same coding scheme does not yield identical results for direct video analysis and transcript analysis of the same interaction (Table 3). When the same rater used the modified TAT in two types of analysis at the highest level of detail, Cohen's kappa was 0.47 , which is well below the inter-rater reliability of the direct video analysis $(0.56)$ and the transcript analysis (0.59) for this level of detail. So, the modified TAT appears to have acceptable reliability for video or transcript analysis, but using the two methods in a mixed way may seriously harm reliability.

The efficiency of the modified TAT for direct video analysis of face-to-face communication is demonstrated by the time needed for the analysis (Table 4). Analysing the transcripts took more than twice as much time: 5.5 hours versus two hours for the direct analysis. Nearly all of the extra time needed for the transcript analysis was related to the coding process, not to segmentation. It is unlikely that this difference is attributable to a training effect, because the second raters, besides the first rater (BdL), in the direct (JD) and the indirect analysis (MU) were different persons. Furthermore, the principal researcher $(\mathrm{BdL})$ performed the transcript analysis after the direct video analysis, so a training effect, if any, would have been in favour of transcripts. We think that another explanation for the time difference is that the verbal interactions are easier to interpret directly from video than from text and that the computer program facilitated the assignment of conjugated codes. This efficiency was not diminished by the time needed for training the coding schemes. Yet it should be noted that raters need about two days of training to get acquainted with the ObserverXT software.

What adds to the effectiveness and efficiency of the direct video analysis is the richness of the data, the ease of playback of parts of the video based on the coding results (Figure 1) and the possibility to quickly compile and present the results in different ways (Figures 2 and 3). Non-verbal behaviour, like glances and gestures, or the intonation of speech can help to identify and interpret 'utterances'. In the direct 
video analysis the two raters together identified a total of 96 'utterances', while the analysis of the transcript of the same video yielded only 89 'utterances'. And an 'utterance' like 'bia....(inaudible) patients or something' as cited above, is likely easier to interpret as a question in direct video analysis where the rater can see the speaker's face and hear the intonation.

The benefit of using the modified TAT for direct video analysis of face-to-face communication in small group sessions is that it yields a rich description of these sessions. We were able to quantify qualitative information from verbal presentations and discussion in small group sessions (Figure 2 and 3). During the case presentation a substantial number of referential statements (answers and comments) were identified, indicating that the participants responded to each other and built on their contributions (Figure 2). Although most of the questions asked for authoritative 'correct' answers from more capable participants (vertical questions), there were also several horizontal questions, which we deem valuable because they challenge students to organise their thoughts on the spot and explain what they are thinking.

The analysis with the modified TAT also showed that the participants did not spend much time on 'utterances' related to process (Figure 3). In other words, they didn't waste a great deal of precious contact time on coordination or off the job activities. We see that most of the talking was done by one student. On one hand this is not surprising considering this was the student presenting the case. On the other hand, however, the contribution of the other students appears to be rather modest, particularly when we consider that these sessions are intended to elicit group discussion on basic science topics. What we also see is that the paediatrician takes up a quarter of the available air time and talks much more than the physiologist. This may be of interest because the main objective of these case presentations is to address physiological issues underlying the patient cases. Nevertheless, despite the fact that the paediatrician talks mostly about clinical content, the overall focus of the session was largely on physiology.

A limitation of this study is the small number of face-to-face sessions that were analysed. More data are needed to obtain more robust evidence of the validity of the modified TAT for face-to-face communication. In addition, this study is restricted to small group sessions with case presentations and discussion, an education format that is only one among a large variety of settings with face-to-face communication. Therefore, before generalising the results, we will have to study a greater variety of face-to-face communication settings, such as tutorial group discussions in problem-based learning or seminars. Furthermore, the results of the direct video analyses with the modified TAT of different interaction patterns should be correlated with experts' opinions on these interactions to obtain evidence of criterion validity.

Based on the results, we conclude that the modified TAT can be successfully used for direct analysis of video recordings of face-to-face communication without the need for a laborious transcript. Therefore we are convinced that this modified instrument is a valuable contribution in response to Henri's call (1992) to refine 
methods of analysis and to improve the technology of analytical tools in order to bring content and interaction analysis within the reach of general educators. Combined with practical instruments for analysing online communication, the modified TAT enables us to explore wide areas of blended learning.

\section{REFERENCES}

Boxtel van, C. (2000). Collaborative concept learning; collaborative learning tasks, student interaction, and the learning of physics concepts. Utrecht University, Utrecht.

Bullen, M. (1998). Participation and critical thinking in online university distance education. Journal of Distance Education, 13(2), 1-32.

De Wever, B., Schellens, T., Valcke, M., \& van Keer, H. (2006). Content analysis schemes to analyze transcripts of online asynchronous discussion groups: a review. Computers and Education, 46, 6-28.

Fahy, P. J., Crawford, G., \& Ally, M. (2001). Patterns of interaction in a computer conference transcript. International Review of Research in Open and Distance Learning, 2(1), 1-24.

Fahy, P. J., Crawford, G., Ally, M., Cookson, P., Keller, V., \& Prosser, F. (2000). The development and testing of a tool for analysis of computer mediated conferencing transcripts. Alberta Journal of Educational Research, 46(1), 85-88.

Garrison, D. R., \& Kanuka, H. (2004). Blended learning: uncovering its transformative potential in higher education. Internet and Higher Education, 7, 95-105.

Garrison, D. R., Anderson, T., \& Archer, W. (2001). Critical thinking, cognitive presence and computer conferencing in distance education. The American Journal of Distance Education, 15(1), 7-23.

Graham, C. (2006). Blended learning systems: definition, current trends, and future directions. In C. Bonk \& C. Graham (Eds.), The Handbook of Blended Learning: Global Perspectives, Local Designs. San Francisco: Pfeiffer.

Gunawardena, C., Carabajal, K., \& Lowe, C. (2001). Critical analysis of models and methods used to evaluate online learning networks. Paper presented at the American Educational Research Association Annual Meeting, Seattle.

Gunawardena, C., Lowe, C., \& Anderson, T. (1997). Analysis of a global online debate and the development of an interaction analysis model for examining social construction of knowledge in computer conferencing. Journal of Educational Computing Research, 17, 397-431.

Henri, F. (1992). Computer conferencing and content analysis. In A. Kaye (Ed.), Collaborative learning through computer conferencing: The Najaden papers (pp. 117-135). Berlin: Springer-Verlag.

Hmelo-Silver, C. E. (2003). Analyzing collaborative knowledge construction multiple methods for integrated understanding. Computers \& Education, 41(4), 397-420.

Howell-Richardson, C., \& Mellar, H. (1996). A methodology for the analysis of patterns of participation within computer mediated communication courses. Instructional Science, 24(1), 47-69. 
Landis, J., \& Koch, G. (1977). The measurement of observer agreement for categorical data. Biometrics, 33, 159-174.

Marra, R. M., Moore, J. L., \& Klimczak, A. (2004). Content analysis of Online discussion forums: A comparative analysis of protocols. Etr\&D-Educational Technology Research and Development, 52(2), 23-40.

Mazur, J. (2004). Conversation analysis for educational technologists: theoretical and methodological issues for researching the structures, pocesses and meaning of on-line talk. In D. H. Jonassen (Ed.), Handbook of research on educational communications and technology (second ed., pp. 1073-1098). Mahwah, New Jersey: Lawrence Erlbaum Associates.

Mercer, N. (1996). The quality of talk in children's collaborative activity in the classroom. Learning and Instruction, 6(4), 359-377.

Newman, D., Webb, B., \& Cochrane, C. (1995). A content analysis method to measure critical thinking in face-to-face and computer supported group learning. Interpersonal Computing and Technology, 3(2), 56-77.

Noldus. (2007). The Observer XT: manual event recorder for the collection, management, analysis and presentation of observational data. Reference manual version 7.0. Wageningen: Noldus Information Technology b.v.

Rourke, L., Anderson, T., Garrison, D. R., \& Archer, W. (2001). Methodological issues in the content analysis of computer conference transcripts. International Journal of Artificial Intelligence in Education, 12, 8-22.

Veerman, A., Andriessen, J., \& Kanselaar, G. (2000). Learning through synchronous electronic discussion. Computers \& Education, 34(2-3), 1-22.

Yagelski, R. P., \& Grabill, J. T. (1998). Computer-mediated communication in the undergraduate writing classroom: A study of the relationship of online discourse and classroom discourse in two writing classes. Computers and Composition, 15(1), 1140. 


\section{APPENDIX}

\begin{tabular}{|c|c|c|}
\hline \multicolumn{2}{|l|}{ TAT categories } & \multirow[t]{2}{*}{ Description with the defining features } \\
\hline Primary category & Secondary category & \\
\hline \multirow[t]{2}{*}{ Questioning } & Vertical question & $\begin{array}{l}\text { - Assumes an authoritative'correct' answer exists and the question can be } \\
\text { answered if the right answer can be found. } \\
\text { Expecting more capable members to give this answer. } \\
\text { - Question to verify if statement of other person is perceived or } \\
\text { understood correctly. }\end{array}$ \\
\hline & Horizontal question (pure) & $\begin{array}{l}\text { - There may not be one right answer, and others are invited to } \\
\text { help provide a plausible or alternate'answer', or to help shed light on the } \\
\text { question. Inviting peers to express their ideas. } \\
\text { - Critical question asking for explanation or justification. }\end{array}$ \\
\hline \multirow[t]{3}{*}{ Statements } & Non-referential statement & $\begin{array}{l}\text { - Main intent is to impart facts or information. The statements contain } \\
\text { little self-revelation and usually do not invite response or dialogue. } \\
\text { The speaker may take a matter-of-fact, a didactic, or even a pedantic } \\
\text { stance, providing information or correction to an audience which he or } \\
\text { she appears to assume is uninformed or in error, but curious and } \\
\text { interested, or otherwise open to information or correction. Statements } \\
\text { may contain implicit values or beliefs, but usually these are inferred, } \\
\text { and are not as explicit as they are in reflections. }\end{array}$ \\
\hline & Referential answer (pure) & $\begin{array}{l}\text { - Direct answer to a preceding question. } \\
\text { - Justification as a response to a critical question or negation. }\end{array}$ \\
\hline & Referential comment & $\begin{array}{l}\text { - Comment making reference to a preceding statement. } \\
\text { - Answering a self posed question. } \\
\text { - Repeating a statement } \\
\text { - Critical statement to contradict preceding statement }\end{array}$ \\
\hline Reflections & & $\begin{array}{l}\text { - Significant personal revelation: the speaker expresses thoughts } \\
\text { (thinking aloud), opinions, judgements, doubts or information which } \\
\text { are personal. The listener/reader receives both information about some } \\
\text { aspect of the world and insights into the speaker. } \\
\text { Listeners are assumed to be interested in and empathetic toward these } \\
\text { personal revelations, and are expected to respond with understanding } \\
\text { and acceptance (though the speaker may act somewhat apologetic). } \\
\text { The speaker implicitly welcomes questions (even personal ones), as } \\
\text { well as self-revelations in turn, and other supportive responses. } \\
\text { - Verifying if own thoughts or syntheses are correct. } \\
\text { - 'utterances' of (non) comprehension, only if provided with an } \\
\text { explanation of why (content or process). Without explanation the } \\
\text { 'utterance' is a statement. } \\
\text { - When there is doubt if an 'utterance' is a question or a reflection, label } \\
\text { it as reflection. Any statement as a follow-up of this reflection is then a } \\
\text { referential comment. }\end{array}$ \\
\hline \multirow[t]{2}{*}{$\begin{array}{l}\text { External } \\
\text { references }\end{array}$} & Unverifiable & $\begin{array}{l}\text { - Referring to external information without explicitly stating the } \\
\text { source in such a way that the information can be verified by others. } \\
\text { The speaker merely suggests the existence of an external foundation } \\
\text { for statements or reflections. References are always concerned with } \\
\text { content. }\end{array}$ \\
\hline & Verifiable & $\begin{array}{l}\text { - Referring to external information while explicitly stating the source, } \\
\text { so the information can be verified by others. }\end{array}$ \\
\hline
\end{tabular}

Table 5. The modified version of Fahy's TAT. 


\begin{tabular}{|l|l|l|}
\hline Main category & Subcategory & Description with defining features \\
\hline $\begin{array}{l}\text { Process } \\
(=\text { non content })\end{array}$ & $\begin{array}{r}\text { - Questions and statements used to coordinate the discussion or group } \\
\text { process. Reflections on a personal or group-related problem solving or } \\
\text { learning strategy. External references can't be combined with processes. }\end{array}$ \\
\hline Content & Clinical & $\begin{array}{r}\text { - Formal knowledge: lists of clinical presentations, diagnosis and } \\
\text { treatments, procedures, story-like descriptions of clinical cases, } \\
\text { symptoms and disease probabilities, decision trees. } \\
\text { - Experiential knowledge: exemplar models of categorisation. }\end{array}$ \\
\hline & Basic science & $\begin{array}{l}\text { - Analytical knowledge: dissecting information in detail, causal reasoning } \\
\text { using basic science concepts to explain clinical presentations, talking } \\
\text { about mechanisms at the level of organ systems, cells and molecules. }\end{array}$ \\
\hline
\end{tabular}

Table 6. Main categories and subcategories of the content category. 


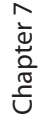


Chapter 7

Discussion 


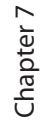




\section{DISCUSSION}

The aim of this thesis is to increase our knowledge on how to structure interpersonal interactions in small groups of learners, working with computers in higher education, to optimise the chance that higher order cognitive processes are elicited and fostered.

To facilitate the discussion of the findings from the different studies described in the previous chapters, we first explain the concepts we will use in this chapter to characterise the structure applied to the interpersonal interactions in the individual studies. We then proceed by giving a short overview of the methods that were used in the different studies to assess the interpersonal interaction and cognitive processes that occurred. After these considerations follows the discussion of the findings and the lessons learned for each chapter, which we conclude by weighing the strengths and limitations of this thesis and considering the implications for practice and future research.

\section{Concepts to characterize the structure}

We characterise the structure applied to the interpersonal interactions in small group learning with computers by: 1) the role of the computer in the group processes and 2) the 'scripts' that guided the interpersonal interactions in these settings.

\section{Role of the computer}

Based on categories introduced by Crook (Crook, 1996), we distinguish two arrangements of small group learning with computers:

1 'Interaction at computer' arrangements are settings in which a shared computer is used during face-to-face discussions to introduce tasks or problems to the group or to make representations of understandings in the group. In this arrangement the role of the computer is that of a catalyst of faceto-face interactions.

2 'Interaction through computers' arrangements are settings in which computers, linked in a network, are the medium through which the discussion takes place. The role of the computer is that of a conduit for interpersonal interactions.

\section{Scripts guiding interpersonal interactions}

The 'script' concept we borrowed from the Computer Supported Collaborative Learning literature (Fischer, Kollar, Mandl, \& Haake, 2007). Scripts make explicit the instructional means that are used to structure interpersonal interactions during group learning. Scripts that focus on global organisational issues, like the schedule for the group work, the group tasks, the participants and their roles and the sequencing of activities, are called macro-scripts. Scripts that focus on instructions regarding the activities themselves, such as which specific activities to engage in and how to perform them, are called micro-scripts. Although macro- and microscripts are not so much two clear-cut mutually exclusive categories, but rather two poles of a scale, they can be helpful in indicating at which process level instructions are aimed (Fischer, Kollar, Haake, \& Mandl, 2007). 


\section{Assessment methods}

In the different studies several methods were used to acquire the data on interpersonal interactions and cognitive processes. In the studies of chapters 2-5 we measured students' perceptions using questionnaires, focus group interviews and individual interviews. In the study of chapter 5 we analysed the interactions and content of online discussions using an existing validated instrument. Because a feasible instrument to analyse interpersonal interactions in face-to-face discussions was lacking, we investigated in the study of chapter 6 whether a modified version of an existing instrument for analysing online discussions could be used for direct video analysis of face-to-face discussions.

The studies in this thesis were all conducted among medical students. Within the context of undergraduate medical education small group work with computers and higher order cognitive processes, like 'critical thinking,' are highly relevant, while computer-mediated communication is not a topic of interest in itself.

\section{Lessons learned}

\section{For interaction 'at' and 'through' computers arrangements}

In the study of chapter $\mathbf{2}$ we investigated learners' experiences with a virtual learning environment that supported both'interaction at computer'and'interaction through computers' arrangements.

The interpersonal interactions at the computer in tutorial groups of about ten students and a tutor were structured by a macro-script that regulated:

- the weekly schedule of group sessions, comprising three phases: a preliminary meeting at the start of the week, several days for individual self-study and a reporting meeting at the end of the week;

- the presentation by a group computer of the problem to be dealt with by the group;

- the student roles of discussion leader, secretary and group member and the supervisor role of the teacher;

- the 'seven step' approach to problem solving that is characteristic of the problem-based sessions we studied.

For the interpersonal interactions in the online discussions during the self-study phase no script was available nor were there explicit schedules, tasks or roles for students and tutor.

The questionnaire survey showed that first and second year undergraduate medical students perceived the 'interaction at computer' arrangement with the virtual learning environment effective in supporting face-to-face interactions in tutorial group sessions. On the other hand they did not think that the interaction through computers' arrangements stimulated interpersonal interactions. They felt that free and untargeted use of the discussion board was not useful in settings in which they had regular face-to-face contacts. 
Lesson:

'Interaction at computer' arrangements in tutorial groups in a problem-based learning setting in higher education can foster interpersonal interactions. When students meet regularly face to face, 'interaction through computer' arrangements are unlikely to be used, if they are not combined with a specific script.

\section{For 'interaction at computer' arrangements}

In the study of chapter 3 we investigated medical students' experiences with digital videos in 'interaction at computer' arrangements in the first two years of a problembased curriculum. The videos were used as part of the problem presentation in small group sessions in tutorial rooms. Focus group interviews with second year medical students revealed that in this setting videos are preferably used in a structured and purposeful manner. Students indicated that cues and prompts that focused their attention on key issues in the videos promoted productive and valuable group discussions. The need for this kind of structure, which can be characterised as micro-scripts for video cases, may be due to the greater ambiguity of information in videos compared to text. Novices may easily miss important elements or pay too much attention to irrelevant extraneous elements in videos (Kozma, 1991). Microscripts can also counteract the frequent misconception that videos require little mental effort to elaborate, thereby preventing shallow information processing of video material (Kozma, 1991). On the other hand students also cautioned against videos being too directive or too complete and detailed, because this was thought to oversimplify problems, leaving nothing to be discussed in the group.

When digital videos are used in 'interaction at computer' arrangements in the early years of higher education, it is advisable to include micro-scripts to stimulate interpersonal interactions that foster higher order cognitive processes in elaborating the videos. However, it is important to beware of 'overscripting'.

In the study of chapter 4, we investigated students' experiences with computerbased simulated cases or virtual patients in 'interaction at computers' arrangements. The work-up of these virtual patients by triads of fourth year medical students was intended to foster face-to-face discussions, the elaboration of case material and reflection on clinical reasoning. In order to provide minimum structure to the interpersonal interactions in the triads a macro-script regulated that:

- the role of discussion leader rotated among the students together with the keyboard control in each of the three parts of the computer case.

- the inquiry of the computer case followed the standard workflow of a clinical consultation: exploratory examinations resulting in an initial diagnosis, specific examinations resulting in a working diagnosis, and therapeutic interventions monitored in follow-up activities.

No micro-scripts were provided to structure specific activities, for instance by thought provoking questions or suggestions to reflect on the presented findings.

The results did not support our hypothesis that a collaborative work-up of a virtual patient by senior students would result in more intense elaboration of 
case material and more reflection on decisions compared to students tackling the cases individually. Although working in triads compared to individually increased the time and frequency of inquiry, it did not increase interpretative and reflective activities based on the results of the inquiry. Possible explanations may be that students, while being engaged in simulations, tend to concentrate on manipulating objects without generating a deeper understanding of the principles underlying the observed behaviours (Pilkington \& ParkerJones, 1996) or 'game the system' by performing actions that take them through the system with a minimum of effort (Baker, Corbett, Koedinger, \& Wagner, 2004). We conclude that even advanced students, working on computer-based simulated cases, need prompts to sit back from the computer screen and engage in discussion before responding to the computer.

Lesson:

Digital videos and computer-based simulated cases used in 'interaction at computer' arrangements in higher education require micro-scripts to elicit interpersonal interactions that foster higher order cognitive processes.

\section{For 'interaction through computers' arrangements}

In the study of chapter 5, we facilitated learning in distributed groups by means of an 'interaction through computers' arrangement, in which groups of four medical students close to graduation discussed basic science topics while on work placements in different locations. The aim of these asynchronous computermediated discussions moderated by a content expert (clinician) was to foster critical thinking on basic science concepts during the clinical phase of medical education.

A macro-script structured the organisational aspects of the discussions, by:

- scheduling a face-to-face introductory session at the start of the three-week period in which the discussions took place;

- giving a group of four peers and an expert access to a specific discussion;

- offering a separate discussion forum for each week, dedicated to consecutive phases of the Practical Inquiry model of Cognitive Presence (Garrison, Anderson, \& Archer, 2001);

- assigning the role of 'starter' of the discussion to every student in the group in the first week. In this role students had to introduce issues they had personally encountered in practice. At the end of the first week the students had to reach consensus on the topic of the group discussions for the next two weeks.

Micro-scripts structured which specific activities the students had to undertake and how:

- The students had to select a 'knowledge type' for each message that reflected the purpose of their contribution. They did so via a structured dialogue interface in the discussion board.

- The'knowledge types' were combined with checklists to verify if the appropriate type of contribution was selected as well as with examples of starter sentences for different types of contribution. 
In this study Garrison's coding scheme for Cognitive Presence was used to analyse the postings in the online discussions. The degree of higher order cognitive processes was determined from the relative numbers of integration and resolution messages posted in the discussions. The numbers and percentages of these messages were quite high and it appeared that macro-scripts led to an increase. Noticeable was that, notwithstanding the restrictive character of the macro-script based on the Practical Inquiry model, many students said that this macro-script provided a structure for their online discussions, which was valuable and responsive to their needs. This may be explained by the fact that the restrictions, for example postponing the use of literature until after the exploration of prior knowledge, closely resembled the 'seven jump' method of problem-based learning with which the students were very familiar.

Lesson:

In distributed learning groups of advanced students in higher education, higher order cognitive processes can be achieved in 'interaction through computers' arrangements with macro- and micro-scripts to structure the desired interpersonal interactions.

\section{For the evaluation of verbal face-to-face interactions}

In the study of chapter 6 we investigated if Fahy's Transcript Analysis Tool (an instrument originally developed for interaction analysis of asynchronous online discussions) could be modified and used for video analysis of face-toface discussions. We found that the modified TAT was an efficient and effective instrument for the direct analysis of video recordings of face-to-face discussions and that it could be used to quantify types of interactions that are indicative of or valuable for higher cognitive processes.

Lesson:

The Transcript Analysis Tool, modified for direct video analysis of face-to-face discussions, provides educators with a feasible instrument for evaluating interpersonal interactions in 'interaction at computer' arrangements of small group learning with computers.

\section{Strengths}

The strengths of this thesis are the authentic settings, its grounding in prior knowledge and existing instruments from computer-mediated communication (CMC) research, and the combination of different research methods.

It is authentic because the studies were conducted in an 'in vivo' setting in higher education. This enhances the value of the findings for educational practice. In addition the studies were situated in the context of medical education, in which computer technology or linguistics are not topics of study in their own right. This prevents bias due to participants having an intrinsic interest in the use of computers or computer mediated communication and increases the value of the findings for higher education as a whole. 
It builds on a prior knowledge base by using existing instruments and frameworks derived from the CMC literature to analyse and present the findings of the studies. For a research field characterised by small scale qualitative studies and a wealth of evaluation instruments, we thought it was preferable to build on existing validated and valued instruments, such as Garrison's coding scheme and Fahy's TAT rather than add yet another new instrument. Using existing instruments enables comparison with earlier studies and provides additional data to supplement those of other qualitative research, which is generally based on small populations.

The mixed methods approach is reflected in the use of quantitative and qualitative methods, sometimes within one study. The results of the questionnaire survey of the study of chapter 2 were refined by a follow-up focus group study in chapter 3 . In chapter 5 we triangulated quantitative data from log files with qualitative data from interviews and we used descriptive statistics to provide quantitative details of qualitative findings. This mix of methods afforded a more complete picture and enhanced our understanding of the issues studied.

\section{Limitations}

The studies looked at the immediate effects of scripts on interpersonal interactions and cognitive processes during small group learning with computers. These 'process' outcomes are transient effects of the scripts we applied. Whether these processes will lead to more permanent outcomes with regard to knowledge gains or higher order thinking competence is likely to depend on the number and duration of students' experiences with these scripts. Another closely related question is whether improved processes remain dependent on the availability of scripts or persist also when the script is no longer in use.

The study on the 'interaction through computers' arrangement was restricted to asynchronous or delayed time communication, although this type of communication in distributed learning groups can be combined with synchronous or real time communication. Scripts that exploit the strength of each communication medium and offer strategies by which these media can complement each other, however, were outside the scope of our research. The same holds for scripts for 'blended learning' in which face-to-face classroom learning and online learning are combined (Graham, 2006).

All the studies in this thesis were conducted within the context of undergraduate medical education, which may affect the generalisability of the results.

\section{Future research}

Suggestions for future research can be derived from our considerations in the limitations section. Firstly, future studies should examine the application of scripts for small group learning with computers over longer periods of time and evaluate the more permanent effects. These outcomes might be assessed by individual tests or group products (Bereiter, 2002). In addition ways should be explored to 'fade away' external scripts in order to enable learners to progressively tackle tasks independently. 
Secondly, important topics for future research are scripts that shape the combined use of asynchronous communication, synchronous communication and other tools (like multi-media resources) by distributed learning groups in computersupported learning environments (Hmelo-Silver, Chernobilsky, \& Jordan, 2008). But also scripts for 'blended learning,' in which learning with and without computers is combined, are of interest. For instance in line with work that looked at the effects of asynchronous online discussions on subsequent face-to-face discussions (DietzUhler \& Bishop-Clark, 2001), we might explore different sequences of online and face-to-face learning and their effects on interpersonal interactions during the different activities.

\section{Implications}

The studies of this thesis show that computers can have significance in triggering and fostering interpersonal interactions and higher order cognitive processes in small group learning. However, they also show that this added value cannot be achieved without targeted efforts. To exploit the full potential of computers for small group learning, curriculum designers must be well informed about their possibilities and limitations. At an early stage of curriculum development schools should define where and how computers are to be used to stimulate small-group learning and how these learning activities with computers are linked to those without computers. On the basis of such choices, ICT (information and communication technology) facilities can be arranged. In addition, curriculum designers and teachers should be asked to envision the tasks students have to perform with computers in these settings. To ensure that the tasks will engage students in critical thinking, macro- and micro scripts have to be developed. These scripts can be provided in separate guides, embedded in the electronic learning environment or in the content itself. If these scripts are implemented in a flexible manner, they can be offered as long as they are needed and left out once learners have shown proof of mastery of independent critical appraisal, reflection and discourse.

\section{REFERENCES}

Baker, R. S., Corbett, A. T., Koedinger, K. R., \& Wagner, A. Z. (2004). Off-task behavior in the cognitive tutor classroom: when students 'game the system'. Paper presented at the ACM Computer-Human Interaction 2004, Vienna, Austria.

Crook, C. (1996). Computers and the collaborative experience of learning. London: Routledge.

Dietz-Uhler, B., \& Bishop-Clark, C. (2001). The use of computer-mediated communication to enhance subsequent face-to-face discussions. Computers in Human Behavior, 17(3), 269-283.

Fischer, F., Kollar, I., Haake, J. M., \& Mandl, H. (2007). Perspectives on collaboration scripts. In F. Fischer, I. Kollar, H. Mandl \& J. M. Haake (Eds.), Scripting computersupported collaborative learning: cognitive, computational and educational perspectives (Vol. 6, pp. 1-10). New York: Springer Science and Business Media. 
Fischer, F., Kollar, I., Mandl, H., \& Haake, J. M. (2007). Scripting computer-supported collaborative learning: cognitive, computational and educational perspectives (Vol. 6). New York: Springer Science and Business Media.

Garrison, D. R., Anderson, T., \& Archer, W. (2001). Critical thinking, cognitive presence and computer conferencing in distance education. The American Journal of Distance Education, 15(1), 7-23.

Graham, C. (2006). Blended learning systems: definition, current trends, and future directions. In C. Bonk \& C. Graham (Eds.), The Handbook of Blended Learning: Global Perspectives, Local Designs. San Francisco: Pfeiffer.

Hmelo-Silver, C., Chernobilsky, E., \& Jordan, R. (2008). Understanding collaborative learning processes in new learning environments. Instructional Science, 36(5), 409430.

Kozma, R. B. (1991). Learning with media. Review of educational research, 61(2), 179-211.

Pilkington, R., \& ParkerJones, C. (1996). Interacting with computer-based simulation: The role of dialogue. Computers \& Education, 27(1), 1-14. 
$\frac{0}{n}$
$\stackrel{n}{4}$
$\frac{n}{2}$ 
Summary 
This thesis examines ways in which computers can support cognitive learning in small groups in higher education. Chapter 1 introduces the background and aims of the studies. Departing from the societal relevance of the research questions, the introduction focuses on the psychological theories that have made active and small group learning pivotal notions in contemporary education, then moves on to the state of the art in the research of effective small group learning and considers the gaps in our knowledge about small group learning with computers. This description of the context of the research culminates in the formulation of the central research question:

How should we structure interpersonal interactions in small groups of learners, working with computers in higher education, to optimise the chance that higher order cognitive processes are elicited and fostered?

The question is addressed for different social arrangements in groups using computers to support their learning:

- face to face communication at a computer, 'interaction at computer' arrangements;

- computer-mediated communication, 'interaction through computers' arrange-ments;

- a combination of the two.

Chapter 2 presents the results of a questionnaire survey among first- and secondyear undergraduate medical students $(\mathrm{N}=355)$. The questionnaire explored students' perceptions of the affordances of a virtual learning environment (VLE) and the interpersonal interactions that result when this VLE is used in a problembased learning curriculum. The students indicated that the VLE stimulated faceto-face interaction in the tutorial groups but not computer-mediated distance interaction during self study. The use of multimedia in case presentations led to a better quality group discussion than when case presentations were exclusively text based.

These results suggest that the use of multimedia in case presentations enhances the face-to-face interaction in tutorial groups but further research is needed to confirm this. This prompted the study described in chapter 3 . The results also suggest that asynchronous computer-mediated communication during self study should be applied selectively and deliberately if it is to foster higher order cognitive processes. This issue is investigated in the study reported in chapter 5.

Chapter 3 presents the results of a focus group study among second-year undergraduate medical students $(\mathrm{N}=21)$ to explore which conditions students perceive to be essential for productive interpersonal interactions in tutorial groups studying video cases. The students indicated that video cases were valuable provided they were neither too directive nor too complete, tailored to students' prior knowledge, short, varied in design and complementary to other materials. They also recommended that the cases should be viewed in a structured, purposeful manner, with cues, instructions and prompts to focus attention on essential issues. We conclude that these findings suggest that video cases are a valuable stimulus for the interpersonal interactions we aim for in higher education but that their value is conditional on the fulfilment of specific requirements. 
Chapter 4 presents the results of an experiment among fourth-year undergraduate medical students $(\mathrm{N}=47)$ working on computer-based simulated cases. The students were assigned to an experimental group and a control group. The experimental group worked in triads and the students in the control group worked individually. All participating students gave their perceptions of the elaboration process by completing a questionnaire. Additionally, the time spent by the students on the various parts of one computer-based simulated case was obtained from the log-files of the computer case. Comparison of the data from the two groups demonstrated no significant effect of 'social context' (triads versus individuals) on the degree of elaboration of the computer case.

We conclude that working with computer-based simulated cases in small groups as opposed to individually is in itself not sufficient to achieve an increase in the scope and depth of the elaboration of computer cases.

Chapter $\mathbf{5}$ describes a method to structure learners' interpersonal interactions in distributed online learning groups using asynchronous computer-mediated communication. The aim of the moderated online communication is to promote critical thinking about basic science topics by students during work placements. This method, which is based on Garrison's 'Practical Inquiry Model of Cognitive Presence,' is embedded in a computer-supported collaborative learning environment.

Furthermore, the chapter presents the results of two case studies in which this method was used by sixth year undergraduate medical students during clinical work placements $(\mathrm{N}=8)$. For the assessment of the effects of the method on the interactions and cognitions in small distributed groups, we used a mixed methods approach, which included content analysis of the online messages and interviews with students and moderators. The results demonstrated substantial numbers of messages and a great deal of social activity on the discussion board. The proportion of messages classified as integration and resolution contributions was satisfactory, which is indicative of the occurrence of higher order thinking activities.

We conclude that the application of Garrison's 'Practical Inquiry Model' in an approach that combines a human moderator and a computer-supported collaborative learning program can be useful in facilitating online discussions about basic science concepts among small groups of students during clinical work placements.

Chapter 6 presents the results of a reliability and usability study that addresses the present need, in research, for a comprehensive analysis of both face-to-face and online communication in situations where blended learning is used. The study investigated whether an existing coding scheme for online communication, the Transcript Analysis Tool (TAT), could be modified and used for the analysis of verbal interactions during small group face-to-face discussions. Analysis of the 'utterances' of fourth- and fifth-year undergraduate medical students $(\mathrm{N}=17)$ during small group discussions was performed directly from video, using the modified TAT. The resulting inter-rater reliability was moderate $(\kappa=0.56)$.

We conclude that the modified TAT is an effective and efficient instrument to analyse face-to-face communication in small group sessions with presentations and discussions. 
Chapter 7 discusses the findings of the various studies and puts them into perspective. For this purpose we reviewed the studies of this thesis and used two dimensions to characterise the way the interpersonal interactions were structured in the individual studies: 1) the role of the computer in group processes and 2) the macro- and micro-scripts that guide the interpersonal interactions. Using this perspective we found the following lessons learned from the studies in this thesis:

- 'Interaction at computer' arrangements in tutorial groups in a problembased learning setting in higher education can foster interpersonal interactions. When students meet regularly face to face, 'interaction through computer' arrangements are unlikely to be used if they are not combined with a specific script.

- Digital videos and computer-based simulated cases used in 'interaction at computer' arrangements in higher education require micro-scripts to elicit interpersonal interactions that foster higher order cognitive processes.

- In distributed learning groups of advanced students in higher education, higher order cognitive processes can be achieved in 'interaction through computers' arrangements in which macro- and micro-scripts are used to structure the desired interpersonal interactions.

- The Transcript Analysis Tool, modified for direct video analysis of faceto-face discussions, provides a feasible instrument for the evaluation of interpersonal interactions in 'interaction at computer' arrangements.

Finally we suggest topics for future research: the long-term effects of sustained application of scripts for small group learning and scripts for distributed group learning that shape the combined use of asynchronous communication, synchronous communication and other tools. 
Samenvatting 


\section{Voor leren bekabeld}

Hoe computers in het hoger onderwijs interactie bij leren in kleine groepen kan ondersteunen

Dit proefschrift onderzoekt manieren waarop computers in het hoger onderwijs cognitief leren in kleine groepen studenten kunnen ondersteunen. Hoofdstuk1 beschrijft de achtergrond en de doelen van de studies. Vanuit het perspectief van de maatschappelijke relevantie van de onderzoeksvragen wordt aandacht besteed aan de volgende onderwerpen: de psychologische theorieën die hebben bijgedragen aan de centrale positie van actief leren en groepsleren in het hedendaagse onderwijs, de stand van zaken in het onderzoek naar effectief leren in groepen, en bestaande hiaten in de kennis over het leren in groepen met behulp van computers. Deze beschrijving van de context van het onderzoek mondt uit in de formulering van de centrale onderzoeksvraag:

Hoe zouden de interacties in kleine groepen studenten in het hoger onderwijs die samen leren met behulp van computers gestructureerd moeten worden om hogere cognitieve processen in gang te zetten en te stimuleren?

De vraag wordt gesteld voor verschillende sociale arrangementen waarin groepjes studenten computers gebruiken ter ondersteuning van het leren:

- directe onderlinge communicatie waarbij de groep fysiek aanwezig is (faceto-face-communicatie) en samenwerkt op een computer, 'interactie aan de computer'-arrangementen;

- onderlinge communicatie via computers, 'interactie via de computer'arrangementen;

- een combinatie van de eerste twee arrangementen.

Hoofdstuk 2 beschrijft de resultaten van een schriftelijke enquête bij eerste- en tweedejaars studenten ( $\mathrm{N}=355)$ geneeskunde. De mening van de studenten werd gepeild over de functies van een virtuele leeromgeving (VLO) en hun onderlinge interacties bij toepassing van deze VLO in een probleemgestuurd curriculum. De studenten gaven aan dat de VLO de face-to-face-interactie in de tutorgroepen bevorderde, maar dat dit niet gold voor computergemedieerde communicatie wanneer de studenten bezig waren met zelfstudie. De groepsdiscussies waren volgens de studenten van betere kwaliteit als bij de presentatie van de casuistiek niet alleen tekst maar ook multimedia werden gebruikt. De resultaten geven aan dat het gebruik van multimedia bij de presentatie van casuïstiek de face-to-faceinteracties in de tutorgroep versterkt, maar ook dat er verder onderzoek nodig is om dit te bevestigen. Dit laatste vormde de aanleiding voor de studie die in hoofdstuk 3 wordt beschreven. De resultaten geven ook aan dat asynchrone communicatie via de computer in de periode dat studenten bezig zijn met zelfstudie, selectief en gericht moet worden toegepast om hogere cognitieve processen te ondersteunen. Dit onderwerp is onderzocht in de studie die in hoofdstuk 5 wordt beschreven.

Hoofdstuk 3 beschrijft de resultaten van een focusgroepstudie waaraan werd deelgenomen door tweedejaars studenten $(\mathrm{N}=21)$ geneeskunde. Nagegaan werd welke condities volgens de studenten noodzakelijk zijn om productieve interactie tot stand te brengen in een tutorgroep bij het bestuderen van videocasussen. 
De studenten gaven aan dat videocasussen tot waardevolle interacties kunnen leiden als aan de volgende voorwaarden wordt voldaan: de casussen zijn noch te directief noch te volledig, ze sluiten goed aan bij de voorkennis van de studenten, ze zijn kort van duur en gevarieerd van ontwerp, en ze vormen een aanvulling op andere leermaterialen. De studenten raadden aan om videocasussen op een 134 gestructureerde en doelgerichte manier te laten bekijken, waarbij vingerwijzingen, instructies en aansporingen tot actie gebruikt worden om de aandacht te vestigen op de belangrijkste onderwerpen.

Wij concluderen uit deze resultaten dat videocasussen een waardevolle stimulans kunnen zijn voor het tot stand brengen van het type groepsinteractie dat wenselijk geacht wordt in het hoger onderwijs, mits er aan specifieke voorwaarden wordt voldaan.

Hoofdstuk 4 beschrijft de resultaten van een experiment met vierdejaars studenten $(\mathrm{N}=47)$ geneeskunde die een computercasus uitwerkten. De deelnemende studenten werden ingedeeld in een experimentele of een controlegroep. De studenten in de experimentele groep werkten in drietallen, de studenten in de controlegroep werkten alleen. In een enquête werd aan alle studenten gevraagd hoe zij het werken met de computercasus ervaren hadden. Tevens werd de tijd die de studenten aan de verschillende onderdelen van de casus hadden besteed, afgeleid uit de logbestanden van de computer. Vergelijking van de gegevens van beide groepen leverde geen significant effect op van de variabele 'sociale context' (drietallen versus individuen) op de intensiteit waarmee de studenten de computercasus hadden uitgewerkt.

Wij concluderen dat, vergeleken met individueel uitwerken, het uitwerken van casuistiek op de computer in groepjes op zichzelf niet voldoende is om de breedte en diepgang waarmee de studenten de casus bestuderen, te vergroten.

Hoofdstuk 5 beschrijft een methode voor het structureren van de interactie in groepjes studenten die op afstand, met behulp van asynchrone computergemedieerde communicatie, samen leren. Het doel van deze online communicatie, met begeleiding van een moderator, is om tijdens werkstages het kritisch denken over onderwerpen uit de basiswetenschappen te stimuleren. De toegepaste methode is gebaseerd op Garrison's'Practical Inquiry Model of Cognitive Presence' en ingebouwd in een computerprogramma voor samenwerkend leren op afstand.

Verder geeft het hoofdstuk de resultaten van twee 'case studies' naar de toepassing van de beschreven methode door zesdejaars studenten $(\mathrm{N}=8)$ geneeskunde tijdens stages in het ziekenhuis. Wij hebben een combinatie van onderzoeksinstrumenten gebruikt, waaronder een inhoudsanalyse van de online berichten en interviews met de studenten en hun moderatoren, om te meten wat het effect was van de methode op de interacties en het denken in de online groepjes. Er was sprake van een aanzienlijk aantal berichten en een grote mate van sociale activiteit op het discussieforum. Het gedeelte van de berichten dat gekwalificeerd werd als 'integratie' en 'concluderende' bijdrage was voldoende groot om gezien te worden als indicatie dat er sprake was van hogere denkprocessen.

Wij concluderen dat deze toepassing van Garrison's 'Practical Inquiry Model' - met een moderator van 'vlees en bloed' en een computerprogramma voor 
samenwerkend leren op afstand - geschikt is om een online discussie te faciliteren over concepten uit de basiswetenschappen tussen studenten die op verschillende locaties hun stages lopen.

Hoofdstuk 6 geeft de resultaten van een betrouwbaarheids- en bruikbaarheidsonderzoek dat beantwoordt aan de huidige behoefte aan brede analyses van zowel 'face-to-face-' als online-communicatie in situaties waarbij beide vormen in het onderwijs worden gecombineerd. Nagegaan werd of een bestaand codeerschema voor online-communicatie, de Transcript Analysis Tool (TAT), aangepast en toegepast kon worden voor het analyseren van de verbale interactie in groepsdiscussies. De uitspraken tijdens face-to-face groepsdiscussies van vierdeen vijfdejaars studenten geneeskunde $(\mathrm{N}=17)$ werden rechtstreeks vanaf videoopnamen van deze discussies met behulp van de aangepaste versie van de TAT geanalyseerd. Dit resulteerde in een redelijke interbeoordelaarsbetrouwbaarheid ( $\mathrm{K}=0.56)$.

Wij concluderen dat de aangepaste TAT een effectief en efficiënt instrument is voor het analyseren van face-to-face-communicatie in groepsbijeenkomsten van studenten met presentaties en discussies.

Hoofdstuk 7 bespreekt de bevindingen uit de verschillende studies en plaatst deze in perspectief. Hiertoe hebben wij de studies in dit proefschrift opnieuw bekeken en per studie beoordeeld hoe de structuur van de interactie gekenschetst kan worden. We hebben dit gedaan voor twee dimensies: 1) de rol van de computer in groepsprocessen en 2) de macro- en microscripts die de interacties sturen. Vanuit dit perspectief zijn uit de studies in dit proefschrift de onderstaande lessen afgeleid:

- In het hoger onderwijs kunnen de interacties tussen studenten in probleemgestuurde tutorgroepen bevorderd worden door 'interactie aan de computer'-arrangementen. Als de studenten elkaar in het onderwijs regelmatig face-to-face treffen, is het onwaarschijnlijk dat de studenten gebruik zullen maken van 'interactie via de computer'-arrangementen, tenzij er tegelijkertijd specifieke scripts worden aangeboden.

- Bij het gebruik van digitale video-opnamen en gesimuleerde casuïstiek op de computer in 'interactie aan de computer'-arrangementen in het hoger onderwijs zijn microscripts nodig om interacties te bewerkstelligen die hogere cognitieve processen kunnen stimuleren.

- In het hoger onderwijs zijn 'interactie via de computer'-arrangementen, gecombineerd met macro- en microscripts om de interacties te structureren, geschikt om hogere cognitieve processen teweeg te brengen in groepjes gevorderde studenten die 'op afstand' samenwerken.

- Het 'Transcript Analysis Tool', aangepast voor directe video-analyse van face-toface-discussies, is een bruikbaar instrument om interacties te evalueren tussen personen in 'interactie aan de computer'-arrangementen.

Tenslotte doen wij aanbevelingen voor toekomstig onderzoek: onderzoek naar de langetermijneffecten van langdurige toepassing van scripts tijdens groepsleren en onderzoek naar scripts voor op afstand samenwerkende groepjes die vorm geven aan het gecombineerde gebruik van asynchrone communicatie, synchrone communicatie en andere instrumenten. 


\section{Curriculum vitae}

Together with his twin brother, Bas de Leng was born in Arnhem, the Netherlands on July 24th 1961. After earning his medical master's degree from the University of Nijmegen in 1985, he obtained a bachelor's degree in physiotherapy from the HAN University of Applied Sciences in Nijmegen in 1991. In that same year, he was appointed as a lecturer at that university and worked as a physiotherapist at a rehabilitation clinic. In 1994, Bas decided to further develop his skills in the direction of educational technology by following a postgraduate course at Rotterdam University. After working for several years as an educational consultant for a middle-sized software company and for an innovation centre of Fontys University of Applied Sciences in Eindhoven, he was appointed as an assistant professor at the Faculty of Health, Medicine and Life Sciences of Maastricht University in 2000. In line with his work as chairman of the e-learning task force, he started to work on a PhD thesis in this domain. He is interested in research on e-learning in medical education in general and in computer supported collaborative learning and virtual patients in particular. Bas is married to Sabine and has two daughters, Julia and Anne-Mees. 